INSTITUTO DE PESQUISAS ENERGÉTICAS E NUCLEARES

Autarquia associada à Universidade de São Paulo

\title{
OTIMIZAÇÃO DA ANÁLISE ISOTÓPICA DE UF UTILIZANDO-SE A TÉCNICA DE ESPECTROMETRIA DE MASSAS POR QUADRUPOLO
}

\author{
PETERSON PORTO
}

Dissertação apresentada como parte dos requisitos para a obtenção do Grau de Mestre em Ciências na Área de Tecnologia Nuclear - Materiais.

Orientador:

Dr. José Oscar Vega Bustillos

São Paulo

2006 
INSTITUTO DE PESQUISAS ENERGÉTICAS E NUCLEARES

Autarquia associada à Universidade de São Paulo

\title{
OTIMIZAÇÃO DA ANÁLISE ISOTÓPICA DE UF 6 UTILIZANDO-SE A TÉCNICA DE ESPECTROMETRIA DE MASSAS POR QUADRUPOLO
}

\section{PETERSON PORTO}

\author{
Dissertação apresentada como parte dos \\ requisitos para a obtenção do Grau de \\ Mestre em Ciências na Área de \\ Tecnologia Nuclear - Materiais. \\ Orientador: \\ Dr. José Oscar Vega Bustillos
}

São Paulo 2006 


\section{AGRADECIMENTOS}

Agradeço ao Dr. José Oscar Vega Bustillos, meu orientador, pela orientação segura, confiança e horas de discussão.

Ao Instituto de Pesquisas Energéticas e Nucleares (IPEN), pela oportunidade.

Ao Centro Tecnológico da Marinha em São Paulo (CTMSP) pelo apoio e incentivo.

Aos meus colegas do CTMSP e IPEN que, de alguma forma, contribuíram para a realização deste trabalho. 


\title{
OTIMIZAÇÃO DA ANÁLISE ISOTÓPICA DE UF 6 UTILIZANDO-SE A TÉCNICA DE ESPECTROMETRIA DE MASSAS POR QUADRUPOLO
}

\author{
Peterson Porto
}

\begin{abstract}
RESUMO
Neste trabalho foi estabelecido um procedimento para determinação da razão isotópica ${ }^{238} \mathrm{U} /{ }^{235} \mathrm{U}$ em amostras de $\mathrm{UF}_{6}$, utilizando-se um espectrômetro de massas quadrupolar com ionização por impacto eletrônico e detecção de íons por copo de Faraday ou multiplicador de elétrons. Para tanto, o espectrômetro foi otimizado, determinando-se os parâmetros para a fonte de íons que proporcionassem a maior intensidade de corrente iônica, mantendo o pico de forma arredondada, para a massa correspondente ao isótopo mais abundante; a resolução que reduzisse os efeitos não lineares e o número de ciclos analíticos que reduzisse a incerteza nos resultados. O processo de medição foi caracterizado quanto: aos efeitos de discriminação de massa, linearidade e efeito memória. A discriminação de massas mostrou ser linearmente dependente da pressão da amostra no tanque de expansão nas faixas de 0,15 a 0,30 mbar e de 0,30 a 0,40 mbar. O espectrômetro mostrou-se linear na medição de razões isotópicas entre 0,005 e 0,045. Os fatores de memória para a fonte de íons e para o sistema de introdução são, respectivamente, 1,000 \pm 0,001 e $1,003 \pm 0,003$; o primeiro pode ser desprezado e o segundo eliminado por procedimentos de lavagem do sistema de introdução. O trabalho apresenta, em sua parte final, um roteiro para as análises de amostras de $\mathrm{UF}_{6}$ e a determinação das incertezas nos resultados.
\end{abstract}




\title{
OPTIMIZATION OF THE ISOTOPIC ANALYSIS OF UF 6 BY QUADRUPOLE MASS SPECTROMETRY TECHNIC
}

\author{
Peterson Porto
}

\begin{abstract}
In the present work a procedure for determination of the isotopic ratio ${ }^{238} \mathrm{U} /{ }^{235} \mathrm{U}$ in $\mathrm{UF}_{6}$ samples was established using a quadrupole mass spectrometer with ionization by electron impact and ion detection by Faraday cup or electron multiplier. For this, the following items were optimized in the spectrometer: the parameters in the ín source that provided the most intense peak, with good shape, for the corresponding mass of the most abundant isotope; the resolution that reduced the non linear effects and the number of analytic cycles that reduced the uncertainty in the results. The measurement process was characterized with respect to the effects of mass discrimination, linearity and memory effect. The mass discrimination showed to be linearly dependent of the sample pressure in the batch volume, for the pressure ranges from 0.15 to $0.30 \mathrm{mbar}$ and from 0.30 to 0.40 mbar. The spectrometer was shown linear in the measurement of isotopic ratios between 0.005 and 0.045 . The memory factor for the ín source and for the introduction system were, respectively, $1.000 \pm 0.001$ and $1.003 \pm 0.003$; the first one can be ignored, the second one can be eliminated by washing the batch volume with the new sample. A methodology for routine analysis of $\mathrm{UF}_{6}$ samples and the determination of the uncertainties were set up in details as well.
\end{abstract}




\section{SUMÁRIO}

Página

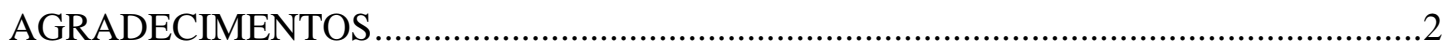

1 INTRODUÇÃ

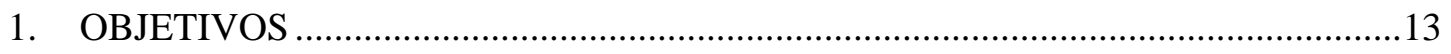

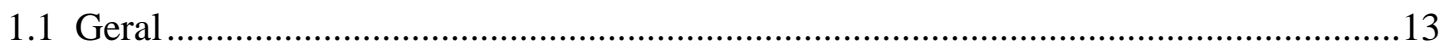

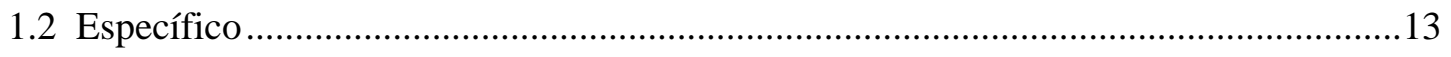

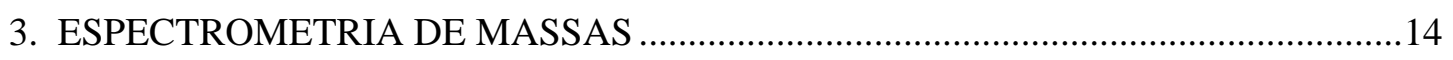

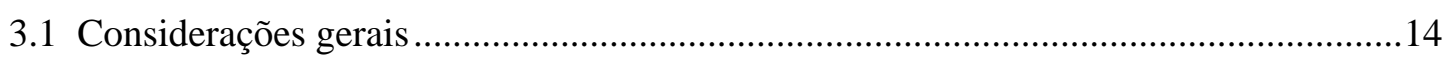

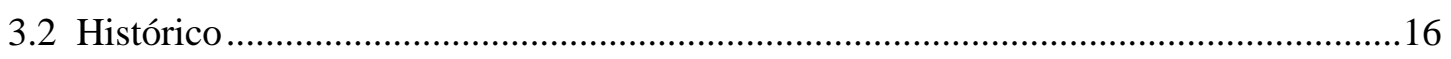

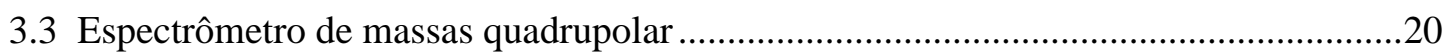

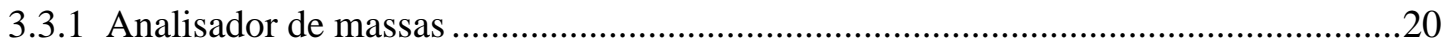

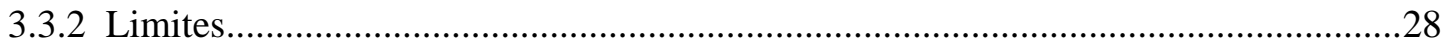

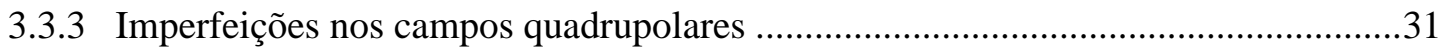

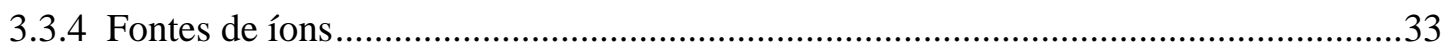

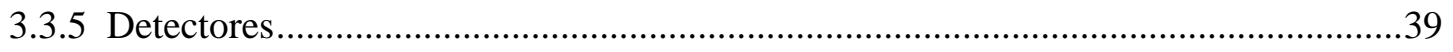

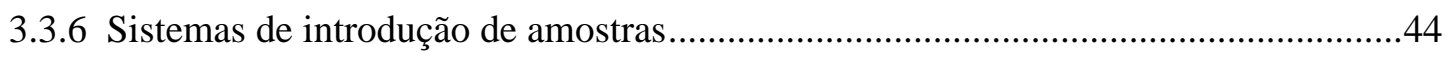

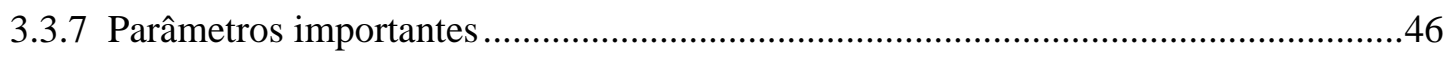

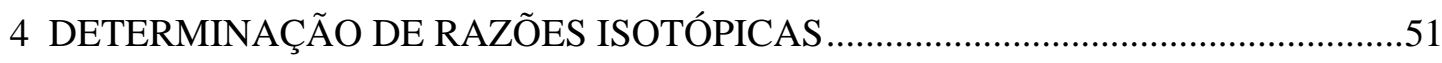

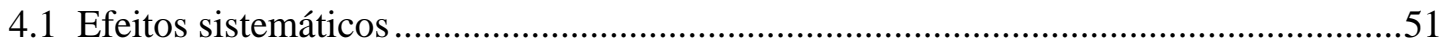

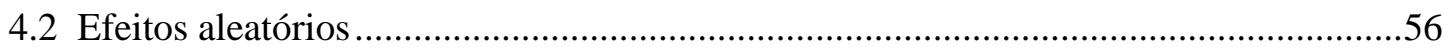

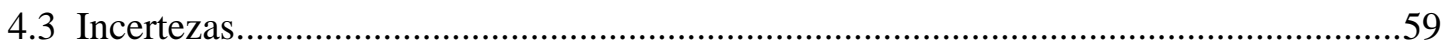

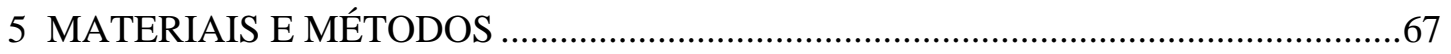

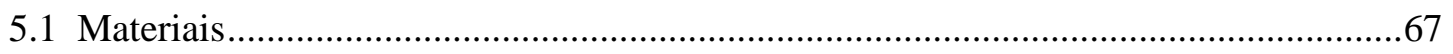

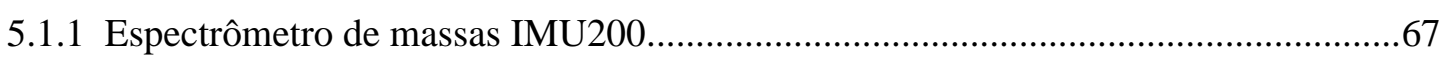

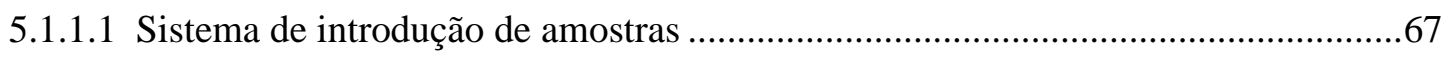

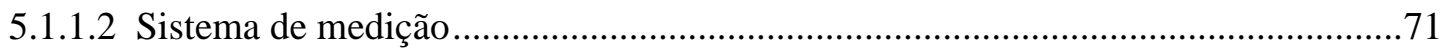

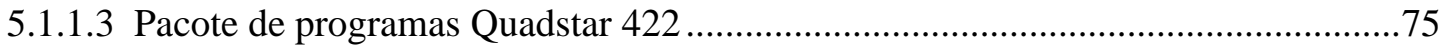

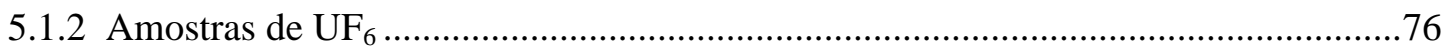

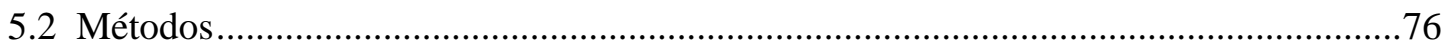


5.2.1 Otimização da fonte de íons e da resolução ..............................................................77

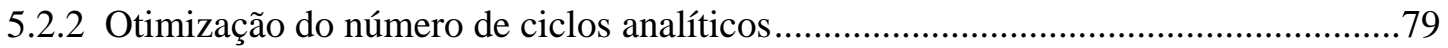

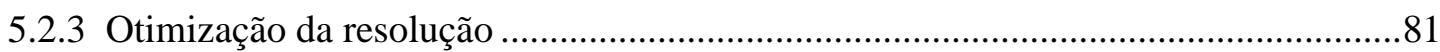

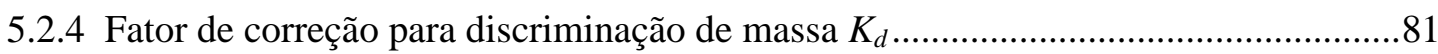

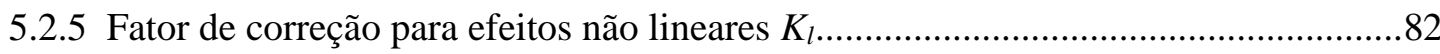

5.2.6 Fator de correção para efeito memória $K_{m}$ e para efeito de impurezas $K_{i}$...............83

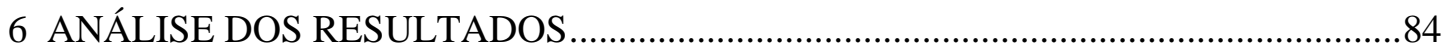

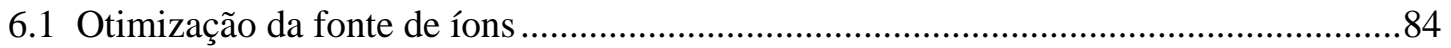

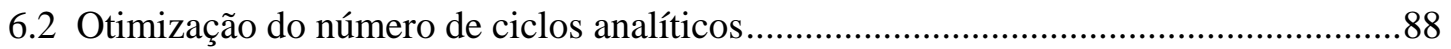

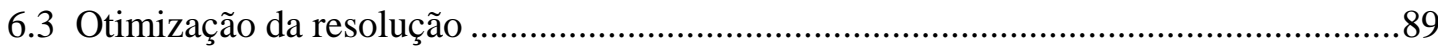

6.4 Dependência entre o valor da razão isotópica medida e a pressão no tanque de expansão, determinação do fator de correção para discriminação de massa ........................95

6.5 Dependência entre o valor da razão isotópica medida e a razão isotópica real, determinação do fator de correção para não linearidade....................................................109

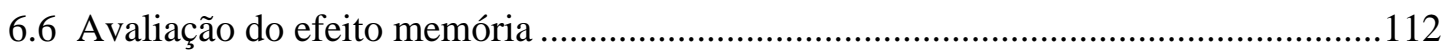

6.7 Procedimento a ser adotado na realização de análises isotópicas ..............................115

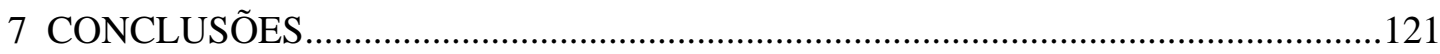

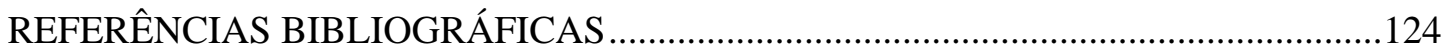




\section{LISTA DE TABELAS}

Página

Tabela 1. Composição isotópica do urânio natural. ........................................................... 10

Tabela 2. Razões isotópicas das amostras de referência ................................................... 76

Tabela 3. Potenciais de ionização críticos para o $\mathrm{UF}_{6}$ gasoso . ...........................................78

Tabela 4. Parâmetros da fonte e largura do pico para diferentes resoluções. ........................85

Tabela 5. Razões isotópicas e fatores de correção em função da resolução. ........................90

Tabela 6. Razões isotópicas e fatores de correção em função da resolução. ........................92

Tabela 7. Valores médios medidos de $R_{m}$ para dez pressões em dez datas...........................96

Tabela 8. Parâmetros das funções ajustadas para os 10 dias................................................104

Tabela 9. Fator de discriminação de massa em função de da pressão. ...............................106

Tabela 10. Valores certificados e valores medidos da razão isotópica para as quatro amostras padrão. ............................................................................ 110

Tabela 11. Valores das razões isotópicas medidas para as amostras de referência, corrigidos para discriminação de massa. ....................................................111

Tabela 12. Valores dos fatores de correção para efeitos não lineares $K_{l}$. .........................111

Tabela 13. Razões isotópicas das amostras enriquecida e empobrecida obtidas em medições sucessivas, com as amostras enriquecida e empobrecida em tanques

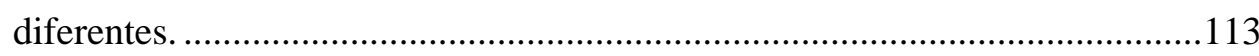

Tabela 14. Razões isotópicas das amostras enriquecida e empobrecida obtidas em medições sucessivas, com as amostras enriquecida e empobrecida no mesmo tanque. 


\section{LISTA DE FIGURAS}

Página

Figura 1. Correntes de alimentação, produto e rejeito em uma cascata de enriquecimento

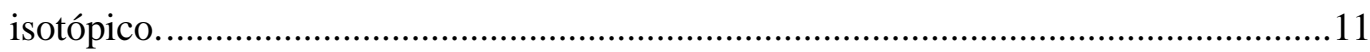

Figura 2. Principais componentes de um espectrômetro de massas ...................................15

Figura 3. Estrutura de eletrodos de um filtro de massas quadrupolar ................................21

Figura 4. Linhas equipotenciais de um campo quadrupolar . ............................................22

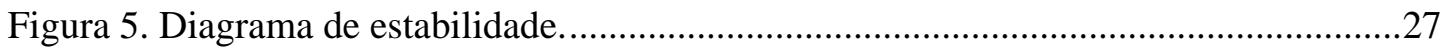

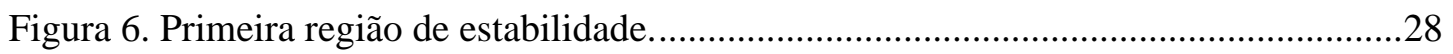

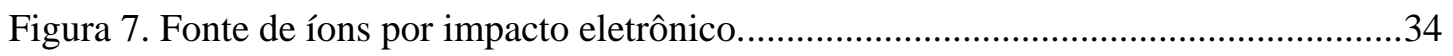

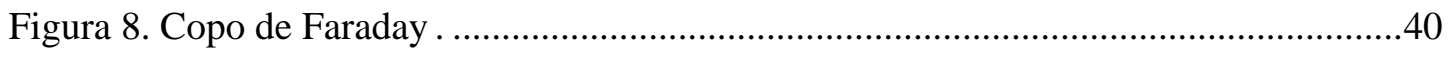

Figura 9. Detector de íons com multiplicador de elétrons ..............................................42

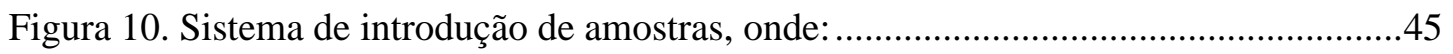

Figura 11. Dois picos idênticos separados por uma unidade de massa atômica, onde são mostradas as três definições da largura do pico............................................................4

Figura 12. Pico característico de intensidade na massa $M$ do espectro de massa, com identificação dos parâmetros que definem a sensibilidade à abundância.....................50

Figura 13. Etapas necessárias a estimativa da incerteza. ....................................................66

Figura 14. Sistema de vácuo do espectrômetro de massas IMU200 ..................................68

Figura 15. Sistema de medição do espectrômetro de massas IMU200 ..................................69

Figura 16. Fonte de íons com tubo capilar para introdução de amostras do espectrômetro de

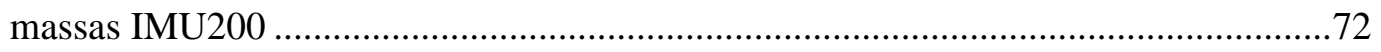

Figura 17. Principais componentes e potenciais elétricos da fonte de íons por impacto

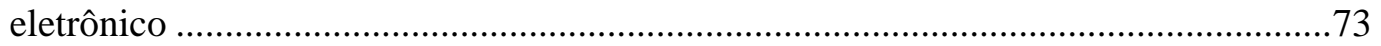

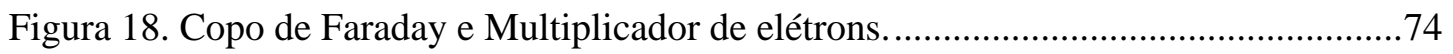

Figura 19. Relação entre a resolução em unidades arbitrárias usada pelo QMG422 e a

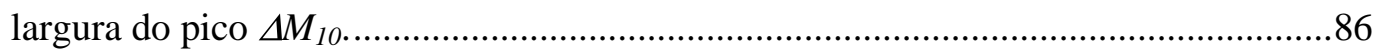

Figura 20. Espectro de massas do $\mathrm{UF}_{6}$ com resolução unitária. ......................................... 87

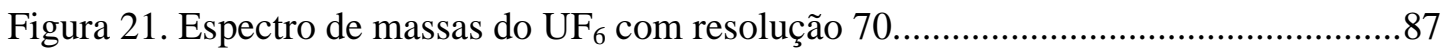


Figura 22. Variação da razão isotópica média com relação a $n$, para diversos valores de $N$.

Figura 23. Variação da razão isotópica média com relação a $N, \operatorname{com} n=15 \ldots \ldots \ldots \ldots \ldots \ldots . . . . .89$

Figura 24. Discriminação de massa em função da resolução..............................................91

Figura 25. Discriminação de massa em função da resolução.............................................93

Figura 26. Sensibilidade a abundância para massa alta. ...................................................94

Figura 27. Variação da razão isotópica medida com relação à pressão no tanque ( $1^{\circ}$ dia)..97

Figura 28. Variação da razão isotópica medida com relação à pressão no tanque ( $2^{\circ}$ dia)..97

Figura 29. Variação da razão isotópica medida com relação à pressão no tanque ( $3^{\circ}$ dia)..98

Figura 30. Variação da razão isotópica medida com relação à pressão no tanque ( $4^{\circ}$ dia)..98

Figura 31. Variação da razão isotópica medida com relação à pressão no tanque ( $5^{\circ}$ dia)..99

Figura 32. Variação da razão isotópica medida com relação à pressão no tanque ( $6^{\circ}$ dia)..99

Figura 33. Variação da razão isotópica medida com relação à pressão no tanque ( $7^{\circ}$ dia).

Figura 34. Variação da razão isotópica medida com relação à pressão no tanque ( $8^{\circ}$ dia).

Figura 35. Variação da razão isotópica medida com relação à pressão no tanque ( $9^{\circ}$ dia).

101

Figura 36. Variação da razão isotópica medida com relação à pressão no tanque $\left(10^{\circ}\right.$ dia $)$.

Figura 37. Valores médios (10 dias) das razões isotópicas medidas em função da pressão.

Figura 38. Fator de discriminação de massa em função da pressão no tanque.

Figura 39. Fator de correção para efeitos não lineares $\left(K_{l}\right)$ em função da razão isotópica da amostra certificada

Figura 40. Diagrama de Ishikawa com os componentes da incerteza 


\section{INTRODUÇÃO}

No campo da tecnologia nuclear, um programa abrangente de garantia da qualidade que compreenda todas as medidas planejadas e sistemáticas necessárias para assegurar que uma estrutura, sistema, componente ou equipamento tenha um desempenho satisfatório, quando em serviço, é de vital importância. É no contexto da fabricação de combustível nuclear que o nível da qualidade requerida exige padrões mais rigorosos, visto que seus efeitos são traduzidos diretamente em questões de segurança e vida útil de uma central nuclear. Uma das fases principais do ciclo do combustível nuclear é a de enriquecimento isotópico do urânio ${ }^{1}$.

O urânio é o elemento químico de número atômico 92 e massa atômica 238,02891(3) ${ }^{2}$. Possui 14 isótopos radioativos ${ }^{3}$, sendo naturais os isótopos ${ }^{234} \mathrm{U},{ }^{235} \mathrm{U}$ e ${ }^{238} \mathrm{U}$. As massas atômicas exatas destes isótopos, bem como as faixas de variação de suas frações molares são apresentadas na TAB. 1.

Tabela 1. Composição isotópica do urânio natural ${ }^{2}$.

\begin{tabular}{cccc}
\hline Isótopo & Massa atômica em u.m.a. & $\begin{array}{c}\text { Faixa de variação natural } \\
\text { da fração molar }\end{array}$ & $\begin{array}{c}\text { Fração molar mais } \\
\text { representativa }\end{array}$ \\
\hline${ }^{234} \mathrm{U}$ & $234,0409447(22)$ & $0,000050-0,000059$ & $0,000054(5)$ \\
${ }^{235} \mathrm{U}$ & $235,0439222(21)$ & $0,007198-0,007207$ & $0,007204(6)$ \\
${ }^{238} \mathrm{U}$ & $238,0507835(22)$ & $0,992739-0,992752$ & $0,992742(10)$ \\
\hline
\end{tabular}

$\mathrm{O}$ isótopo natural mais importante para a indústria nuclear é o ${ }^{235} \mathrm{U}$, porque este é o isótopo do urânio que sofre a fissão de seu núcleo quando bombardeado por nêutrons lentos ${ }^{1}$. Ao passo que, o ${ }^{238} \mathrm{U}$ é físsil por nêutrons de alta energia ${ }^{1}$, sendo a probabilidade de fissão por nêutrons lentos muito pequena.

Por esta razão, o urânio destinado a ser usado como combustível nas centrais nucleares que utilizam reatores de água pressurizada (PWR), ou reatores de água fervente (BWR) precisa ter a fração molar do ${ }^{235} \mathrm{U}$ compreendida entre 0,02 e $0,05^{1}$. 
Dentre os vários processos que permitem o enriquecimento isotópico do urânio, o Brasil adotou o enriquecimento por ultracentrífugas que, interligadas, formam cascatas de enriquecimento isotópico.

O gás de processo utilizado é o hexafluoreto de urânio $\mathrm{UF}_{6}$, por ser o único composto do urânio volátil a temperatura ambiente (pressão de vapor $=149,08$ mbar a $\left.25^{\circ} \mathrm{C}\right){ }^{1}$. Uma vantagem adicional deste composto é o fato de o flúor ter apenas um único isótopo estável $\left({ }^{19} \mathrm{~F}\right)^{2}$, de modo que o enriquecimento isotópico do $\mathrm{UF}_{6}$ não é perturbado por uma possível separação isotópica de outro elemento.

Nas cascatas de enriquecimento isotópico (FIG. 1), uma corrente de alimentação $(F)$ de $\mathrm{UF}_{6}$, com a razão isotópica, isto é, a razão entre o número de átomos de ${ }^{235} \mathrm{U}$ e do ${ }^{238} \mathrm{U}$, dada por $R$ é separado em duas correntes com composições isotópicas diferentes, uma corrente de rejeito $(W)$, empobrecida em ${ }^{235} \mathrm{U}$, com razão isotópica $R$ "' e uma de produto $(P)$, enriquecida em ${ }^{235} \mathrm{U}$, com razão isotópica $R^{\prime}$.

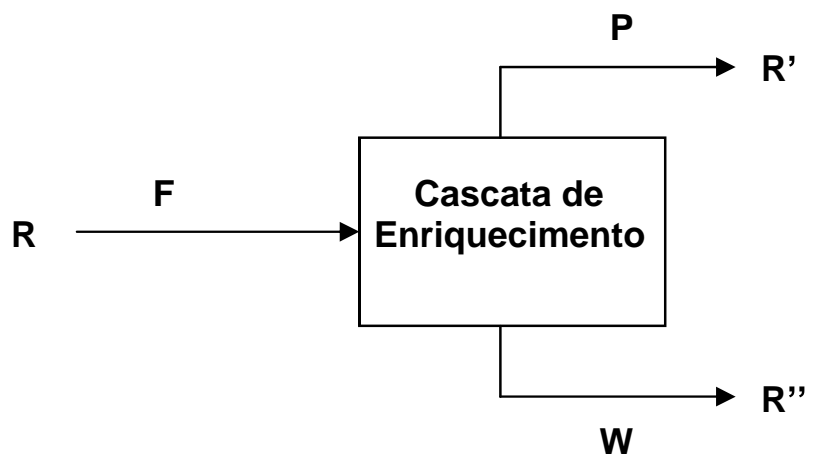

Figura 1. Correntes de alimentação, produto e rejeito em uma cascata de enriquecimento isotópico.

As determinações das razões isotópicas da alimentação, do produto e do rejeito, para controle de processo em cascatas de enriquecimento isotópico, bem como do $\mathrm{UF}_{6}$ armazenado em cilindros, são realizadas por espectrômetros de massas. 
Para que os resultados das análises isotópicas por espectrometria de massas sejam confiáveis, é necessária de caracterização de seu processo de medição e o estabelecimento de um procedimento analítico, no qual as razões isotópicas sejam determinadas dentro de uma faixa de incerteza com grau de confiança conhecido. 


\section{OBJETIVOS}

\subsection{Geral}

O objetivo deste trabalho é estabelecer um procedimento analítico para determinação da razão isotópica ${ }^{235} \mathrm{U} /{ }^{238} \mathrm{U}$, em amostras de $\mathrm{UF}_{6}$, utilizando-se a técnica de espectrometria de massas quadrupolar. $\mathrm{O}$ procedimento deve atender às rotinas de controle de processo e caracterização isotópica de cilindros de $\mathrm{UF}_{6}$ em uma usina de enriquecimento isotópico.

\subsection{Específico}

Otimizar o processo de medição de um espectrômetro de massas quadrupolar, determinando-se os valores ideais para os parâmetros da fonte de íons, a resolução e o número de análises.

Caracterizar o processo de medição quanto à influência que a pressão de trabalho, a razão isotópica e o efeito memória possam ter no resultado da razão isotópica medida.

Caracterizar o processo de medição quanto a repetitividade e reprodutibilidade.

A partir dos resultados obtidos, estabelecer uma metodologia para análises de rotina da amostras de $\mathrm{UF}_{6}$. 


\section{ESPECTROMETRIA DE MASSAS}

\subsection{Considerações gerais}

A espectrometria de massas é uma das técnicas analíticas mais largamente usadas hoje em dia, encontrando aplicações na maioria das ciências. O motivo é a grande variedade de informações que podem ser obtidas por meio dela, tais como ${ }^{4}$ :

a. composição qualitativa e quantitativa de compostos orgânicos ou inorgânicos em misturas complexas;

b. estrutura de grande variedade de espécies moleculares complexas;

c. razão isotópica dos átomos em uma amostra;

d. estrutura e composição de superfícies sólidas.

A técnica se baseia na conversão dos componentes de uma amostra, seja ela sólida, líquida ou gasosa, em íons gasosos rápidos que são separados com base na razão entre a massa e a carga elétrica. Isto pode ser feito com o uso de um campo elétrico ou magnético, ou por uma combinação de ambos ${ }^{5}$.

Embora todos os espectrômetros de massas se baseiem nestes mesmos princípios, um grande número de técnicas diferentes têm sido desenvolvidas, tanto para a ionização, como para a separação e a detecção dos íons. Cada uma delas mais apropriada a um tipo de amostra e à informação que se deseja obter.

Em geral, os espectrômetros de massas são constituídos de quatro componentes principais: sistema de introdução de amostras, fonte de íons, analisador de massas e detector de íons, mostrados na FIG. 2. 


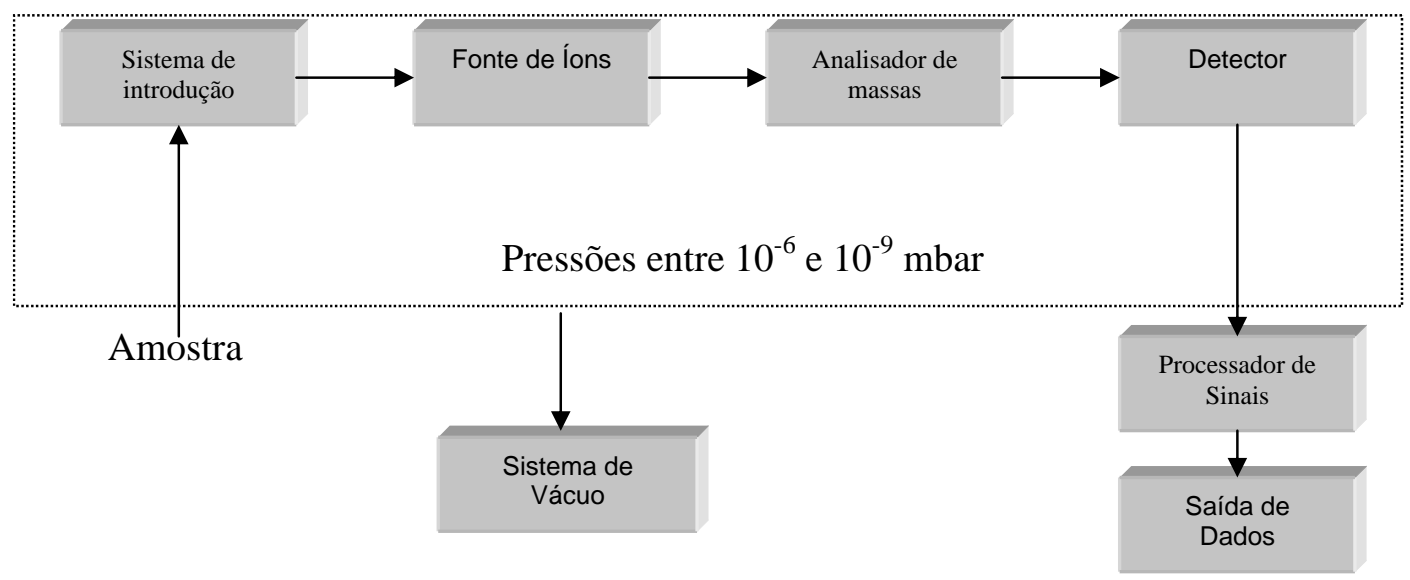

Figura 2. Principais componentes de um espectrômetro de massas 4 .

O sistema de introdução de amostras introduz uma quantidade muito pequena de amostra no espectrômetro de massas, onde será convertida em íons gasosos.

Na fonte de íons os componentes da amostra são convertidos em íons gasosos, seja pelo bombardeio da amostra com elétrons, íons, moléculas ou fótons, seja pelo uso de energia térmica ou elétrica. Os íons produzidos são retirados da fonte e acelerados para dentro do analisador de massas. Embora possam ser gerados feixes de íons positivos ou negativos, os íons positivos são mais comumente usados. Em alguns aparelhos, como o espectrômetro por termo-ionização, um único componente faz as vezes de sistema de introdução de amostras e de fonte de íons ${ }^{3}$.

O analisador de massas separa os íons por sua relação $\mathrm{m} / \mathrm{z}$ (quantidade adimensional formada pela divisão do número de massa de um íon pelo seu grau de ionização) ${ }^{6}$. Existem vários métodos para se fazer esta separação e, como conseqüência, vários tipos de espectrômetros de massas. Os mais utilizados na análise isotópica do $\mathrm{UF}_{6}$ são o espectrômetro por setor magnético ${ }^{7}$ e o espectrômetro por quadrupolo ${ }^{6}$. O primeiro separa os íons espacialmente, ao atravessar o analisador os íons são dispersos de acordo com sua razão $m / z$; o segundo separa os íons temporalmente, só permite a passagem de íons com uma razão $\mathrm{m} / \mathrm{z}$ determinada. 
Os detectores medem as correntes dos feixes de íons separados pelo analisador. Os detectores mais comumente usados em espectrometria de massas são o copo de Faraday e o multiplicador de elétrons ${ }^{4}$.

Além destes componentes principais, dois outros componentes são essenciais: um sistema de vácuo e um sistema para processamento de sinais e saída de dados (FIG. 2).

Processador de Sinais e Saída de Dados - os espectrômetros de massas modernos são todos integrados por microprocessadores e conectados a microcomputadores ${ }^{4}$. As razões disso são:

$>$ Um simples espectro de massas fornece uma imensa quantidade de dados em razão da fragmentação sofrida pelas moléculas na fonte de íons.

Devido a esta grande quantidade de informações, é essencial que a aquisição e o processamento de dados sejam rápidos.

Durante a operação de um espectrômetro de massas, diversas variáveis instrumentais devem ser cuidadosamente monitoradas e controladas.

Sistema de vácuo - todos os componentes do espectrômetro de massas, a exceção dos dedicados ao processamento e saída de dados, trabalham em alto vácuo. Para tanto, estes aparelhos são dotados de sistemas de vácuo capazes de alcançar pressões da ordem de $10^{-6}$ a $10^{-9}$ mbar. Normalmente, possuem sistemas independentes de vácuo para a parte de introdução de amostras e para a parte de ionização e análise em si.

\subsection{Histórico}

A espectrometria de massas surgiu como disciplina científica quando J. J. Thomson ${ }^{8}$, usando seu espectrógrafo de parábolas de raios positivos descobriu que o neônio é uma mistura de dois isótopos ${ }^{20} \mathrm{Ne}$ e ${ }^{22} \mathrm{Ne}$. Entretanto, até o espectrógrafo de Thomson, um longo caminho foi percorrido. Um resumo deste caminho histórico, baseado nos trabalhos de Beynon ${ }^{8}$ e $\mathrm{Svec}^{9}$, é apresentado a seguir:

Em 1852, Grove descobriu que os gases ofereciam uma grande resistência à passagem de corrente elétrica. Se a pressão fosse suficientemente reduzida surgia uma 
luminosidade no gás e a resistência caía. Uma redução maior da pressão levava ao desaparecimento da luminosidade e aumento da resistência.

Em 1858, Plücker, descreveu uma fluorescência verde na superfície interna de um tubo de descarga de vidro, atribuída à passagem de corrente do catodo para a parede do tubo.

Em 1860, Tyndall mostrou que um imã afetava o feixe de descarga.

Em 1869, Hittorf, usando um tubo de descarga em L, mostrou que a fluorescência ocorria no lado oposto ao catodo e que um objeto colocado no caminho dos raios lançava uma sombra na área de fluorescência, provando que os raios saiam do catodo e se moviam em linha reta. Goldstein, 1876, chamou estes raios de raios catódicos.

Em 1886, Goldstein, fazendo experimentos com um catodo perfurado, observou raios fracos emergindo atrás do catodo e chamou-os raios canais.

Em 1892, Hertz descobriu que os raios catódicos podiam penetrar folhas metálicas.

Em 1895, Perrin demonstrou que os raios catódicos consistiam de partículas negativamente carregadas, defletindo os raios com um campo magnético em direção a um copo de Faraday.

Em 1897, Thomson determinou a relação entre a carga e a massa das partículas nos raios catódicos, enviando um feixe de raios colimados por dois campos transversais, um elétrico e um magnético. Descobriu que a massa destas partículas era pequena se comparada à do átomo de hidrogênio.

Entre 1898 e 1902, Wien mostrou que ao passo que os raios catódicos podiam ser defletidos por campos magnéticos modestos, os raios canais só podiam ser defletidos por campos fortes. Além disso, os raios canais eram desviados na direção oposta a dos raios catódicos. Assim, Wien concluiu serem aqueles positivamente carregados. 
Durante a primeira década do século vinte, Thomson abandonou os experimentos com os raios catódicos e passou a se interessar pelos raios canais. Em experimentos em um bulbo de descarga, onde o catodo continha um tubo fino, ele direcionou os raios positivos emergindo deste tubo através de um campo elétrico e um campo magnético combinados. O resultado foram linhas parabólicas visíveis em uma tela fluorescente.

Equacionando o movimento das partículas carregadas nos campos elétrico e magnético combinados, e conhecendo suas intensidades, Thomson pode identificar a razão $\mathrm{m} / \mathrm{z}$ das partículas que causavam cada linha parabólica. Foi com este espectrógrafo de massas que Thomson identificou os dois isótopos no neônio.

Posteriormente, ele substitui seu sistema de fotodetecção por um sistema elétrico de detecção, inventando o espectrômetro de massas.

Thomson também estudou os íons negativos, observou íons com carga múltipla e as transições meta-estáveis e sugeriu a existência de reações íon moleculares.

O trabalho de Thomson foi continuado por Aston, que aperfeiçoou o instrumento de Thomson dando-lhe o nome espectrógrafo de massas. Ao longo de sua carreira Aston construiu três espectrógrafos, sempre melhorando sua precisão, com os quais identificou 212 dos 287 isótopos naturais, entre eles o terceiro isótopo no neônio

${ }^{21} \mathrm{Ne}$. Aston mediu as massas desses isótopos com incerteza de $0,1 \%$, determinou suas abundâncias e calculou a massa atômica dos elementos. Em seus estudos observou que os isótopos não têm massa inteira, sendo caracterizados por um defeito de massa ao qual ele chamou fração de empacotamento. Este defeito esta relacionado à energia de formação do núcleo, que é menor quanto maior for a fração de empacotamento.

Em 1918, Dempster publicou detalhes da construção de seu espectrômetro de massas por setor magnético de $180^{\circ}$, com projeto mais simples que o espectrógrafo de Aston. Neste aparelho os íons eram gerados por impacto eletrônico ou por termo-ionização e após a separação detectados por um eletrômetro. O aparelho de Dempster era melhor que o de Aston para determinação de abundâncias isotópicas, mas não podia ser usado para determinação precisa de massas. 
Em 1935, Dempster ${ }^{7}$ construiu o primeiro espectrógrafo de focagem dupla, obtendo um poder de resolução de aproximadamente 7.000. Este aparelho foi seguido pelos de Baindridge $-\operatorname{Jordan}^{7}$, com poder de resolução de 7.000 e de Mattauch - Herzog ${ }^{7}$ com poder de resolução de 3.000 .

Em 1939, Nier ${ }^{3}$ fez as primeiras analises precisas de razão isotópica. $\mathrm{UCl}_{4} \mathrm{e}$ $\mathrm{UBr}_{4}$ foram evaporados e ionizados por impacto eletrônico.

Em 1940, Nier $^{7}$ construiu o primeiro espectrômetro de massas dedicado a determinação de razão isotópica em gases.

Em 1947, Nier $^{7}$ melhora a precisão das determinações de razão isotópica incorporando um sistema de coletores duplos, para medida simultânea das correntes iônicas de dois isótopos.

McKinney em 1950 e Wanless e Thode em 1953 trouxeram novo avanço ao introduzirem sistemas duplos de introdução de gás, para admissão alternada da amostra e do padrão no espectrômetro ${ }^{7}$.

Em 1958 ocorreu um dos mais significativos desenvolvimentos em espectrometria de massas, notadamente para aplicações químicas da técnica, a invenção do filtro de massas quadrupolar por Paul ${ }^{10}$. A principal razão para o sucesso desta técnica é que suas características a tornam ideal para a combinação com a cromatografia gasosa. Paul descreveu três modos de operação para o quadrupolo ${ }^{10,11}$ : como um filtro de íons, como um sistema de varredura capaz de produzir um espectro de massas e como um sistema para rejeição de íons.

Em 1963, Brunnee ${ }^{12}$ descreveu um espectrômetro de massas por setor magnético, de duplo coletor, com um sistema especial de introdução de amostras e fonte de íons, dedicadas à análise isotópica de $\mathrm{UF}_{6}$, que reduziam a formação de camadas isolantes e o efeito memória na fonte de íons. 
Em 1976, baseado neste sistema, Rettinghaus ${ }^{13}$ descreveu um espectrômetro de massas baseado no filtro de massas quadrupolar, dotado de um sistema de introdução de amostras e uma fonte de íons dedicados à análise isotópica do $\mathrm{UF}_{6}$.

Ao longo dos anos, além da evolução dos analisadores em si, muito progresso vem sendo feito em todos os componentes ao redor dele. A substituição das válvulas por transistores revolucionou os componentes eletrônicos, aumentando em muito sua estabilidade. O uso de microprocessadores, o controle computadorizado dos equipamentos juntamente com sistemas automáticos de aquisição de dados; as melhoras nos sistemas de vácuo, nas fontes de íons e na óptica eletrônica tornaram os equipamentos muito mais confiáveis.

O espectrômetro utilizado no presente trabalho é baseado no modelo apresentado em 1976, por Rettinghaus, mas incorporando toda a evolução em eletrônica, informática e técnicas de vácuo.

\subsection{Espectrômetro de massas quadrupolar}

\subsubsection{Analisador de massas}

$\mathrm{O}$ analisador de massas por quadrupolo, ou filtro de massas quadrupolar foi desenvolvido por Wolfgang Paul ${ }^{10}$ e seu grupo na Universidade de Bonn na década de 1950 e, pelo fato de serem geralmente mais compactos, baratos e robustos que os espectrômetros por setor magnético, seu uso tem crescido desde então. Hoje em dia são os analisadores de massa mais populares ${ }^{4}$.

O desenvolvimento a seguir foi feito, mormente, a partir do trabalho de Dawson ${ }^{11}$.

Um filtro de massas quadrupolar ideal é composto por um conjunto de quatro barras metálicas paralelas de perfil hiperbólico, como as mostradas na FIG. 3. Estas barras são mantidas a potenciais elétricos $\pm \Phi_{0} / 2$, sendo de mesmo sinal o potencial das barras opostas e contrário o das barras adjacentes. 


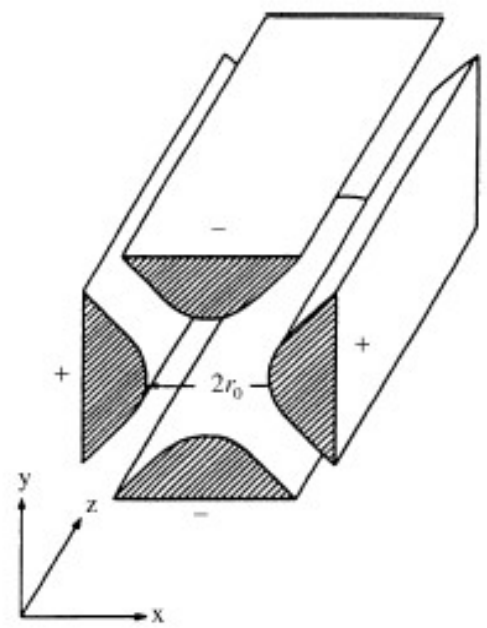

Figura 3. Estrutura de eletrodos de um filtro de massas quadrupolar ${ }^{11}$.

O campo elétrico gerado por este arranjo, considerando as barras muito longas, forma superfícies equipotenciais hiperbólicas, como as mostradas na FIG. 4, que podem ser expressas, em coordenadas retangulares, pela equação (1), onde $r_{0}$ é a meia distância entre barras opostas.

$$
\Phi=\frac{\Phi_{0}\left(x^{2}-y^{2}\right)}{2 r_{0}^{2}}
$$

Na prática, em virtude das dificuldades de fabricação e montagem, são usados cilindros circulares, que produzem aproximadamente o mesmo campo na região próxima ao eixo. A melhor aproximação é obtida quando o raio da seção transversal das barras é $r=1,148 r_{0}$, obtendo-se resultados suficientemente exatos para a maior parte das aplicações práticas. 


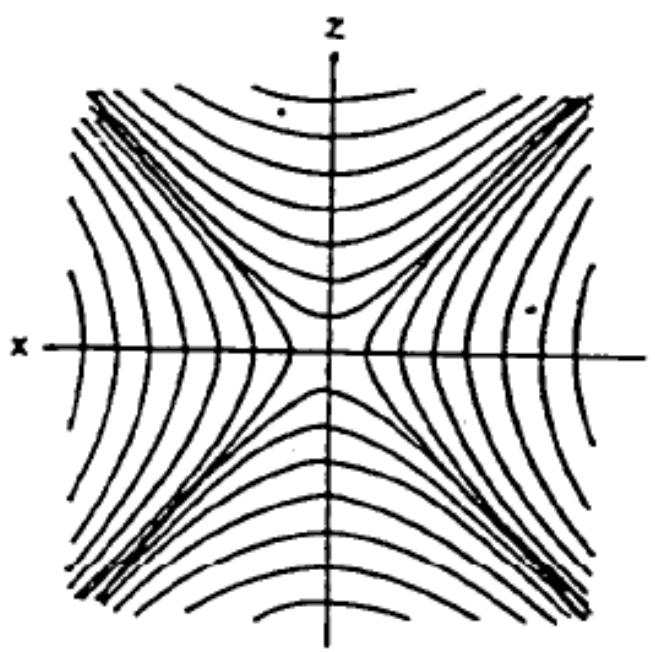

Figura 4. Linhas equipotenciais de um campo quadrupolar ${ }^{11}$.

O campo elétrico gerado por este arranjo pode ser expresso em coordenadas polares pelas equações:

$$
\begin{aligned}
& E_{x}=-\frac{d \Phi}{d x}=-\frac{\Phi_{0}}{r_{0}^{2}} x \\
& E_{y}=-\frac{d \Phi}{d y}=\frac{\Phi_{0}}{r_{0}^{2}} y \\
& E_{z}=-\frac{d \Phi}{d z}=0
\end{aligned}
$$

As equações de movimento para um íon, de massa $(m)$ e carga $(e)$, trafegando no interior do quadrupolo são:

$$
\frac{d^{2} x}{d t^{2}}+\left(\frac{e}{m}\right)\left(\frac{\Phi_{0}}{r_{0}^{2}}\right) x=0
$$




$$
\begin{aligned}
& \frac{d^{2} y}{d t^{2}}-\left(\frac{e}{m}\right)\left(\frac{\Phi_{0}}{r_{0}^{2}}\right) y=0 \\
& \frac{d^{2} z}{d t^{2}}=0
\end{aligned}
$$

O movimento de um íon, entrando no quadrupolo com velocidade $v_{z}$ na direção $z$, será descrito, nos planos $x-z$ e $y-z$, pelas equações (5) e (6), respectivamente, e sua natureza dependerá da forma do potencial elétrico $\Phi_{0}$.

Se $\Phi_{0}$ for constante, isto é, $\Phi_{0}=U$.

No plano $x-z$, a trajetória do íon será descrita por uma oscilação senoidal de amplitude finita.

No plano $y-z$, o íon se afasta exponencialmente do eixo $z$, escapando do quadrupolo ou chocando-se com as barras.

Se $\Phi_{0}$ for uma função periódica do tempo, da forma $\Phi_{0}=V \cos \omega t$, onde $V$ é constante; o campo elétrico será alternadamente convergente e divergente em ambos os planos. De acordo com as equações (5) e (6), a aceleração dos íons no plano $x$-y é inversamente proporcional a sua massa, conseqüentemente, a amplitude de oscilação dos íons mais pesados será menos que a dos mais leves. Para freqüências $(\omega)$ suficientemente altas, trajetórias estáveis podem ser obtidas em ambos os planos, para os íons mais pesados. Portanto, o quadrupolo operando com um potencial alternado atua como um filtro de massas passa - alta.

Se $\Phi_{0}$ for composto de um potencial contínuo combinado com um potencial alternado, conforme a equação 8 , as equações de movimento para um íon no interior do quadrupolo tomarão a forma das equações (9), (10) e (11).

$$
\Phi_{0}=U-V \cos \omega t
$$


onde:

$U$ é a tensão contínua.

$V$ é a amplitude máxima da tensão alternada.

$\omega=2 \pi f(f$ em Hertz) é freqüência angular do componente de rádio-freqüência (r.f.) aplicado.

$$
\begin{aligned}
& \frac{d^{2} x}{d t^{2}}+\left(\frac{e}{m r_{0}^{2}}\right)[U-V \cos (\omega t)] x=0 \\
& \frac{d^{2} y}{d t^{2}}-\left(\frac{e}{m r_{0}^{2}}\right)[U-V \cos (\omega t)] y=0 \\
& \frac{d^{2} z}{d t^{2}}=0
\end{aligned}
$$

O comportamento dos íons no quadrupolo será:

No plano $x-z$, os íons mais pesados, pouco sensíveis ao potencial oscilante, manterão sua trajetória estável, ao passo que os íons mais leves terão sua trajetória afastada do eixo $\mathrm{z}$ sempre que a componente alternada for maior que a contínua, fazendo com que a amplitude de suas oscilações seja cada vez maior, até se chocar com as barras ou sair do sistema. Portanto, a direção $x$ funciona como um filtro de massas passa - alta.

No plano $y-z$, os íons pesados terão trajetórias instáveis em razão da componente contínua do potencial, ao passo que os mais leves poderão ter sua trajetória estabilizada pela componente cíclica do campo, desde que suas magnitude e freqüência sejam tais que corrijam a trajetória sempre que sua amplitude tenda a crescer. Portanto, a direção $y$ funciona como um filtro de massas passa - baixa.

Uma escolha adequada de $U, V$ e $\omega$ faz com que apenas íons com massa dentro de uma faixa estreita atravessem o quadrupolo. A razão $U / V$ é crítica na largura da banda de passagem do filtro, ao passo que o valor de $V$ determina a posição da banda ${ }^{14}$. 
Definindo-se:

$$
\begin{aligned}
& a_{u}=a_{x}=-a_{y}=\frac{4 e U}{m \omega^{2} r_{0}^{2}} \\
& q_{u}=q_{x}=-q_{y}=\frac{2 e V}{m \omega^{2} r_{0}^{2}} \\
& \xi=\frac{\omega t}{2}
\end{aligned}
$$

as equações de movimento (9) e (10) tomam a forma:

$$
\frac{d^{2} u}{d \xi^{2}}+\left[a_{u}-2 q_{u} \cos 2\left(\xi-\xi_{0}\right)\right] u=0
$$

onde $u$ representa tanto $x$ quanto $y$ e o parâmetro $\xi_{0}$, chamado fase inicial, leva em conta a fase do campo o íon sofre sua influência pela primeira vez.

A equação (15) é a forma canônica da equação de Mathieu e descreve as trajetórias dos íons.

As soluções da equação de Mathieu podem ser expressas por:

$$
u=\alpha^{\prime} e^{\mu \xi} \sum_{n=-\infty}^{\infty} C_{2 n} e^{2 i n \xi}+\alpha^{\prime \prime} e^{-\mu \xi} \sum_{n=-\infty}^{\infty} C_{2 n} e^{-2 i n \xi}
$$

$\alpha$ ' e $\alpha$ ' são constantes de integração dependentes das condições iniciais $u_{0}$ (posição), $\stackrel{\varkappa}{0}_{0}$ (velocidade) e $\xi_{0}$ (fase).

As constantes $C_{2 n}$ e $\mu$ dependem dos valores de $a$ e $q$, mas não das condições iniciais. 
Portanto, a natureza do movimento iônico depende de $a$ e $q$, mas não das condições iniciais. Todos os íons com mesmos $a$ e $q$ (para uma dada direção coordenada) têm a mesma periodicidade de movimento.

As soluções da equação (15) são de dois tipos, dependendo da natureza de $\mu$.

1. Se $\mu$ permanece finito quando $\xi \rightarrow \infty$, as soluções são estáveis e, desde que a amplitude máxima do movimento do íon não ultrapasse a meia distância entre as barras opostas $\left(u_{\max }<r_{0}\right)$, os íons descrevem trajetórias estáveis, atravessando todo o comprimento do filtro.

2. Se $\mu \rightarrow \infty$ quando $\xi \rightarrow \infty$, as soluções são instáveis, os íons seguem trajetórias que atingem as barras ou saem do filtro. Não é útil para este instrumento.

Existem quatro possibilidades para $\mu$ :

1. $\mu$ é real e diferente de zero. A instabilidade se origina dos fatores $e^{\mu \xi}$ ou $e^{-\mu \xi}$

2. $\mu=i \beta$ é puramente imaginário e $\beta$ não é um número inteiro. Estas soluções são as periodicamente estáveis.

3. $\mu$ é um número complexo. As soluções são instáveis.

4. $\mu=$ im é puramente imaginário e $m$ é um inteiro. As soluções são periódicas, mas instáveis. Para $m=2 n$ a periodicidade é $\pi$ em $\xi$ e para $m=$ $2 n+1$ a periodicidade é $2 \pi$. Estas soluções são chamadas funções de Mathieu de ordem integral e formam as linhas divisórias, no espaço $(a, q)$, entre as regiões estáveis e instáveis.

Como $\mu$ depende apenas de $a$ e $q$, as condições de estabilidade podem ser representadas em um diagrama $a-q$, como o da FIG. 5, onde são mostradas as regiões de estabilidade e instabilidade para as direções $x$ e $y$. 


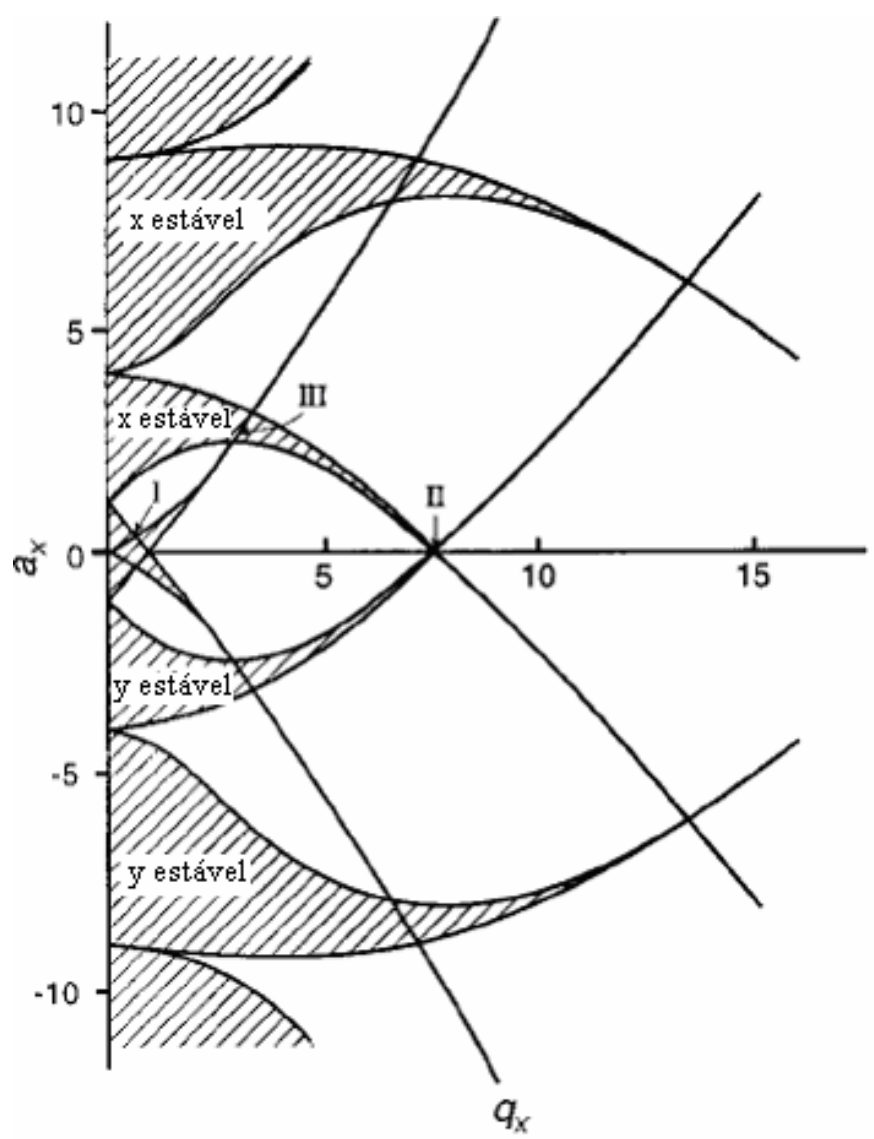

Figura 5. Diagrama de estabilidade ${ }^{11}$.

Embora haja uma série de regiões de estabilidade, apenas a mais próxima da origem, chamada por Dawson ${ }^{11}$ de primeira região de estabilidade, é correntemente usada em equipamentos comerciais. Umas visão mais detalhada desta região é dada na FIG. 6. 


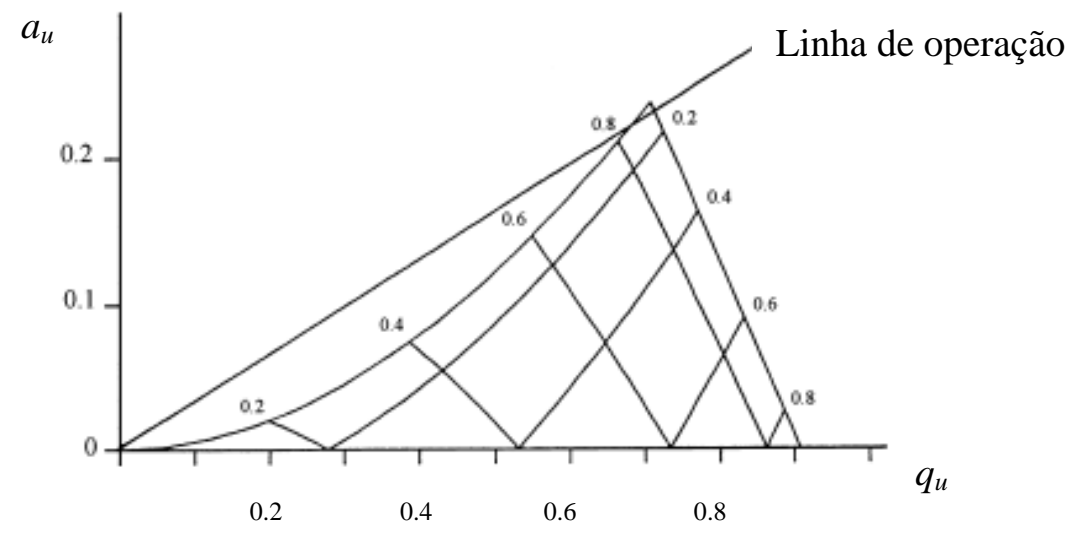

Figura 6. Primeira região de estabilidade.

Como a razão $a / q=2 U / V$ é independente da carga específica $e / m$, os pontos operacionais para todas as massas estão sobre uma linha, chamada linha de operação, que passa pela origem e tem inclinação $2 U / V$ (FIG. 6). A interseção da linha de operação com o diagrama de estabilidade determina a faixa de massas dos íons para os quais a trajetória é estável.

Variando-se os valores de $U$ e $V$, mas mantendo-se constante a razão $U / V$, o número de massa dos íons na região de estabilidade para transmissão pode ser varrido, enquanto a resolução é mantida constante. A resolução aqui é definida como a razão entre a distância do ponto central da região de estabilidade à origem e a largura da região de estabilidade, medida ao longo da linha de operação.

O espectro de massas pode ser varrido de duas maneiras. Na primeira, as tensões $U$ (tensão contínua) e $V$ (amplitude da r.f.) são mantidas constantes e a freqüência angular $\omega$ da r.f.é variada. Este método é pouco usado em razão das dificuldades técnicas encontradas na variação da freqüência em uma faixa de valores ampla. Na segunda maneira, a frequiência da r.f. é mantida constante e os valores de $U$ e $V$ são variados, mantendo-se fixa a razão $U / V$.

\subsubsection{Limites}

Duas características importantes para um dado analisador quadrupolar são: o intervalo de massas no qual ele pode trabalhar e a resolução máxima que pode ser atingida. 
Em um quadrupolo ideal de comprimento infinito, perfil hiperbólico e em que a freqüência e a amplitude da rf pudessem ser variadas sem restrições, não haveria limites para o intervalo de massas e a resolução. Um sistema real, entretanto, esta sujeito a limitações físicas e tais características, que não podem ser variadas independentemente entre si, dependem dos seguintes fatores ${ }^{7}$ :

$\Rightarrow$ comprimento das barras;

$\Rightarrow$ amplitude da rf aplicada;

$\Rightarrow$ freqüência da rf;

$\Rightarrow$ energia de injeção dos íons.

A maior massa que íon pode ter para poder ser focado pelo quadrupolo é:

$$
M_{m}=\frac{7 \times 10^{6} V_{m}}{f^{2} r_{0}^{2}}
$$

onde:

$V_{m}=$ voltagem máxima, em volts, da rf aplicada entre barras adjacentes $=2 \mathrm{~V}$.

$r_{0}=$ raio inscrito pelas barras (FIG. 1) em metro.

$f=$ freqüência da rf em hertz.

$M_{m}=$ massa máxima em u.m.a.

A resolução de um quadrupolo pode ser ajustada variando-se a inclinação de linha de operação (FIG. 5), quanto mais próximo do pico for a interseção da linha com o região estável do diagrama, localizado em $a_{y}=0,23699$ e $q_{y}=0,70600$, maior a resolução. Como a inclinação da reta é proporcional a $U / V$, a resolução pode ser ajustada eletricamente.

De acordo com o diagrama de estabilidade, a resolução não depende das condições de entrada do íon no quadrupolo, entretanto este diagrama não leva em conta as dimensões finitas do filtro. 
Para um quadrupolo real, a separação de massas não depende da oscilação iônica ser estável ou instável, mas de o íon atravessar o comprimento finito do quadrupolo sem atingir as barras, ou seja, os íons só atingem o detector se a amplitude de sua trajetória permanecer menor que o raio do quadrupolo $\left(r_{0}\right)$ ao longo do comprimento deste, portanto, a posição radial e a divergência angular dos íons ao entrar no quadrupolo devem ser os menores possíveis ${ }^{5}$.

Além disso, o limite de resolução depende do número de ciclos de rádiofreqüência ao qual os íons estão expostos e número de ciclos é limitado pelo comprimento finito do quadrupolo e pela energia dos íons na direção $z$.

A relação entre o número de ciclos ao qual os íons estão expostos e comprimento do quadrupolo é:

$$
N=f L\left(\frac{M}{2 E_{z}}\right)^{\frac{1}{2}}
$$

onde:

$f=$ freqüência da rf em Hertz.

$L=$ comprimento do quadrupolo em metros.

$M=$ massa do íon em $\mathrm{kg}$.

$E_{z}=$ energia axial de injeção dos íons em eV.

$N=$ número de ciclos ao qual o íon está exposto.

A relação normalmente aceita entre a resolução e o número de ciclos é:

$$
\frac{M}{\Delta M}=\frac{1}{\lambda} N^{\eta}
$$

para todos os propósitos práticos, $\lambda=20$ e $\eta=2$. Assim, a resolução máxima de um quadrupolo é: 


$$
\frac{M}{\Delta M}=0,05\left[f L\left(\frac{M}{2 E_{z}}\right)^{\frac{1}{2}}\right]^{2}
$$

\subsubsection{Imperfeições nos campos quadrupolares}

Além das limitações referentes às suas dimensões, aos parâmetros da rádiofreqüência e à energia dos íons, existem certas imperfeições que podem ocorrer no campo quadrupolar. Estas imperfeições podem ser divididas em 3 categorias:

1. Imperfeições causadas pelos campos de borda, na entrada e na saída dos íns. Nas bordas do quadrupolo, os campos deixam de ter o perfil hiperbólico, apresentando uma distribuição de equipotenciais mais complexa. Ainda não existe uma descrição completa dos efeitos dos campos de borda, mas certamente são prejudiciais quando os íon permanecem mais de três ou quatro ciclos em seu interior, o que ocorre sobretudo com os íons de baixa energia e/ou massa alta. Este efeito provoca discriminação de massas, porque os íons de massa menor são transmitidos com mais eficiência.

2. Imperfeições causadas por defeitos sistemáticos no campo. Estes defeitos decorrem sobretudo do desalinhamento das e barras e do uso de barras cilíndricas.

\section{a) Desalinhamento das barras.}

Limita a resolução máxima. Sua influência é maior que a dos fatores da equação para resolução máxima. Definindo-se o erro de construção como ${ }^{11}$ :

$$
E=\frac{2 \varepsilon+\varepsilon^{\prime}}{D}
$$

onde, $D$ é o diâmetro das barras, $\varepsilon$ é a tolerância na fabricação e $\varepsilon$ 'é qualquer erro adicional introduzido deliberadamente.

A resolução máxima dependerá deste erro da forma ${ }^{7}$ : 
Resolução máxima $\propto E^{1,3}$

\section{b) Uso de barras cilíndricas.}

Por causa da dificuldade de fabricação de superfícies hiperbólicas, barras cilíndricas de seção transversal circular são usadas como eletrodos na maioria dos aparelhos.

A melhor aproximação é conseguida montando os eletrodos em um arranjo quadrado com $r=1,148 r_{0}$, onde $\mathrm{r}$ é o raio dos eletrodos e $2 r_{0}$ é a distância entre eletrodos opostos $^{11}$.

Experiências realizadas por Brubaker ${ }^{15}$ mostraram que a substituição da superfície circular por hiperbólica melhora a resolução por um fator dois.

Apesar da melhora na resolução, o uso prático de superfícies hiperbólicas é questionável, por que as grandes dificuldades na fabricação e montagem destes eletrodos aumentam as chances de erros de alinhamento grandes e assimétricos, superando as vantagens de um campo teoricamente mais perfeito, especialmente em instrumentos de alta resolução.

\section{Imperfeição local do campo decorrente de contaminação das barras.}

Em razão da dependência crítica com a exatidão e estabilidade dos potenciais contínuo e alternado, o analisador quadrupolar é muito sensível ao acumulo de cargas eletrostáticas. Um potencial de apenas $10 \mathrm{mV}$ desenvolvido por impurezas na superfície das barras já suficiente para reduzir a sensibilidade do equipamento. Portanto, a limpeza do quadrupolo é essencial ${ }^{11}$.

As características peculiares do analisador por quadrupolo são ${ }^{15}$ :

a. são instrumentos pequenos e leves (comparados aos de setor magnético);

b. varredura rápida do espectro de massas;

c. operação linear;

d. fontes de íons de baixa energia $(<10 \mathrm{eV})$;

e. variação elétrica da resolução. 


\subsubsection{Fontes de íons}

Existe uma grande variedade de maneiras de se produzirem íons, positivos ou negativos, o que levou ao desenvolvimento de diversos modelos de fontes de íons. Não existe fonte que seja ideal para todos os tipos de análise nem todo tipo de analisador. Sua escolha depende do tipo de amostra e das informações desejadas ${ }^{3}$.

Uma fonte de íons adequada ao uso em um espectrômetro de massas para determinação de razões isotópicas deve ter as seguintes características ${ }^{3,7}$ :

- baixo consumo de amostra;

- alta estabilidade;

- baixa dispersão de energia no feixe de íons;

- produzir correntes de íons maiores que $10^{-10} \mathrm{~A}$;

- não produzir efeito memória;

- contagem de fundo reduzida;

- a discriminação de massas deve ser reduzida.

Duas fontes com estas características são as mais usadas em espectrômetros de massas para determinação de razões isotópicas, as fontes de termo-ionização, para amostras sólidas e líquidas e as de impacto eletrônico, para amostras gasosas ${ }^{7}$. Recentemente, também tem sido muito empregada a técnica de ionização por plasma induzido $^{14}$.

O espectrômetro de massas utilizado neste trabalho é dotado de uma fonte de íons por impacto eletrônico, cujo diagrama é apresentado na FIG. 7. 


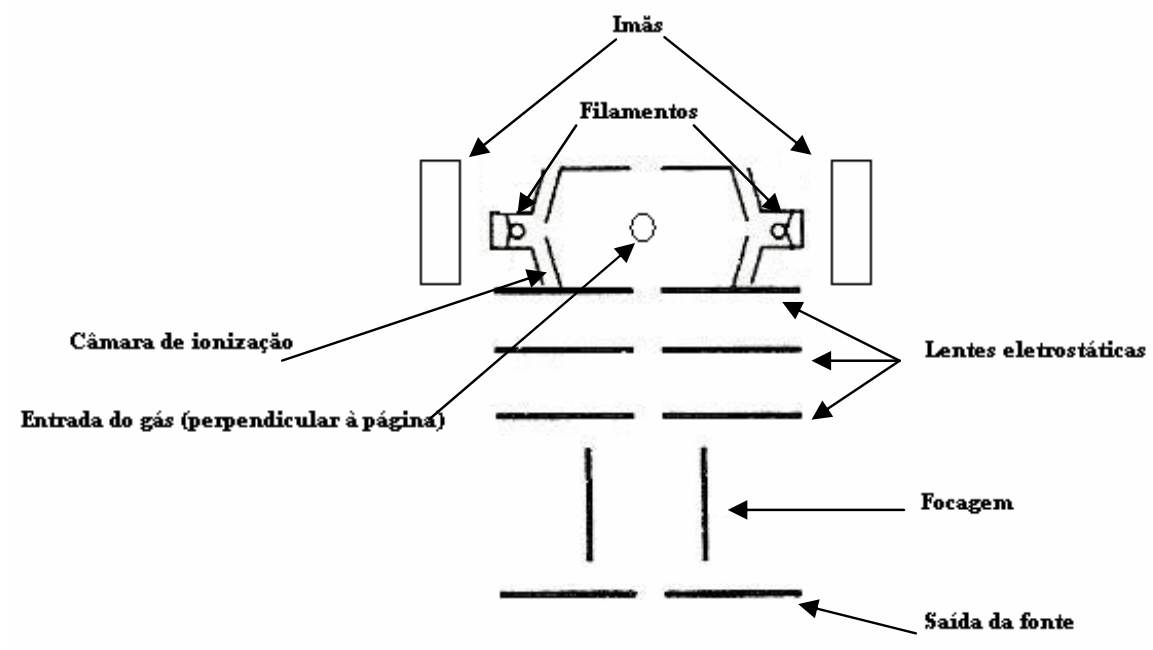

Figura 7. Fonte de íons por impacto eletrônico.

O gás a ser analisado chega à fonte de íons por um tubo capilar, em regime de escoamento molecular, passa por três anteparos colimadores e entra na câmara de ionização em direção perpendicular ao feixe de elétrons, produzido por um dos dois filamentos, e ao eixo principal do quadrupolo. O fluxo de gás e o feixe de elétrons se interceptam no centro da fonte, onde ocorrem a colisão e a ionização. Quando a energia dos elétrons for ligeiramente maior que o primeiro potencial de ionização, o impacto dos elétrons com as moléculas $A B$ do gás poderá causar apenas a reação primária caracterizada pela relação ${ }^{7}$ :

$$
A B+e^{-} \rightarrow A B^{+}+2 e^{-} \text {(ionização) }
$$

Como a ionização por impacto eletrônico não é muito eficiente, apenas uma molécula em um milhão sofre este tipo de ionização.

Para que a fonte produza um número significativo de íons a uma razão constante, os elétrons emitidos pelo filamento devem ser acelerados por potenciais maiores que $50 \mathrm{~V}^{4}$. Por causa da pequena massa dos elétrons, o impacto não provoca variação mensurável na energia das moléculas do gás, mas as deixa em estados vibracionais e rotacionais altamente excitados, que levam à sua fragmentação em um grande número de 
íons positivos, com massas menores que a do íon molecular, como a representada na expressão:

$$
A B+e^{-} \rightarrow A^{+}+B^{0}+2 e^{-} \text {(ionização e dissociação) }
$$

A produção de cada tipo de íon é proporcional a seção de choque para o processo.

O número e o tipo de íons formados na colisão entre os elétrons e as moléculas depende da energia dos elétrons. Em energias pouco maiores que o potencial de ionização das moléculas, ocorre pouca fragmentação, mas, a medida que a energia dos elétrons é aumentada, íons mais ionizados e vários tipos de fragmentos da molécula podem ser gerados $^{5}$. A abundância de cada fragmento dependerá da energia do elétron, que deve ser escolhida de modo a maximizar a eficiência da ionização do íon mais abundante. Para a maioria das moléculas, este máximo ocorre quando a energia dos elétrons está entre 50 e $90 \mathrm{eV}$, portanto é nesta faixa de valores que operam as fontes de íons por impacto eletrônico ${ }^{3}$.

Os íons positivos gerados sofrem repulsão das paredes da câmara, mantidas a um potencial positivo $V l$, e são atraídos, colimados e lançados para o interior do quadrupolo na direção de seu eixo principal (eixo z), pelo conjunto de lentes eletrostáticas.

A intensidade de corrente iônica produzida por uma fonte de íons por impacto eletrônico, para uma dada energia $E$ dos elétrons, é dada pela expressão ${ }^{3}$ :

$i^{+}=\alpha i^{-} l_{e} \sigma_{E} n_{g}$

onde:

$i^{-}=$intensidade da corrente eletrônica penetrando as moléculas do gás.

$l_{e}=$ comprimento efetivo do feixe de elétrons interagindo com a amostra.

$\sigma_{E}=$ seção de choque de ionização do gás a energia $E$.

$n_{g}=$ densidade do gás.

$\alpha=$ eficiência com que os íons são extraídos da fonte. 
Os parâmetros da equação (23) devem ser tais que a fonte produza a maior corrente iônica possível com o menor consumo de amostra (alta sensibilidade). Estes parâmetros dependem tanto do projeto e construção da fonte quanto de ajustes posteriores.

A intensidade da corrente eletrônica $i^{-}$é controlada pela emissão do filamento. A corrente iônica aumenta com o aumento da corrente eletrônica até um certo limite, quando, em razão do aumento da carga espacial, um acréscimo em $i^{-}$não produz aumento de $i^{+}$.

Quanto maior o caminho percorrido pelos elétrons dentro do gás, maior a corrente. Para que a fonte de íons tenha dimensões reduzidas, este caminho é aumentado com o uso de um campo magnético paralelo a direção da corrente eletrônica. Em um campo magnético longitudinal, os elétrons divergentes percorrem uma trajetória espiralada ao longo do eixo do campo, em razão da componente radial da velocidade, aumentando o caminho percorrido.

A focagem do feixe de elétrons tem dois efeitos favoráveis ${ }^{3}$ :

1. limita as dimensões laterais do feixe de elétrons e, conseqüentemente, o volume de ionização direta, resultando na produção de íons com baixa dispersão de energia;

2. caminho dos elétrons através do gás fica duas vezes mais longo, fazendo com que mais íons sejam produzidos para uma dada pressão.

Entretanto, o campo magnético não tem apenas efeitos positivos. Ele representa, para os íons lentos produzidos no volume de ionização, um pequeno espectrômetro de massas. Como conseqüência, o número de íons que deixam a fonte em uma dada direção depende da massa da espécie ${ }^{3}$, isto é, ocorre discriminação de massas.

Outro efeito importante é chamado auto interferência ${ }^{3}$. A produção de íons produz uma carga espacial positiva dentro do volume de ionização, que é maior quanto mais lentos forem os íons produzidos. Embora o número de elétrons no volume seja muito maior que o número de íons, os elétrons não compensam as cargas positivas por serem muito mais rápidos. O resultado é que a carga espacial reduz o campo de retirada de cargas da fonte, isto é, íons impedem os íons de serem retirados da fonte. Em combinação com a 
discriminação de massas no campo magnético da fonte, este efeito resulta em uma dependência da razão isotópica medida com a pressão e com a corrente eletrônica. Além disso, em aplicações que usam um gás carregador para trazer a amostra isotópica até a fonte, a carga espacial do gás carregador pode ter um grande efeito na razão isotópica medida da amostra (interferência cruzada).

Deve-se trabalhar com íon cuja seção de choque de produção seja a maior entre todos os possíveis fragmentos, isto é, com o íon mais abundante.

A densidade do gás na fonte é um parâmetro ao qual não se tem acesso, já que a pressão na fonte não é conhecida, entretanto esta densidade deve ser proporcional a pressão do gás antes de passar pelo capilar e esta pressão pode ser medida. Aumentando-se a pressão na entrada da fonte a densidade do gás aumenta, mas a linearidade entre a corrente iônica e a densidade, exibida pela equação (23), não é ilimitada. O aumento da densidade causa um aumento da carga espacial, cujos efeitos, difíceis de quantificar, fazem com que a equação (23) deixe de ser válida.

A eficiência com que os íons são extraídos da fonte dependerá da geometria da fonte, das tensões elétricas na câmara de ionização e nas lentes eletrostáticas e da carga espacial no volume de ionização. Para uma fonte com dada geometria, o valor de $\alpha$ pode ser maximizado alterando-se os parâmetros elétricos da fonte até que se atinja a maior corrente iônica do fragmento com maior seção de choque.

Com o fim de maximizar o fluxo de íons entrando no quadrupolo, a abertura de saída da fonte, que corresponde à abertura de entrada do quadrupolo, deveria ser grande o suficiente para permitir a passagem de todos os íons produzidos, mas, como foi visto em 3.3.2, para que se obtenha boa resolução, o feixe de íons deve ser estreito.

A relação entre o tamanho da abertura de entrada no quadrupolo e a resolução, para que a transmissão seja de $100 \%$, pode ser derivada a partir do deslocamento axial máximo dos íons, para todas as fases do campo de rádio-freqüência, e é dada por: 


$$
D_{m}=r_{o}\left(\frac{\Delta M}{M}\right)^{\frac{1}{2}}
$$

onde $D_{m}$ é o diâmetro de abertura para transmissão de $100 \%$.

O comportamento destas fontes não depende apenas da abertura de saída, mas também da divergência do feixe de íons quando entra no campo de borda do quadrupolo (item 3.3.3), que pode provocar um aumento da energia média do feixe. Além disso, para alta resolução seja obtida os íons devem ter baixa energia ${ }^{11}$.

A partir das expressões (18) e (19) com $K=20$ e $n=2$, a energia máxima dos íons entrando no quadrupolo, para que se obtenha a resolução máxima $\left(R_{\max }\right)$ é $^{7}$ :

$$
E_{z}=2,25 \cdot 10^{-2} f^{2} L^{2} \frac{M}{R_{\max }}
$$

A energia radial $E_{r}$ e ângulo máximo de entrada $\psi_{m}$, para que a transmissão de $100 \%$ ocorra, são:

$$
\begin{aligned}
& E_{r}<5,24 \cdot 10^{-3} r_{0}^{2} f^{2} \frac{M}{R_{\max }} \\
& \Psi_{m}=\tan ^{-1}\left[0,351\left(\frac{r_{0}}{L}\right)\right]
\end{aligned}
$$

O raio típico desta abertura, combinando as duas necessidades, é aproximadamente $r_{0} / 2^{10}$.

As restrições quanto à energia, à dispersão e à largura do feixe de íons, tornam a montagem e o alinhamento da fonte de íons um fator limitante do desempenho do espectrômetro de massas como um todo. 
Um deslocamento lateral da fonte provoca três efeitos ${ }^{11}$ :

- redução da resolução;

- necessidade do aumento da energia dos íons;

- degradação da forma dos picos.

Além de alinhada, a fonte deve ser montada próxima à entrada do quadrupolo para reduzir o efeito dos campos de borda.

\subsubsection{Detectores}

Após a separação, a corrente iônica que deixa o quadrupolo deve ser medida da maneira mais exata e precisa possível. A corrente iônica é formada por uma sequiência de partículas, que chegam ao detector de íons separadas por intervalos de tempo, cuja distribuição segue a estatística de Poisson ${ }^{3}$.

Segundo esta estatística, se num dado intervalo de tempo são contados $N$ íons chegando ao coletor, o desvio padrão relativo desta contagem é dado por $\sigma / N=1 / \sqrt{ } N$, que é, em princípio, o limite máximo de precisão com que uma corrente iônica pode ser medida.

Entretanto, para as intensidades usuais de corrente iônica encontradas na determinação de razões isotópicas (entre $10^{-12}$ e $10^{-10} \mathrm{~A}$ ), o que se mede é a corrente total e não o número de íons chegando; nesta situação, a estatística de Poisson não é mais válida ${ }^{3}$.

Os dois detectores de íons mais usados na determinação de razões isotópicas são o copo de Faraday e o multiplicador de elétrons.

\section{COPO DE FARADAY}

Na FIG. 8 é apresentado um esquema de um detector de íons do tipo copo de Faraday. O detector é alinhado de modo que os íons deixando o analisador atinjam o eletrodo coletor. 


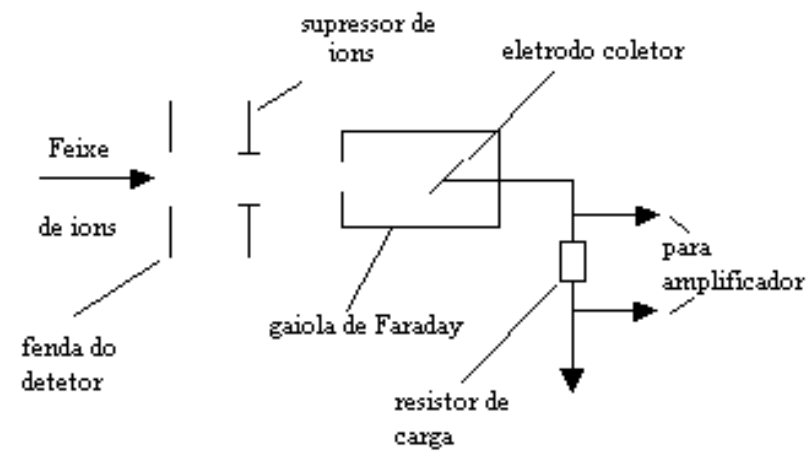

Figura 8. Copo de Faraday ${ }^{4}$.

Para evitar a saída de elétrons secundários, que alterariam o valor das medidas de corrente, o eletrodo coletor é rodeado por um cilindro metálico, formando uma gaiola, com apenas uma abertura da direção do fluxo iônico ${ }^{4}$. Além disso, o coletor é geralmente inclinado em relação a direção do feixe iônico para impedir o retorno de partículas refletidas para o analisador.

As superfícies internas do copo de Faraday são geralmente recobertas por uma camada de material com baixa razão de "sputter", como o carbono poroso 4 .

O eletrodo coletor e a gaiola ao redor dele são aterrados por meio de um resistor $\left(10^{6}-10^{8} \Omega\right)$, a queda de potencial através dele é amplificada por um eletrômetro amplificador de alta impedância ${ }^{3}$. O primeiro estágio deste amplificador deve ser montado em uma "cabeça" separada, mas rigidamente presa ao invólucro do quadrupolo, ligada ao eletrodo coletor por um cabo de poucos centímetros ${ }^{10}$. A blindagem eletrostática deve ser perfeita e o eletrômetro livre de vibrações. Isto é essencial para reduzir a captura de sinais espúrios a um mínimo, além de manter a capacitância de entrada em um valor razoável ${ }^{10}$.

Para que a razão isotópica observada seja calculada, as corrente iônicas correspondentes a cada um dos isótopos devem ser medidas. A razão isotópica observada, entretanto, não corresponde à verdadeira razão isotópica da amostra e deve ser calibrada. 
As intensidades das correntes iônicas variam com o tempo em razão do consumo da amostra, como em espectrômetro por quadrupolo as correntes não podem ser medidas simultaneamente, a razão calculada será diferente da verdadeira e deve ser corrigida.

Este efeito pode ser evitado completamente em espectrômetros por setor magnético, empregando-se coletores múltiplos, que medem as correntes dos dois isótopos simultaneamente ${ }^{3}$. Todas as medidas de razão isotópica de alta precisão são feitas utilizando-se detectores múltiplos, cada um para um isótopo.

Este método não pode ser aplicado aos quadrupolos, nos quais as medidas são seqüenciais, mas uma compensação pode ser feita medindo-se diversas, e alternadas, vezes as correntes iônicas correspondentes a cada isótopo e calculando-se o desvio causado pela redução das intensidades ${ }^{4}$.

As principais vantagens dos detectores deste tipo são o baixo custo, sua simplicidade mecânica e elétrica e a resposta independente da energia, da massa e da natureza química dos íons ${ }^{3,7,11}$.

As principais desvantagens são o alto nível de ruído, a sensibilidade limitada e a resposta lenta ${ }^{3,7,10}$.

\section{MULTIPLICADOR DE ELÉTRONS}

Na FIG. 9, é apresentado um esquema de um multiplicador de elétrons, com dinodos separados, para detecção de íons positivos. 


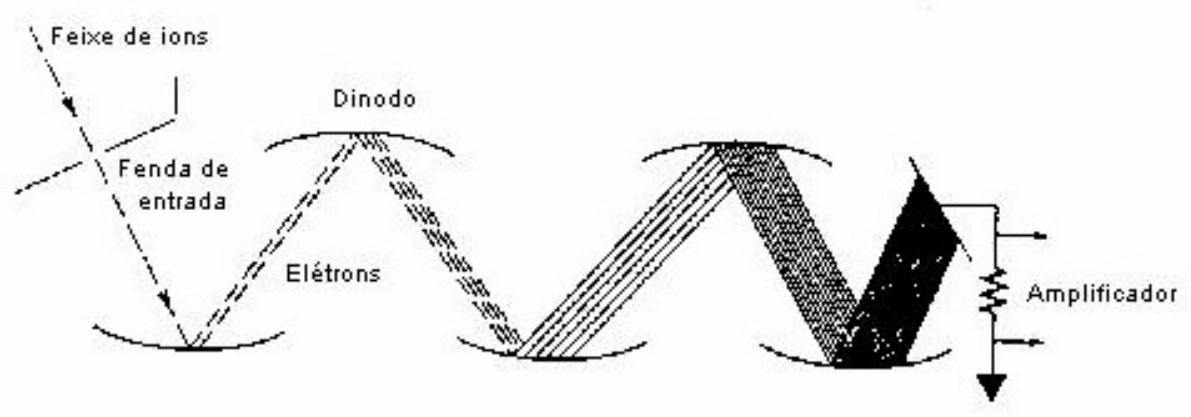

Figura 9. Detector de íons com multiplicador de elétrons ${ }^{4}$.

Os diversos dinodos têm superfícies de $\mathrm{CuBe}^{4}$, que emitem grande quantidade de elétrons quando atingidos por íons ou elétrons energéticos. Existem multiplicadores de elétrons com até 20 dinodos que produzem ganhos de corrente da ordem de $10^{7}$.

Os íons positivos ao atingirem a primeira placa, ou eletrodo conversor, dão origem a elétrons secundários. Estes são acelerados e focados em um segundo dinodo, dando origem a uma segunda e mais numerosa geração de elétrons e assim por diante. Os dinodos são conectados a potenciais sucessivamente maiores. O diodo conversor tem função única, porque é nele que a corrente de íons positivos é convertida em uma corrente de elétrons, ao passo que nos estágios sucessivos a corrente de elétrons é simplesmente multiplicada ${ }^{7}$.

A eficiência de conversão do dinodo conversor depende de uma série de fatores $^{7}$ :

a. Para uma dada espécie de íons positivos, o número de elétrons secundários produzidos por íon incidente aumenta com a energia do íon, sendo o aumento linear para baixas energias. A faixa de linearidade aumenta com a massa dos íons.

b. Em geral, para uma dada energia, a eficiência de conversão decresce com o aumento da massa dos íons positivos. Em energias altas esta tendência pode ser revertida.

c. O número de elétrons secundários produzidos decresce com o aumento do potencial de ionização do íon, isto é, depende da espécie química do íon. 
d. A produção de elétrons secundários aumenta com o ângulo de incidência dos íons, assim como aumenta a reflexão dos íons incidentes. $\mathrm{O}$ balanço destes dois efeitos leva a um ângulo ótimo ao redor de $70^{\circ}$.

e. A eficiência é maior para íons negativos que para íons positivos. Partículas neutras e íons positivos, com carga simples ou dupla, produzem o mesmo efeito se tiverem energias iguais.

f. Íons moleculares produzem um número maior de íons do que íons atômicos de mesma massa.

A eficiência dos outros estágios depende ${ }^{7}$ :

$\Rightarrow$ da geometria das placas;

$\Rightarrow$ da diferença de tensão entre os estágios;

$\Rightarrow$ do material e do estado de ativação das placas;

$\Rightarrow$ do grau de blindagem magnética.

Nos espectrômetros de massas por setor magnético em que os íons deixam o analisador de massas com energia suficiente para ejetar elétrons do dinodo conversor, o multiplicador de elétrons pode ser colocado logo atrás da fenda de saída do analisador. Já nos quadrupolos, os íons que deixam o analisador devem ser acelerados até que sua energia chegue a alguns milhares de elétron-volts antes de atingirem o dinodo conversor ${ }^{3}$.

Para evitar foto-ionização do dinodo conversor, o eixo do multiplicador é disposto fazendo um ângulo de $90^{\circ} \mathrm{com}$ o eixo do quadrupolo.

As principais vantagens do multiplicador de elétrons são ${ }^{11}$ :

$\Rightarrow$ extrema sensibilidade, permitindo a detecção de até um único íon;

$\Rightarrow$ alto ganho de corrente - entre $10^{5}$ e $10^{7}$;

$\Rightarrow$ tempo de resposta muito curto, da ordem de nanosegundos;

$\Rightarrow$ nível de ruído menor que $10^{-17} \mathrm{~A}$. 
As principais desvantagens são ${ }^{11}$ :

$\Rightarrow$ instabilidade do ganho;

$\Rightarrow$ dependência do ganho com a massa do íon, devida a discriminação de massas no dinodo coletor.

Os dois sistemas de detecção estão sujeitos a efeitos não lineares decorrentes, especialmente, da dependência do valor do resistor de carga com a tensão e da não linearidade entre as várias faixas de ganho do amplificador.

\subsubsection{Sistemas de introdução de amostras}

A característica mais importante de um sistema de introdução de amostras gasosas é possibilitar que se introduzam tanto o gás da amostra quanto o gás do material de referência de maneira idêntica na fonte de íons. Deste modo, se alguma adulteração da razão isotópica durante o processo de introdução não puder ser evitada, esta adulteração deve, ao menos, ser idêntica na amostra e no material de referência. Outro requisito importante para este sistema é que a razão isotópica permaneça constante durante a introdução ${ }^{3}$.

Para atender ao requisito de constância da razão isotópica, a maior parte da amostra é usada para garantir condições apropriadas de não fracionamento isotópico por um período longo de medição, sendo apenas uma pequena parcela efetivamente consumida na análise. Este período longo com condições estáveis proporciona análises com grande precisão e exatidão $^{3,11}$.

A FIG. 10 mostra um diagrama simplificado deste sistema de introdução de amostras. Uma certa quantidade de amostra é expandida em um tanque de volume $V$ até uma pressão predeterminada $P V$, o gás no tanque é levado para a fonte de íons, por diferença de pressão, através de um tubo, por escoamento viscoso (o livre caminho médio das moléculas do gás é menor que as dimensões do tubo). Ao final do tubo existe um capilar, que limita o fluxo de gás e mantém a pressão na fonte de íons baixa. Este capilar tem diâmetro menor que o livre caminho médio das moléculas do gás e, portanto, fluxo molecular. 


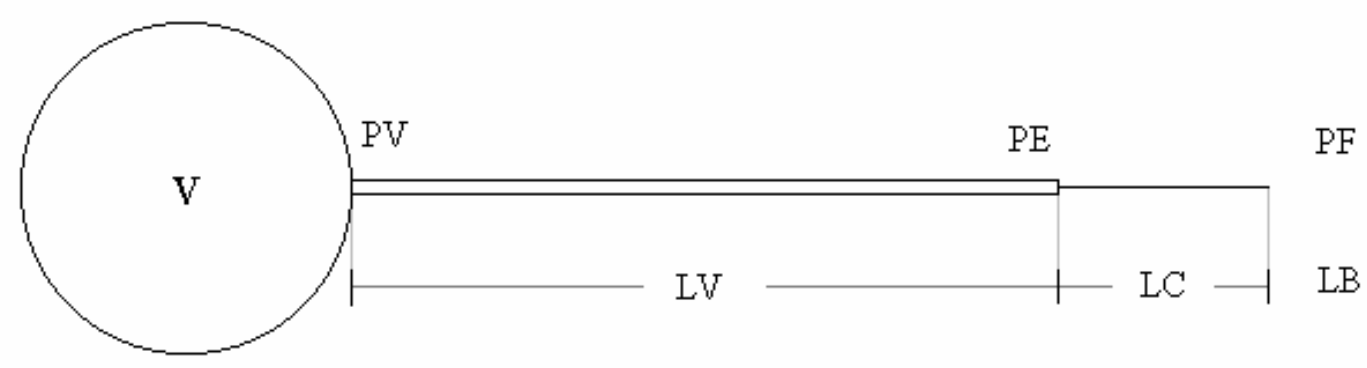

Figura 10. Sistema de introdução de amostras, onde:

$P V=$ pressão do gás no tanque de volume $\mathrm{V}$.

$P E=$ pressão do gás em frente ao capilar.

$P F=$ pressão do gás na fonte de íons.

$L V=$ condutância do tubo em regime viscoso.

$L C=$ condutância do capilar em regime molecular.

$L B=$ condutância da fonte de íons em regime molecular.

O fluxo viscoso no tubo é proporcional à diferença dos quadrados da pressões no início e no final do tubo ${ }^{16}$, ao passo que o fluxo molecular no capilar é proporcional à diferença das pressões no início e no final do capilar. Pode-se provar que ${ }^{3}$ :

$$
P F=\frac{L C}{L C+L P}\left[\sqrt{\frac{L C}{2 L V}+P V^{2}}-\frac{L C}{2 L V}\right]
$$

Como mostra a equação, a pressão na fonte $P F$ e a pressão no tanque no tanque $P V$ não são linearmente relacionadas.

Outra diferença importante entre os fluxos viscoso e capilar está relacionada à dependência dele com as massas das moléculas do gás ${ }^{16}$. Havendo várias espécies isotópicas no tanque, a razão entre os fluxos de duas delas, no regime viscoso, não depende de suas massas moleculares; mas é inversamente proporcional a razão do quadrado de suas 
massas moleculares quando o fluxo é molecular ${ }^{16}$. Deste modo, havendo uma mistura de duas espécies isotópicas, 1 e 2 e sendo:

$$
\begin{aligned}
& M 1=\text { massa molecular do isótopo } 1 . \\
& M 2=\text { massa molecular do isótopo } 2 . \\
& P V 1=\text { pressão parcial do isótopo } 1 \text { no tanque. } \\
& P V 2=\text { pressão parcial do isótopo } 2 \text { no tanque. } \\
& P E 1=\text { pressão parcial do isótopo } 1 \text { no final do tubo, antes do capilar. } \\
& P E 2=\text { pressão parcial do isótopo } 2 \text { no final do tubo, antes do capilar. }
\end{aligned}
$$

A razão isotópica no final do tubo será dada por ${ }^{3}$ :

$$
\frac{P E 2}{P E 1}=\sqrt{\frac{M 2}{M 1}} \frac{P V 2}{P V 1}
$$

Como a quantidade de gás entrando no tubo é igual a que sai do capilar, a razão isotópica do gás no final do tubo será diferente da razão do gás no tanque. Em frente ao capilar o gás é isotopicamente mais pesado.

A condutância do capilar é proporcional ${ }^{16}$ a $1 / \sqrt{ } M$, portanto maior para o componente mais pesado da amostra, por outro lado, a superfície gelada da armadilha criogênica que bombeia o $\mathrm{UF}_{6}$, em regime molecular, para fora da fonte de íons, também tem velocidade de bombeamento proporcional a $1 / \sqrt{ } M$. A razão das pressões das espécies isotópicas na fonte é a mesma que a razão antes do capilar, mas é diferente das razões das pressões no tanque. Portanto pode ocorrer discriminação de massas no sistema de introdução de amostras.

\subsubsection{Parâmetros importantes}

\section{Resolução.}

A capacidade de um espectrômetro de distinguir massas é normalmente dada em termos de sua resolução $\mathrm{R}$, definida, em 3.3.1, como a razão entre a distância do ponto central da região de estabilidade à origem e a largura da região de estabilidade, medida ao longo da linha de operação, embora seja útil para análises teóricas do quadrupolo, esta 
definição não é prática em termos experimentais. Uma outra definição da resolução, $R e$, em termos de parâmetros mensuráveis experimentalmente é:

$$
R e=\frac{M}{\Delta M}
$$

onde: $\Delta M$ é a diferença de massa entre dois picos adjacentes e separados, com mesma intensidade, e $M$ é a massa média dos picos. Geralmente, dois picos são considerados separados quando a altura do vale entre eles é menor que certa porcentagem da sua altura (normalmente $10 \%$ ou 50\%) conforme mostrado na FIG. 11.

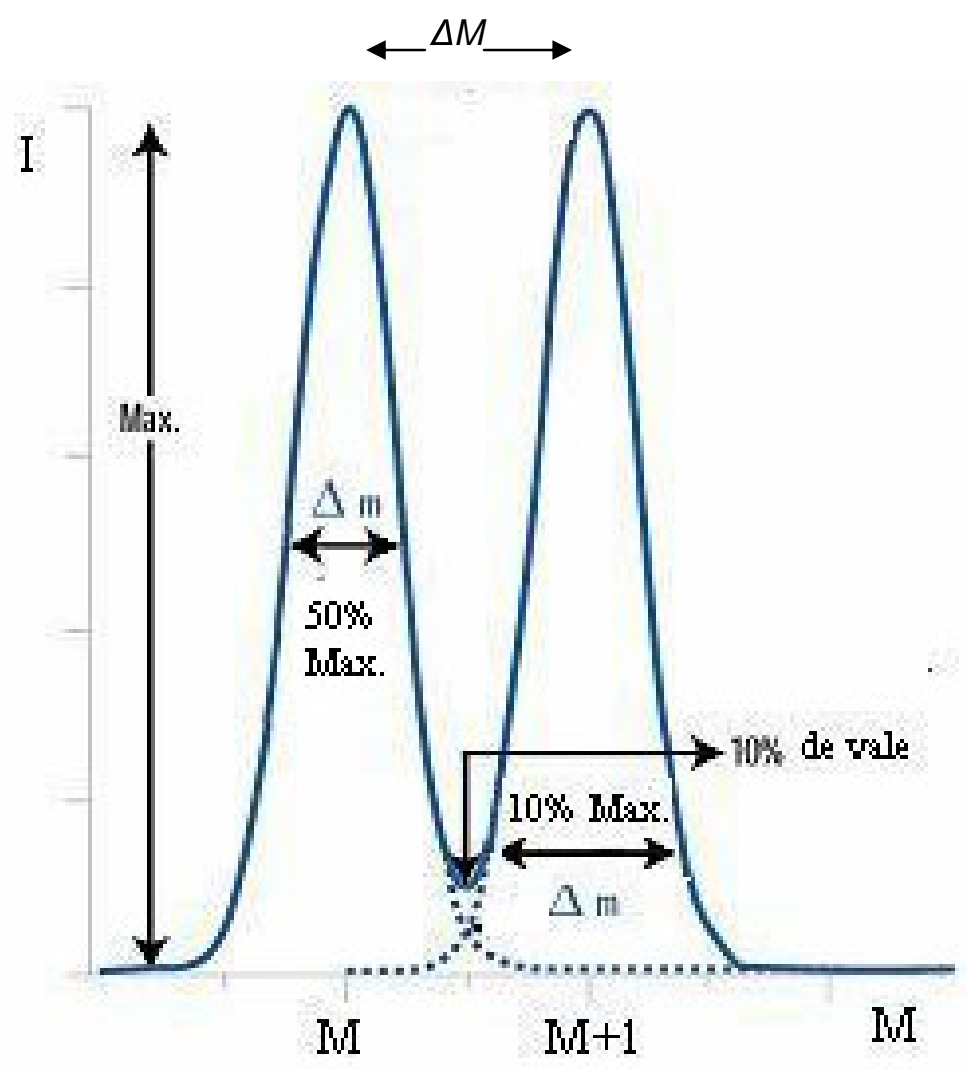

Figura 11. Dois picos idênticos separados por uma unidade de massa atômica, onde são mostradas as três definições da largura do pico. 
Como picos adjacentes de mesma altura e na faixa de massas de interesse são raros, a resolução pode ser definida, alternativamente, com relação à largura do pico de massa $M$ a $10 \%$ ou $50 \%$ de sua altura, sendo $\Delta M_{x}$ a largura do pico nesta altura. A largura a $10 \%$ é a mais usada (FIG. 11).

Existe uma relação inversa entre a resolução e a transmissão dos íons através do quadrupolo. A transmissão diminui com o aumento da resolução, porque a linha de operação é elevada na direção do limite da região de estabilidade, tendo como conseqüência o aumento da amplitude de oscilação dos íons. Para uma largura constante da linha de operação (ou $\Delta M$ constante), a resolução aumenta com o número de massa, ao passo que a transmissão diminui, causando discriminação de massas.

\section{Sensibilidade instrumental.}

Sensibilidade instrumental é definida como a razão entre a corrente iônica medida no detector e a pressão parcial do isótopo correspondente:

$$
S=\frac{i^{+}}{P}
$$

Fixando-se os parâmetros da fonte de íons, a sensibilidade dependerá da resolução e da massa do íon.

\section{Dependência com a resolução.}

A amplitude das oscilações dos íons no interior do quadrupolo depende das condições de entrada (deslocamento axial, divergência angular, fase da rádio freqüência) e da razão entre as tensões alternada e contínua aplicadas às barras $(U / V)$. A medida que a razão $U / V$ aumenta, para aumentar a resolução, uma fração maior dos íons é perdida, levando a uma redução da sensibilidade.

A relação entre a sensibilidade e a resolução é bastante complexa, dependendo da concentração e divergência dos íons deixando a fonte. Esta dependência é complicada pela ação desfocante dos campos de borda entre a fonte e o quadrupolo. Os íons de baixa 
energia ficam mais tempo nestes campos, sendo mais desfocados e, portanto, transmitidos com menos eficiência.

\section{Dependência com a massa.}

Em um quadrupolo ideal a eficiência da transmissão independe da razão $m / z$. Tal não ocorre em um quadrupolo real, porque quanto mais pesado o íon maior o tempo gasto nos campos de borda e, portanto, maior a dispersão no quadrupolo ${ }^{10}$.

Conseqüentemente, existe sempre a tendência de os íons mais pesados serem transmitidos com menor eficiência, resultando em discriminação de massa. Este efeito também depende da resolução. Para resoluções abaixo de um certo valor crítico pode não haver discriminação ao longo de toda a faixa de massas, para resoluções maiores que a crítica a sensibilidade cai drasticamente para massas elevadas ${ }^{11}$.

A magnitude da discriminação e a resolução a partir da qual ela se torna significativa dependem do projeto geral do espectrômetro.

Para melhores resultados, a fonte de íons deve ser alinhada exatamente com o analisador e posta tão próxima quanto possível do final das barras, a fim de minimizar o efeito dos campos de borda.

\section{Sensibilidade a abundância.}

Quando um pico de baixa intensidade, adjacente a um pico alta intensidade, é medido, não basta que o pico menor seja resolvido, é necessário que qualquer contribuição da calda do pico maior ao menor seja mínima. Esta contribuição é quantificada em termos de sensibilidade de abundância, definida como a contribuição do sinal de massa $M$ aos vizinhos de massas $M \pm 1$.

Na FIG. 12, é mostrado um pico de intensidade na massa $M$ e são marcadas algumas dimensões.

$h$ é a altura do pico na massa $M$.

$h l$ é a altura do pico na massa $M-1$.

$h 2$ é a altura do pico na massa $M+1$. 
As razões $h 1 / h$ e $h 2 / h$ são conhecidas como sensibilidade de abundância para massa baixa e para massa alta, respectivamente.

Em um filtro de massas quadrupolar, estes parâmetros não são iguais em razão da assimetria dos picos, tal assimetria decorre da assimetria do diagrama de estabilidade.

Em um quadrupolo usando fonte de íons por impacto eletrônico, as sensibilidades a abundância são bastante baixas em razão da baixa energia dos íons injetados.

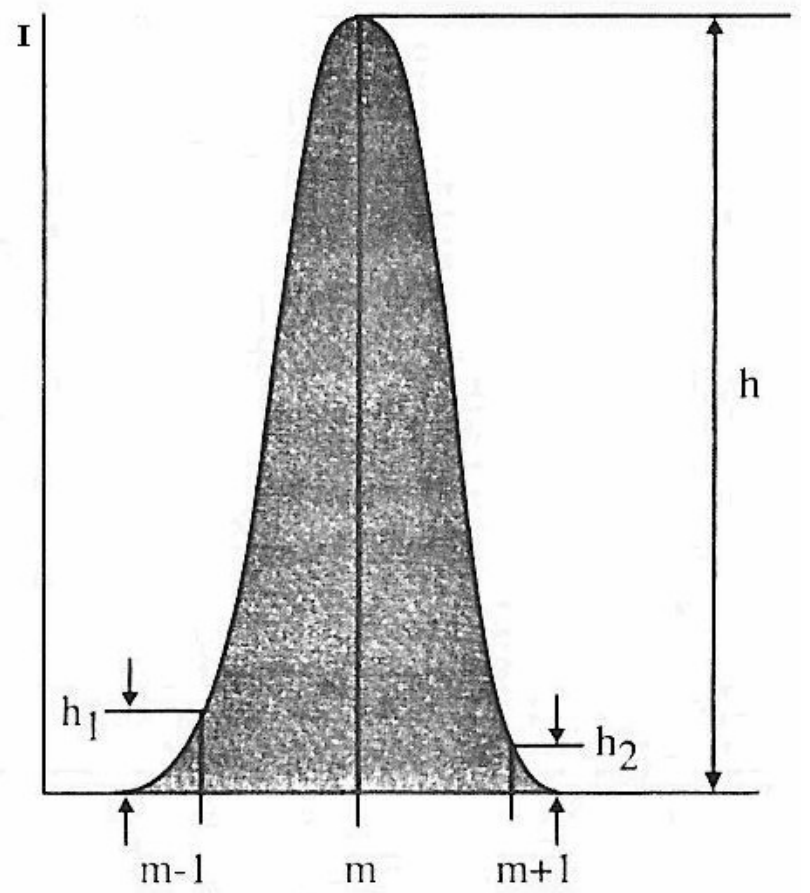

Figura 12. Pico característico de intensidade na massa $M$ do espectro de massa, com identificação dos parâmetros que definem a sensibilidade à abundância. 


\section{DETERMINAÇÃO DE RAZÕES ISOTÓPICAS}

Dada uma amostra composta por dois isótopos de um mesmo elemento (mesmo número atômico $z$ ), contendo $N_{l}$ moléculas do isótopo 1 e $N_{2}$ moléculas do isótopo 2, cujas massas atômicas são, respectivamente, $M_{1}$ e $M_{2}$, a razão isotópica verdadeira $R$ entre o número de átomos do isótopo 2 e o número de átomos do isótopo 1 será:

$$
R=\frac{N_{2}}{N_{1}}
$$

Determina-se a razão isotópica desta amostra, em um espectrômetro de massas quadrupolar, medindo-se as correntes iônicas $I_{1}$ e $I_{2}$ que chegam ao detector quando o espectrômetro é sintonizado para permitir a passagem de íons com massa $M_{1}$ e $M_{2}$, respectivamente. Assim, a razão isotópica medida $R_{m}$ é:

$$
R_{m}=\frac{I_{2}}{I_{1}}
$$

Entretanto, o processo de medição é afetado por uma série de fatores que fazem com que $R_{m}$ não seja igual a $R$. Estes fatores podem $\operatorname{ser}^{16}$ :

a. Fatores de natureza sistemática (ou efeitos sistemáticos).

b. Fatores de natureza aleatória (ou efeitos aleatórios).

\subsection{Efeitos sistemáticos}

Resultam de variações previsíveis e que podem ser corrigidas. Os principais fatores causadores de efeitos sistemáticos são ${ }^{17,18,19}$ :

- Discriminação de massa.

- Não linearidade do sistema de medição.

- Efeito memória.

- Influência de impurezas. 
Estes fatores podem se manifestar ${ }^{3}$ :

- Quando da entrada da amostra na fonte de íons.

- Por processos físicos e químicos envolvidos na produção de íons.

- Durante a transmissão dos íons da fonte até o coletor.

- Nos sistemas de detecção e medição de corrente iônica.

a. A discriminação de massas, como foi visto no item 3 pode ocorrer em praticamente todos os componentes do analisador e, até mesmo, no sistema de introdução de amostras.

No sistema de introdução de amostras (item 3.3.6), ocorre em virtude da proporcionalidade entre a velocidade de deslocamento da molécula e raiz quadrada de sua massa, quando o fluxo é molecular.

$\mathrm{Na}$ fonte de íons (item 3.3.4), ocorre, sobretudo, como resultado do campo magnético na direção do feixe de elétrons.

No analisador, é causado pelos campos de borda (item 3.3.3).

No multiplicador de elétrons, se deve a dependência entre o número de elétrons produzidos nos dinodos e a massa do íon incidente.

Embora possa ser reduzida, sempre estará presente, em maior ou menor grau. Depende da construção mecânica do instrumento e dos parâmetros operacionais ${ }^{3,11}$.

b. Os efeitos não lineares ocorrem sobretudo nos sistemas de detecção de íons, quando o resistor de carga ou o amplificador não forem perfeitamente lineares na faixa de tensões produzidas pela passagem das correntes no resistor, como visto no item 3.3.5. Pode ocorrer também como conseqüência de uma sensibilidade à abundância (item 3.3.7) muito alta no instrumento.

c. O efeito memória ocorre devido à contaminação da fonte de íons ou do sistema de introdução de amostras. Nas análises de $\mathrm{UF}_{6}$, o efeito memória é causado pela 
reação de troca isotópica entre o $\mathrm{UF}_{6}$ gasoso e o $\mathrm{UF}_{4}$ previamente formado nas paredes internas do sistema de introdução de amostras e da fonte de íons. O efeito memória depende unicamente da diferença entre as razões isotópicas entre duas amostras de $\mathrm{UF}_{6} \mathrm{e}$ não da magnitude da razão isotópica em si ${ }^{20}$.

A construção atual das fontes e sistemas de introdução, cujas características são: volume morto reduzido, superfícies internas tratadas para reduzir adsorção de gases ou umidade, arquitetura da fonte aberta, de modo que o gás não ionizado sai sem tocar nas paredes da fonte e seja capturado por uma armadilha criogênica que a circunda, praticamente eliminou este efeito.

O efeito memória pode ser avaliado analisando-se duas amostras $A$ e $B$, cujos valores reais de razão isotópica são conhecidos, e calculando-se o fator de memória $M$, definido na equação $34^{20}$.

$$
M=\frac{R-1}{R_{0}-1}
$$

onde:

$$
R=\left[\frac{\left(\frac{{ }^{235} U}{{ }^{238} U}\right)_{B}}{\left(\frac{{ }^{235} U}{{ }^{238} U}\right)_{A}}\right]_{\text {calculado }}
$$

$\mathrm{e}$

$$
R_{0}=\left[\frac{\left(\frac{{ }^{235} U}{{ }^{238} U}\right)_{B}}{\left(\frac{{ }^{235} U}{{ }^{238} U}\right)_{A}}\right]_{\text {medido }}
$$

sendo: $A$ a amostra empobrecida e $B$ é a amostra enriquecida. 
Se necessário, como no caso de análise de amostras com razões isotópicas muito diferentes, o efeito memória pode ser ainda reduzido por procedimentos analíticos tais como: bombeamento adequado da fonte entre uma análise e outra, lavagem do sistema com o gás a ser analisado ${ }^{20}$.

d. As impurezas na amostra podem ter dois efeitos. Impurezas isobáricas, aquelas que produzem íons com a mesma massa de um dos isótopos analisados, alteram a intensidade medida da corrente iônica produzida por um dos isótopos e, conseqüentemente, a razão isotópica medida. Impurezas não isobáricas podem alterar a carga espacial na fonte de íons e no analisador, influenciando o resultado da análise ${ }^{7}$. O uso de amostras puras elimina este efeito.

Os dois primeiros efeitos sistemáticos podem ser corrigidos calibrando-se o espectrômetro com o uso de uma amostra de referência certificada, isto é, uma amostra de $\mathrm{UF}_{6}$, cuja razão isotópica verdadeira $R_{c}$ é conhecida, dentro um intervalo de confiança, também conhecido. Determinando-se $R_{m}$ para a amostra certificada, calcula-se a razão entre o valor certificado e o valor medido, esta razão é conhecida como fator de correção $K$, isto é ${ }^{17}$ :

$$
K=\frac{R_{c}}{R_{c m}}
$$

onde:

$K=$ fator de correção.

$R_{c}=$ razão isotópica certificada do material de referência.

$R_{c m}=$ razão isotópica medida do material de referência.

Para que o valor verdadeiro $R$ da razão isotópica, de uma amostra de $\mathrm{UF}_{6}$ qualquer, possa ser determinado pela espectrometria de massas, o valor da razão isotópica medida desta amostra deve ser multiplicado pelo fator de correção $K^{17,21}$ :

$$
R=K R_{m}
$$


Onde:

$R=$ razão isotópica corrigida da a amostra.

$R_{m}=$ razão isotópica medida da amostra.

Este fator de correção engloba todos os efeitos sistemáticos discriminados acima e é expresso por ${ }^{19}$ :

$$
K=K_{d} K_{l} K_{m} K_{i}
$$

onde:

$K_{d}=$ fator de correção para a discriminação de massa.

$K_{l}=$ fator de correção para efeitos não lineares.

$K_{m}=$ fator de correção para o efeito memória.

$K_{i}=$ fator de correção para a influência de impurezas.

Para um dado instrumento, a influência dos parâmetros instrumentais nos fatores acima discriminados, pode ser mantida constante se assim o forem a resolução do espectrômetro e os parâmetros elétricos da fonte de íons e do sistema de detecção. O fator de correção dependerá, então, do procedimento analítico: número de ciclos analíticos, tempo de medição de cada isótopo, pressão da amostra e do padrão, razão isotópica da amostra e do padrão.

O número de ciclos analíticos e o tempo de medição, depois de otimizados, são mantidos constantes para todas as medições e deixam de influenciar $K$. As dependências de $K$ com a razão isotópica $R$ e de $K$ com a pressão $P$ no tanque de amostragem devem ser determinadas experimentalmente. A dependência de $K \operatorname{com} P$, associada à discriminação de massas, é importante, porque eventualmente as análises do padrão e da amostra desconhecida não possam ser realizadas na mesma pressão, já a importância da dependência de $K \operatorname{com} R$ está na faixa de valores de $R$ que são rotineiramente analisados, entre 0,002 e 0,04 . 


\subsection{Efeitos aleatórios}

Os efeitos aleatórios resultam de variações imprevistas ou imprevisíveis das quantidades que influenciam o resultado. Estes efeitos, que se refletem na variabilidade dos resultados das medições, não podem ser corrigidos. Afetam tanto as medidas das amostras desconhecidas quanto as de referência e, portanto, o valor do fator de correção.

Variabilidade é a tendência de um processo de medição, no qual as condições de medição podem ser estáveis ou variar com o tempo, produzir medições levemente diferentes de uma mesma amostra,. Duas fontes de variabilidade dependentes do tempo devem ser consideradas ${ }^{22}$ :

- Variabilidade a curto prazo, ou repetitividade das medições.

- Variabilidade a longo prazo, ou reprodutibilidade das medições.

A variabilidade a curto prazo afeta a precisão do instrumento. Mesmo os instrumentos mais precisos, operando com todos os parâmetros constantes, exibem pequenas variações causadas por erros randômicos. Ela pode ser caracterizada pela repetitividade das medições, definida como o grau de concordância entre os resultados de medições sucessivas de um mesmo mensurando efetuadas sob as mesmas condições de medição ${ }^{22}$.

A repetitividade pode ser expressa, quantitativamente, pelas características de dispersão dos resultados, ou seja, pelo desvio padrão de uma série de medições feitas sob condições de repetitividade.

As condições de repetitividade incluem ${ }^{23}$ :

- mesmo procedimento de medição;

- mesmo observador;

- mesmo instrumento de medição, utilizado nas mesmas condições;

- mesmo local;

- repetição em curto período de tempo. 
Realizando-se um número $J$ de medições sucessivas, de uma mesma amostra e sob as mesmas condições, e calculando-se os desvios padrão dos resultados.

Em instrumentos altamente precisos, é comum que a variabilidade, do processo de medição, entre dias, ou variabilidade a longo prazo, exceda à precisão do instrumento, por causa de pequenas variações ambientais ou das técnicas de manuseio que não podem ser controladas ou corrigidas. Esta variabilidade pode ser caracterizada pela reprodutibilidade das medições, definida como o grau de concordância entre os resultados das medições de um mesmo mensurando efetuadas sob condições variadas de medição, em que a única condição variada é a data de execução das análises ${ }^{23}$.

O processo de medição não está completamente caracterizado até que esta fonte de variabilidade seja quantificada.

A reprodutibilidade pode ser expressa, quantitativamente, a semelhança da repetitividade, pela dispersão dos resultados, isto é, pelo desvio padrão de um número $K$ de medições diárias, de uma mesma amostra, realizadas sob as mesmas condições.

Para a determinação da repetitividade e da estabilidade do processo de medição de razões isotópicas de $\mathrm{UF}_{6}$, foi utilizado um arranjo aninhado de nível dois. Uma mesma amostra de foi analisada em $K$ dias, e em cada dia foram realizadas $J$ medições sucessivas, da razão isotópica, sob condições idênticas de análise.

\section{REPETITIVIDADE}

As médias diárias de razão isotópica são dadas por:

$$
\bar{R}_{k}=\frac{1}{J} \sum_{j=1}^{J} R_{k j}
$$

onde:

$\overline{\mathrm{R}}_{\mathrm{k}}=$ média das $J$ medições realizadas no $k$-ésimo dia.

$\mathrm{R}_{\mathrm{kj}}=j$-ésima medição do $k$-ésimo dia. 
O desvio padrão diário sob condições de repetitividade, com o número de graus de liberdade ${ }^{23}$ dado por $v=(J-1)$, é:

$$
s_{k}=\sqrt{\frac{1}{J-1} \sum_{j=1}^{J}\left(R_{k j}-\bar{R}_{k}\right)^{2}}
$$

onde: $\quad \mathrm{S}_{\mathrm{k}}=$ desvio padrão das $\mathrm{J}$ medições do $k$-ésimo dia.

Um desvio padrão individual de período curto não será uma estimativa confiável da precisão se o número de graus de liberdade for menor que dez, neste caso, as estimativas individuais devem ser ponderadas sobre os $K$ dias para se obter uma estimativa confiável. Um desvio padrão ponderado pelos $K$ dias, com o número de graus de liberdade dado por $v=K(J-1)$, é 22

$$
s_{1}=\sqrt{\frac{1}{K} \sum_{k=1}^{K} s_{k}^{2}}
$$

onde:

$\boldsymbol{s}_{\boldsymbol{1}}=$ desvio padrão das $J$ medições ponderado sob os $K$ dias, quantifica a

\section{repetitividade.}

Este desvio padrão, que caracteriza a repetitividade, também é conhecido como desvio padrão de nível-1.

\section{REPRODUTIBILIDADE}

O desvio padrão obtido sob condições de reprodutibilidade, também chamado de desvio padrão de nível-2, é apropriado para representar a variabilidade do processo. É computado com $v=(K-1)$ graus de liberdade ${ }^{23}$.

$$
s_{2}=\sqrt{\frac{1}{K-1} \sum_{k=1}^{K}\left(\bar{R}_{k}-\bar{R}\right)^{2}}
$$


onde

$$
\bar{R}=\frac{1}{K} \sum_{k=1}^{K} \bar{R}_{k}
$$

$\overline{\mathrm{R}}=$ é a média das $K J$ medições.

$\overline{\mathrm{R}}_{\mathrm{k}}=$ média das $J$ medições realizadas no $k$-ésimo dia.

$\boldsymbol{s}_{2}=$ desvio padrão das $K$ medições diárias, quantifica a reprodutibilidade.

\subsection{Incertezas}

O resultado de uma medição é, em geral, apenas uma aproximação, ou estimativa, do valor da quantidade específica sujeita a medição - chamada mensurando - e o resultado só está completo quanto acompanhado da declaração quantitativa de sua incerteza $^{24}$.

Ao se determinar a razão isotópica de uma amostra, mesmo após a correção da tendência para todos os efeitos sistemáticos, continuará existindo uma incerteza associada ao seu valor, decorrente dos efeitos aleatórios do processo de medição e da incerteza nos valores dos materiais de referência utilizados na determinação do fator de correção.

Não se deve confundir a incerteza do resultado de uma medição, com a repetitividade ou a reprodutibilidade do instrumento e do método, que são componentes da incerteza.

Se precisão e tendência são propriedades do método de medição, incerteza é uma propriedade do resultado específico de um único teste, que depende das configurações específicas da medição (laboratório, instrumento, operador) ${ }^{22}$. Ela depende da repetitividade do instrumento, da reprodutibilidade dos resultados ao longo do tempo, do número de medições no resultado do teste e de todas as fontes de erros que possam contribuir para o desacordo entre o resultado e seu valor de referência. 
Assim, os objetivos de uma medição, de razão isotópica ou de outra grandeza qualquer, são ${ }^{25}$ :

- Obter o melhor valor para o mensurando, isto é, a melhor aproximação possível para o valor verdadeiro em termos probabilísticos.

- Obter a incerteza do melhor valor obtido, isto é, estimar uma faixa de valores ao redor do valor do mensurando dentro da qual haja uma probabilidade predefinida de estar o valor verdadeiro do mensurando.

O tratamento das incertezas, neste trabalho, baseou-se na abordagem do "Guia para expressão de incerteza de medição" ${ }^{26}$.

Na maioria dos casos, o mensurando $Y$ não é medido diretamente, mas é determinado com base em $\mathrm{N}$ outras grandezas através da relação funcional (45):

$$
Y=f\left(X_{1}, X_{2}, \ldots, X_{N}\right)
$$

Onde os valores de $X_{i}$, dos quais $Y$ depende, também podem ser considerados como mensurandos e depender de outras grandezas, incluindo correções e fatores de correção para efeitos sistemáticos.

O resultado da medição de $Y$, designado por $y$, é obtido a partir dos valores estimados $x_{1}, x_{2}, \ldots, x_{N}$, das grandezas $X_{1}, X_{2}, \ldots, X_{N}$, aplicados a equação (45), ou seja:

$$
y=f\left(x_{1}, x_{2}, \ldots, x_{\mathrm{N}}\right)
$$

A incerteza do resultado da medição consiste da combinação dos diversos componentes, dados pelas incertezas dos valores de $x_{1}, x_{2}, \ldots, x_{\mathrm{N}}$. Os componentes da incerteza podem ser agrupados em duas categorias - "A" e "B" - baseadas no método utilizado para estimar seu valor numérico:

A - aqueles que são avaliados com auxílio de métodos estatísticos.

B - aqueles que são avaliados por outros meios. 
Para que possam ser combinadas na incerteza do mensurando, as incertezas associadas a cada $x_{\mathrm{i}}$ devem ser representadas por incertezas padrão $\boldsymbol{u}\left(\boldsymbol{x}_{\boldsymbol{i}}\right)$, ou seja, desvios padrão estimados.

Toda estimativa de $x_{\mathrm{i}}$ e de sua incerteza padrão $u\left(x_{i}\right)$ é obtida com base em uma distribuição de valores possíveis de $X_{i}$, esta distribuição de probabilidades pode ser baseada na frequiência, isto é, em uma série de observações $X_{i, k}$ e $X_{i}$, ou pode ser uma distribuição $a$ priori.

Um componente de incerteza da categoria A é representado por um desvio padrão $s\left(x_{i}\right)$, estimado estatisticamente com base em uma série de observações, com $v_{1}$ graus de liberdade. A avaliação da incerteza pela análise de uma série de observações é denominada avaliação do Tipo A.

Um componente de incerteza da categoria B é representado por um desvio padrão obtido de uma distribuição de probabilidades assumida com base em toda informação disponível a respeito da grandeza medida. A avaliação da incerteza por outro meio, que não seja a análise estatística de uma série de observações, é denominada avaliação do Tipo B.

Quando uma grandeza $X_{i}$, da equação (45), for avaliada com base em $\mathrm{n}$ observações repetidas independentes $X_{i, k}$, seu valor estimado $x_{\mathrm{i}}$, usado para determinar o resultado da medição $y$ (equação 46) será dado pela expressão (47):

$$
x_{i}=\bar{X}_{i}=\frac{1}{n} \sum_{k=1}^{n} X_{i, k}
$$

A variabilidade dos valores de $X_{i, k}$ é caracterizada pelo desvio padrão experimental $s\left(X_{i, k}\right)$, expresso pela equação 48 .

$$
s\left(X_{i, k}\right)=\sqrt{\frac{1}{n-1} \sum_{k=1}^{n}\left(X_{i, k}-\bar{X}_{i}\right)^{2}}
$$


A variabilidade dos valores de $\bar{X}_{\mathrm{i}}$ é caracterizada pelo desvio padrão experimental da média $s\left(\bar{X}_{i}\right)$, expresso pela equação 49.

$$
s\left(\bar{X}_{i}\right)=\frac{1}{\sqrt{n}} s\left(X_{i, k}\right)
$$

Tanto $s\left(\bar{X}_{i}\right)$ quanto $s\left(X_{i, k}\right)$ podem ser usados como medidas da incerteza de $x_{\mathrm{i}}$. A incerteza padrão $u\left(x_{i}\right)$, calculada de acordo com a equação 50 , da estimativa $\mathrm{x}_{\mathrm{i}}=\overline{\mathrm{X}}_{\mathrm{i}}$ é :

$$
u\left(x_{i}\right)=s\left(\bar{X}_{i}\right)
$$

Esta incerteza é chamada incerteza padrão do Tipo A.

Os componentes da incerteza referentes a repetitividade e reprodutibilidade são incertezas do tipo A.

Quando uma estimativa $x_{i}$, de uma quantidade $X_{i}$, não for obtida por observações repetidas, sua incerteza padrão $u\left(x_{i}\right)$ será avaliada por julgamento científico baseado em toda a informação disponível a respeito da variabilidade de $X_{i}$. Neste caso, $u\left(x_{i}\right)$ será chamada incerteza padrão do Tipo B.

As incertezas padrão das razões isotópicas dos materiais de referência isotópica (MRI) certificados, são incertezas do tipo B.

Se a estimativa de $x_{i}$ é obtida de um certificado e a incerteza declarada dita ser um múltiplo do desvio padrão, a incerteza padrão $u\left(x_{i}\right)$ será o valor declarado da incerteza dividido pelo multiplicador.

Caso a incerteza declarada de $x_{i}$ defina um intervalo, com nível de confiança de 90, 95 ou 99 por cento, presume-se, caso não haja declaração em contrário, que uma 
distribuição normal foi usada no cálculo da incerteza declarada. Neste caso, a incerteza padrão $u\left(x_{i}\right)$ será dada pelo valor declarado dividido pelo valor correspondente, na distribuição normal, aos níveis de confiança, que são: 1,64 (para 90\%); 1,96 (para 95\%) e 2,58 (para 99\%).

Ocorrem casos em que a única informação disponível, a respeito de $X_{i}$, é a de que seu valor está num intervalo entre $a_{\text {- e }} a_{+}$. nestes casos, assume-se que a distribuição é retangular e $x_{i}$ é o ponto médio do intervalo, isto é, $x_{i}=\left(a_{-}-a_{+}\right) / 2$. Se $2 a=\left(a_{-}-a_{+}\right)$for a largura do intervalo, a incerteza padrão de $x_{i}$ será:

$$
u\left(x_{i}\right)=\frac{a}{\sqrt{3}}
$$

A incerteza padrão do estimador $y$, onde $y$ é dado pela equação 46 , é obtida combinando-se as incertezas dos estimadores $x_{i}$, da mesma equação. A incerteza padrão combinada do estimador $y$, representada por $u_{c}(y)$, é calculada pelo método usual de combinação de desvios padrão.

$$
u_{c}^{2}(y)=\sum_{i=1}^{N}\left(\frac{\partial f}{\partial x_{i}}\right)^{2} u^{2}\left(x_{i}\right)+2 \sum_{i=1}^{N-1} \sum_{j=j+1}^{N} \frac{\partial f}{\partial x_{i}} \frac{\partial f}{\partial x_{j}} u\left(x_{i}, x_{j}\right)
$$

Esta expressão é conhecida como "Lei de Propagação da Incerteza", onde:

$f$ é a relação funcional entre $y$ e os $x_{n}$ da equação 46.

$\frac{\partial f}{\partial x_{i}}$ são chamados coeficientes de sensibilidade e descrevem como o estimador $y$ varia com as mudanças nos estimadores $x_{i}$.

$u\left(x_{i}\right)$ é a incerteza padrão associada a $\mathrm{x}_{\mathrm{i}}$ e pode ser do Tipo A ou do Tipo B. $u\left(x_{i}, x_{j}\right)$ é a covariância estimada associada com $x_{i}$ e $x_{j}$.

O grau de correlação entre $x_{i}$ e $x_{j}$ é caracterizado pelo coeficiente de correlação estimado $r\left(x_{i}, x_{j}\right)$, dado por: 


$$
r\left(x_{i}, x_{j}\right)=\frac{u\left(x_{i}, x_{j}\right)}{u\left(x_{i}\right) u\left(x_{j}\right)}
$$

Quando $x_{i}$ e $x_{j}$ forem independentes, $r\left(x_{i}, x_{j}\right)=0$ e a Lei de Propagação de Incerteza fica reduzida a:

$$
u_{c}^{2}(y)=\sum_{i=1}^{N}\left(\frac{\partial f}{\partial x_{i}}\right)^{2} u^{2}\left(x_{i}\right)
$$

Embora a incerteza padrão combinada $u_{c}(y)$ seja universalmente usada para exprimir a incerteza do resultado de uma medição, existem situações em que é necessário fornecer uma medida de incerteza que defina um intervalo ao redor do resultado da medição $y$, dentro do qual haja grande probabilidade de estar $Y$.

A estimativa da incerteza, que atende a este requisito, é chamada incerteza expandida, representada por $U$, e obtida multiplicando-se $u_{c}(y)$ por um fator de abrangência representado por $\mathrm{k}$.

$$
U=k u_{c}(y)
$$

O valor do fator de abrangência $k$ deve produzir um intervalo correspondendo a um nível de confiança pré-definido $p$, isto é, o fator de abrangência deve ter um valor $k_{p}$, que produza uma incerteza expandida $U_{p}=k_{p} u_{c}(y)$, definindo um intervalo $y-U_{p} \leq Y \leq Y$ $+U_{p}$, que pode ser escrito $Y=y \pm U_{p}$, tendo um nível de confiança aproximado $p$.

$k_{p}$ pode ser calculado seguindo-se o procedimento de quatro passos a seguir ${ }^{24}$ :

1. Obter $y$ e $u_{c}(y)$.

2. Estimar o número de graus de liberdade efetivo $v_{e f}$ de $u_{c}(y)$, a partir da equação de Welch - Satterthwait: 


$$
v_{e f}=\frac{\left[\frac{u_{c}(y)}{y}\right]^{4}}{\sum_{i=1}^{N} \frac{\left[\frac{u\left(x_{i}\right)}{x_{i}}\right]^{4}}{v_{i}}}
$$

onde, todos os $u\left(x_{i}\right)$ são estatisticamente independentes entre si e $v_{i}$ é o número de graus de liberdade de $u\left(x_{i}\right)$.

3. Obter o fator $-t, t_{p}\left(v_{e f}\right)$, para o nível de confiança requerido $\mathrm{p}$, valendo-se de uma tabela de valores $t_{p}(v)$ da distribuição $t$.

4. Tomar $k_{p}=t_{p}\left(v_{e f}\right)$ e calcular $U_{p}=k_{p} u_{c}(y)$.

As etapas necessárias para se estimar a incerteza expandida ${ }^{26}$ são apresentados no fluxograma da FIG. 13. 
Etapa 1

Etapa 2

Etapa 3

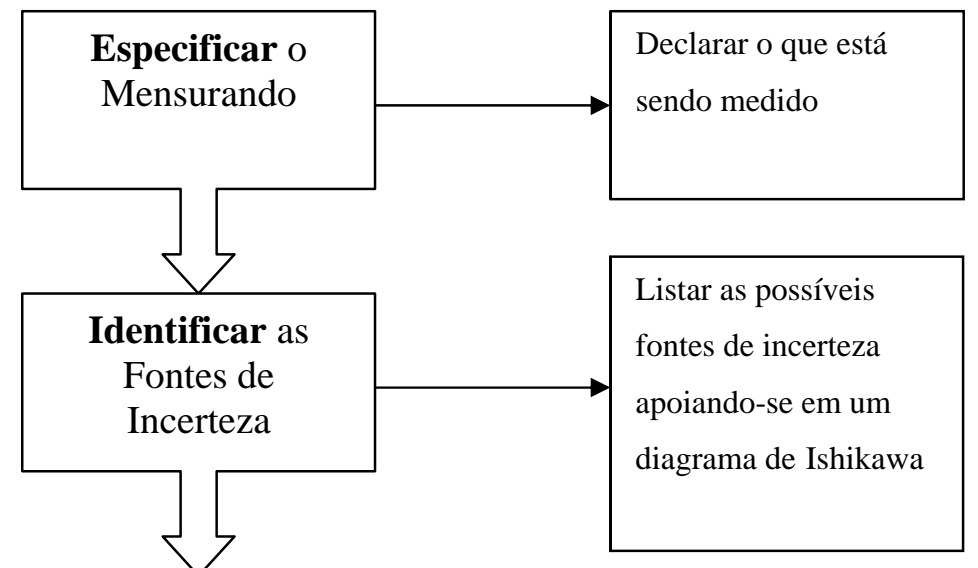

Etapa 3

Etapa 4
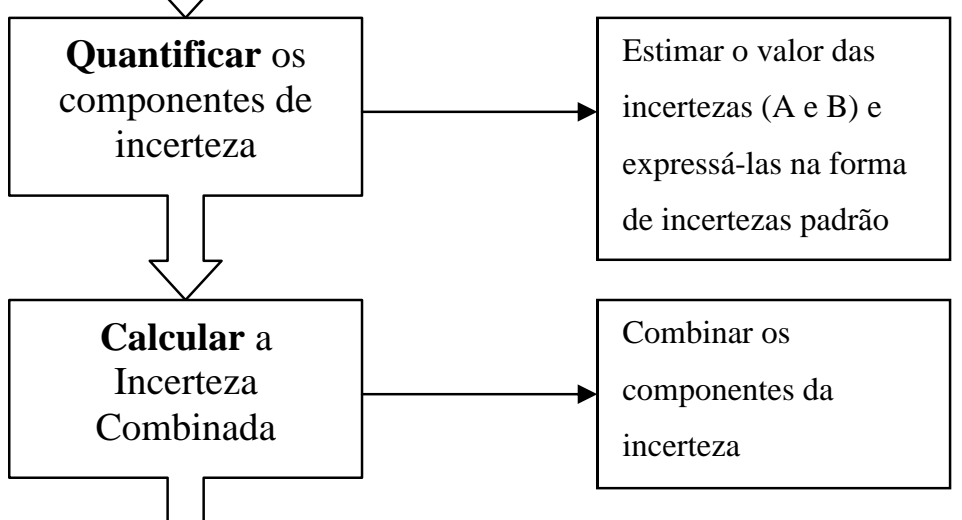

Etapa 5

Calcular a
Incerteza
Expandida

Multiplicar o valor da incerteza combinada

por um fator de abrangência $\mathrm{k}$

Figura 13. Etapas necessárias a estimativa da incerteza ${ }^{27}$. 


\section{MATERIAIS E MÉTODOS}

\subsection{Materiais}

\subsubsection{Espectrômetro de massas IMU200}

O espectrômetro de massas modelo IMU200, marca In Process Instruments (IPI), é um instrumento dedicado à análise isotópica de $\mathrm{UF}_{6} \mathrm{e}$, para melhor compreensão do seu funcionamento, pode ser dividido em dois sistemas independentes:

- Sistema de medição .

- Sistema de introdução de amostras.

Estes dois sistemas, que trabalham em alto-vácuo, conforme mostrado no diagrama da FIG. 14, estão conectados a um painel de controle e de processamento de dados, que se liga a um microcomputador.

A interface entre estes dois sistemas é feita por uma conexão VCR de 1/8" (item 2 da FIG. 15).

\subsubsection{Sistema de introdução de amostras}

O sistema de introdução de amostras subdivide-se em duas seções paralelas, compostas, cada uma, por duas linhas de amostragem conectadas a um mesmo tanque de expansão de 2 litros, como pode ser visto na FIG. 14.

As ampolas, contendo amostras de $\mathrm{UF}_{6}$, são acopladas manualmente aos bocais apropriados no espectrômetro e parte da amostra transferido a um dos tanques T1 ou T2, por expansão volumétrica.

Na seção 1, as ampolas podem ser acopladas aos bocais S3 e S4 ligados, respectivamente, às válvulas Y62 e Y65. O UF6 é transferido para o tanque T1 passando pelas válvulas Y63 e Y66. 
Bocais de acoplamento de ampolas

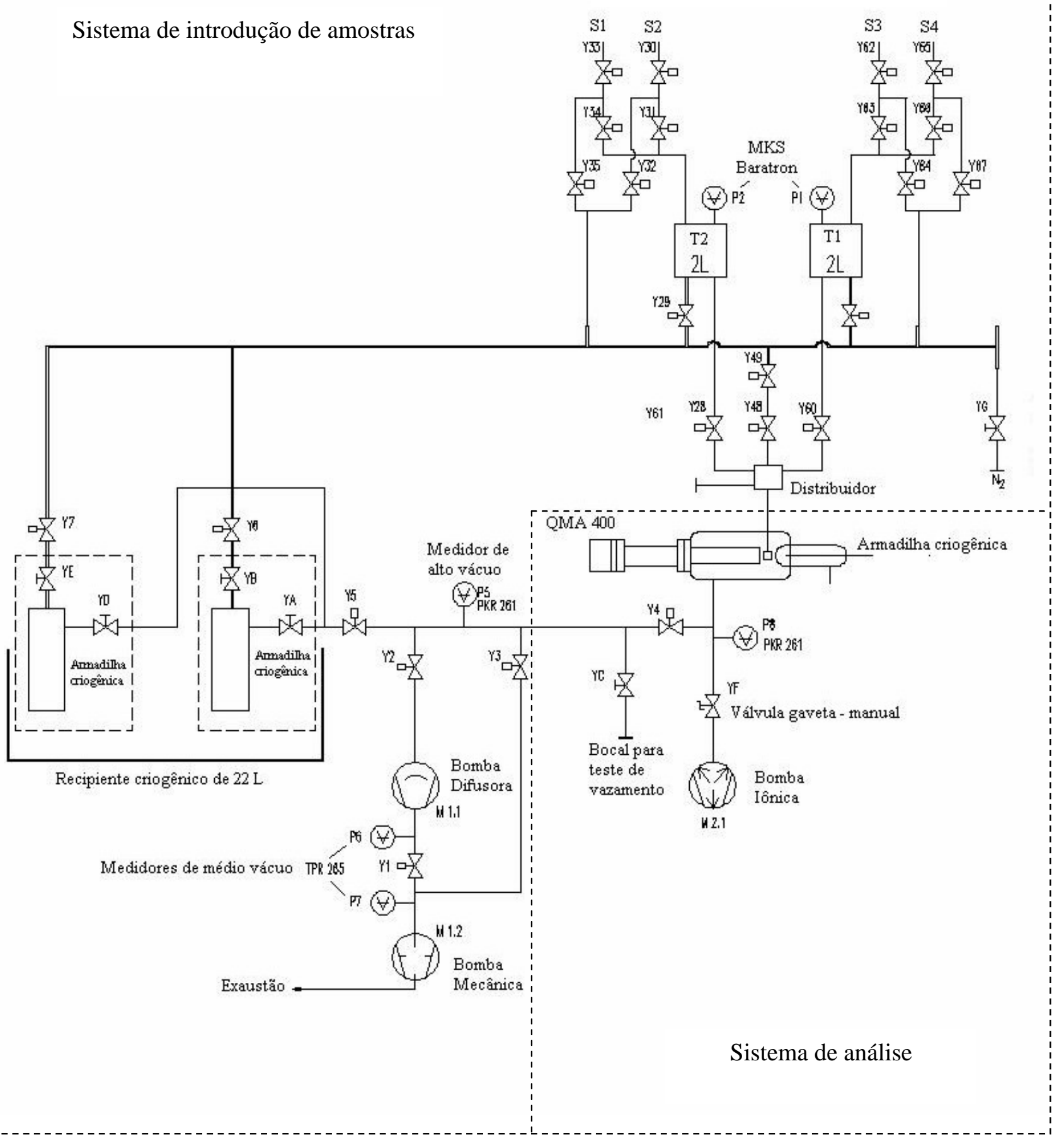

Figura 14. Sistema de vácuo do espectrômetro de massas IMU200 ${ }^{28}$. 


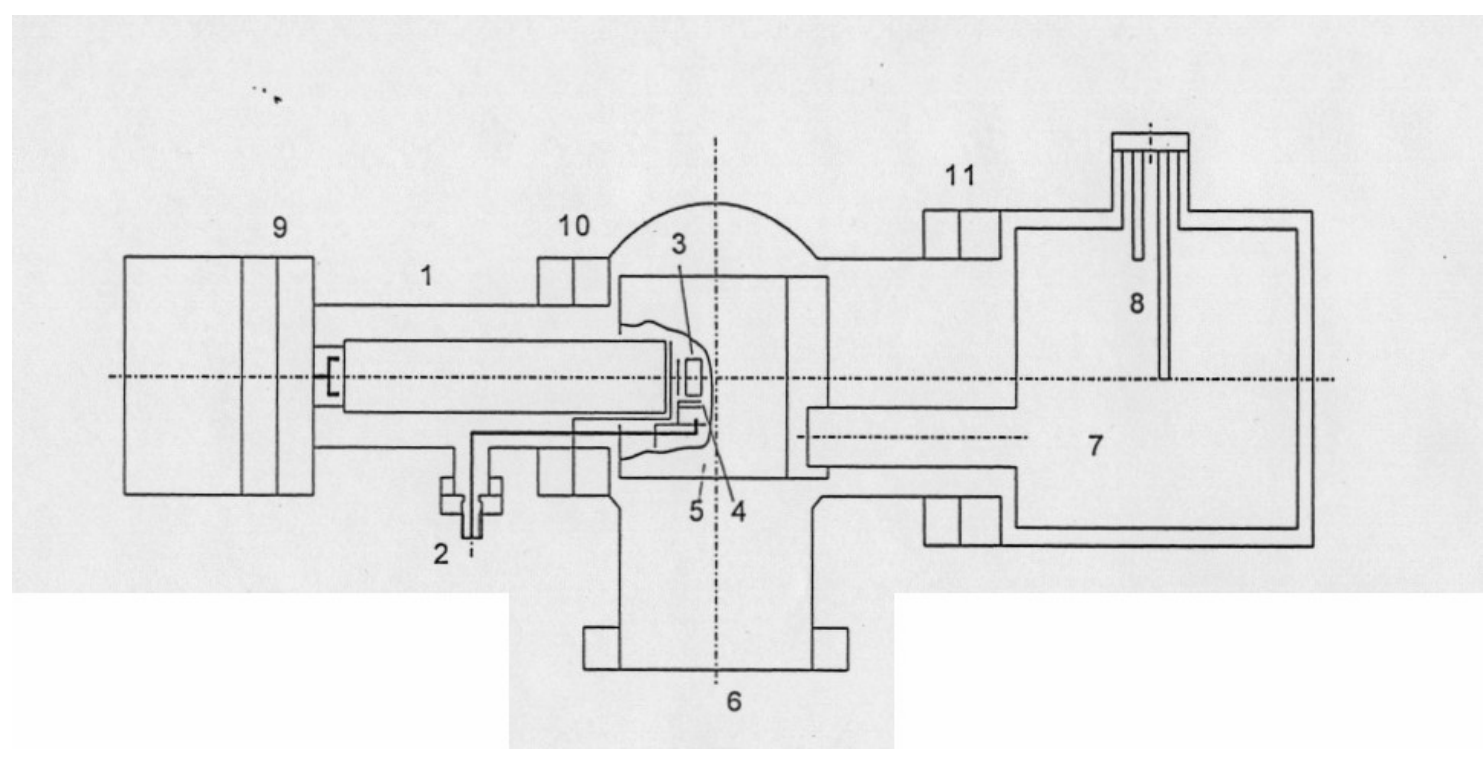

Figura 15. Sistema de medição do espectrômetro de massas IMU200 ${ }^{28}$, onde:

1. Filtro de massas quadrupolar com copo de Faraday.

2. Conexão de introdução de gás para linha com diâmetro interno de $1 \mathrm{~mm}$.

3. Fonte de íons.

4. Unidade de feixe molecular.

5. Armadilha criogênica.

6. Conexão com sistema de bombeamento CF 100.

7. Compartimento para nitrogênio líquido.

8. Sensores de nível do nitrogênio líquido.

9. Flange CF 63.

10. Flange CF 63.

11. Flange CF 100. 
Na seção 2, as ampolas podem ser acopladas aos bocais S1 e S2 ligados, respectivamente, às válvulas $\mathrm{Y} 33$ e Y30. $\mathrm{O} \mathrm{UF}_{6}$ é transferido para o tanque T2 passando pelas válvulas Y34 e Y31.

Ambas as seções se comunicam com o sistema de medição através de um distribuidor, que se liga aos tanques por meio de tubulações flexíveis, com $1 \mathrm{~mm}$ diâmetro. As tubulações são isoladas do distribuidor por válvulas de entrada; Y60 para a seção 1 e Y28 para a seção 2.

A pressão nos tanques de expansão é medida por sensores de vácuo capacitivos da marca MKS, modelo Baratron 626A.

O vácuo do sistema de introdução de amostras, que atinge pressões da ordem de $10^{-7}$ mbar, é mantido por um conjunto de bombeamento composto por:

- uma bomba mecânica da marca Leybold, modelo Trivac D16 BCS-PFPE, com velocidade de bombeamento de $16,5 \mathrm{~m}^{3} / \mathrm{h}$;

- uma bomba difusora da marca Edwards, refrigerada a ar, modelo SI100, com velocidade de bombeamento de $216 \mathrm{~m}^{3} / \mathrm{h}$.

O conjunto de bombeamento liga-se ao sistema de introdução de amostras por meio de duas armadilhas criogênicas conectadas em paralelo, refrigeradas com nitrogênio líquido (FIG. 14), evitando que o $\mathrm{UF}_{6}$ chegue ao conjunto de bombeamento.

Os tanques de expansão T1 e T2 podem ser evacuados abrindo-se as válvulas Y60 e Y28, respectivamente, e o distribuidor abrindo-se Y40 e Y48.

Todas as válvulas denominadas pela letra Y seguida de um número, são pneumáticas e são controladas através do painel de controle ou do microcomputador. As válvulas denominadas pela letra Y seguida de outra letra são manuais. 


\title{
5.1.1.2 Sistema de medição
}

O sistema de medição é composto pelo analisador e pelo sistema de vácuo:

\begin{abstract}
Analisador
O coração do sistema é um analisador de massas do tipo quadrupolar, marca Infcon, modelo QMA400, que trabalha com $\Delta M$ constante ao longo de toda a faixa de massas, composto por:
\end{abstract}

- Fonte de íons.

- Filtro de massa.

- Detectores de íons (multiplicador de elétrons e copo de Faraday).

- Câmara de vácuo com flanges.

A fonte de íons por impacto eletrônico, mostrada na FIG. 16, foi especialmente projetada para $\mathrm{UF}_{6}$. O fluxo de molecular de gás chega à fonte por um capilar (item 8, FIG. 16), é colimado por dois diafragmas (itens 5 e 7 da FIG. 16) e entra na câmara de ionização (item 2 da FIG. 16), o lado da câmara oposto ao de entrada é aberto, permitindo que o gás não ionizado sai da câmara sem entrar em contato com seus elementos. A ionização é provocada pelo feixe de elétrons produzido por um dos dois filamentos de tungstênio (catodos da FIG. 17) e colimados por dois imãs (itens 3 da FIG. 16). Os íons produzidos são extraídos da fonte, focados, colimados e injetados no quadrupolo pelo conjunto de lentes eletrostáticas e orifícios mostrados na FIG. 17.

O quadrupolo é formado por quatro barras de molibdênio de oito milímetros de diâmetro e 20 centímetros de comprimento, capaz de detectar íons com $\mathrm{m} / \mathrm{z}$ de até 512 , com largura de pico, constante para toda faixa de $\mathrm{m} / \mathrm{z}$, podendo ser variada de 0,3 a 7 .

Os íons que saem do quadrupolo podem ser detectados por um copo de Faraday ou por um multiplicador de elétrons, mostrados na FIG. 18. O copo de Faraday, pode detectar pressões parciais menores que $10^{-11}$ mbar e o multiplicador de elétrons pressões parciais menores que $10^{-15}$ mbar. $\mathrm{O}$ multiplicador de elétrons, que opera com voltagens entre 1 e 3,5 kV, é composto por 17 estágios e pode ter um ganho $>10^{8}$, operando na voltagem máxima. Os dinodos são de $\mathrm{Cu}-\mathrm{Be}$. 


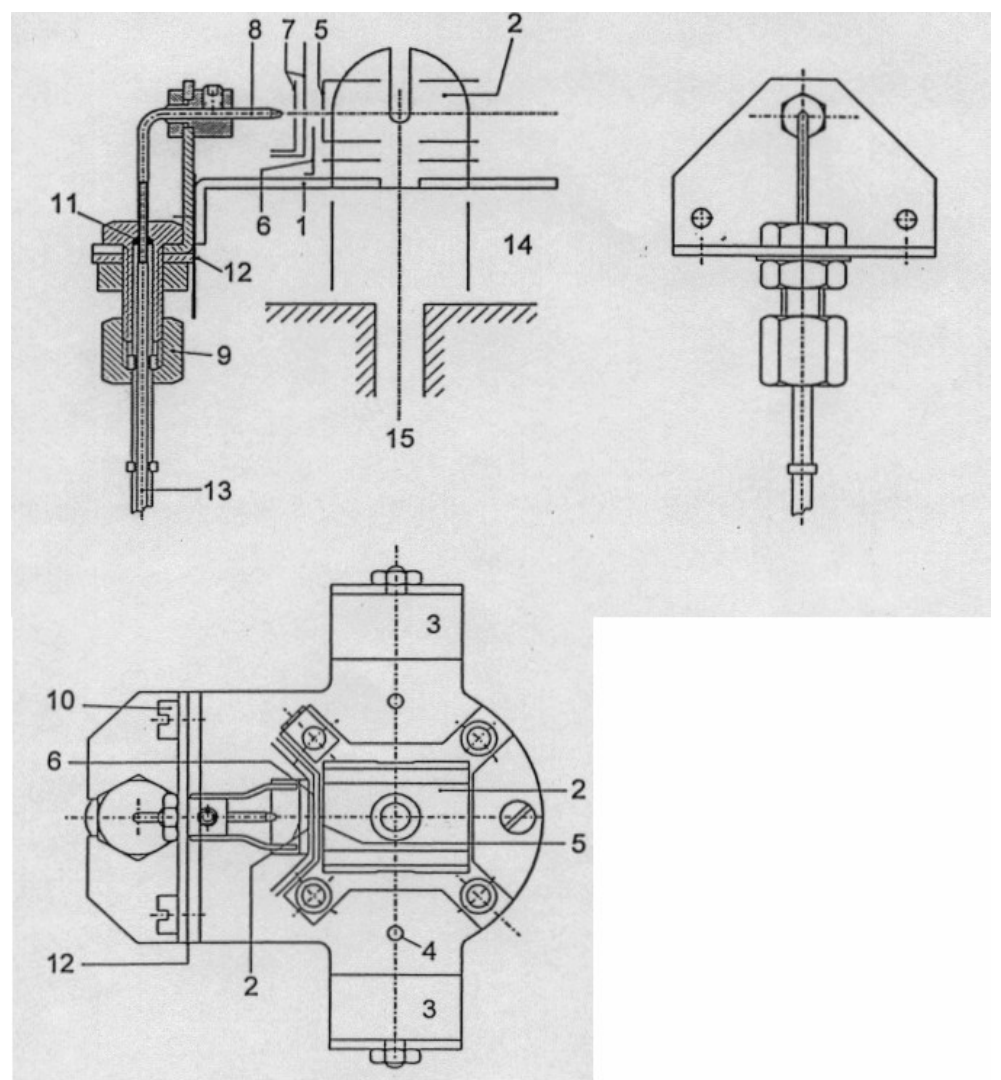

Figura 16. Fonte de íons com tubo capilar para introdução de amostras do espectrômetro de massas IMU200 ${ }^{28}$, onde:

1. Base

2. Câmara de ionização

3. Ímã

4. Parafusos de montagem

5. Diafragma da câmara de ionização.

6. Anteparo colimador

7. Diafragma da unidade de feixe molecular.

8. Capilar com 0,3 mm de diâmetro interno.

9. Porca

10. Parafuso de montagem

11. Vedação e teflon

12. Folha de cobre

13. Tubulação com $1 \mathrm{~mm}$ de diâmetro interno.

14. Lentes eletrostáticas

15. Abertura de entrada do quadrupolo 


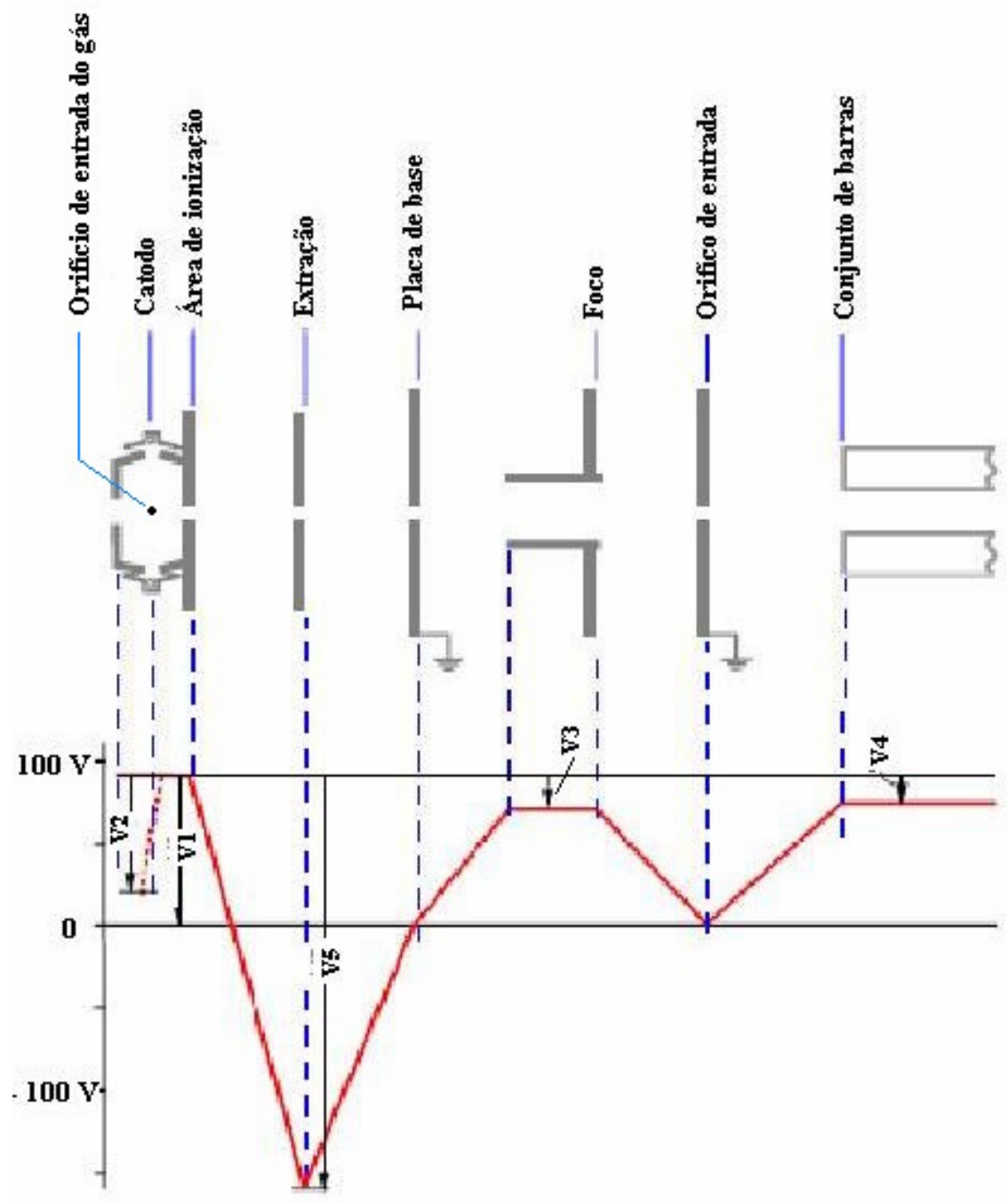

Figura 17. Principais componentes e potenciais elétricos da fonte de íons por impacto eletrônico $^{28}$.

O sistema todo é mantido livre de contaminação por $\mathrm{UF}_{6}$ com o uso integrado de um feixe de entrada molecular, já referido, e de uma superfície refrigerada com nitrogênio líquido (item 5 FIG. 15), que envolve toda a fonte de íons e condensa todo gás no ionizado.

O vácuo no sistema de medição é mantido por uma bomba iônica da marca Varian, modelo VacIon plus 55, tipo Starcell, com velocidade de bombeamento de $180 \mathrm{~m}^{3} / \mathrm{h}$. A contaminação da bomba iônica é evitada pela armadilha criogênica citada no 
parágrafo anterior. A bomba iônica pode ser isolada do sistema de medição por uma válvula gaveta (YF na FIG.14) operada manualmente.

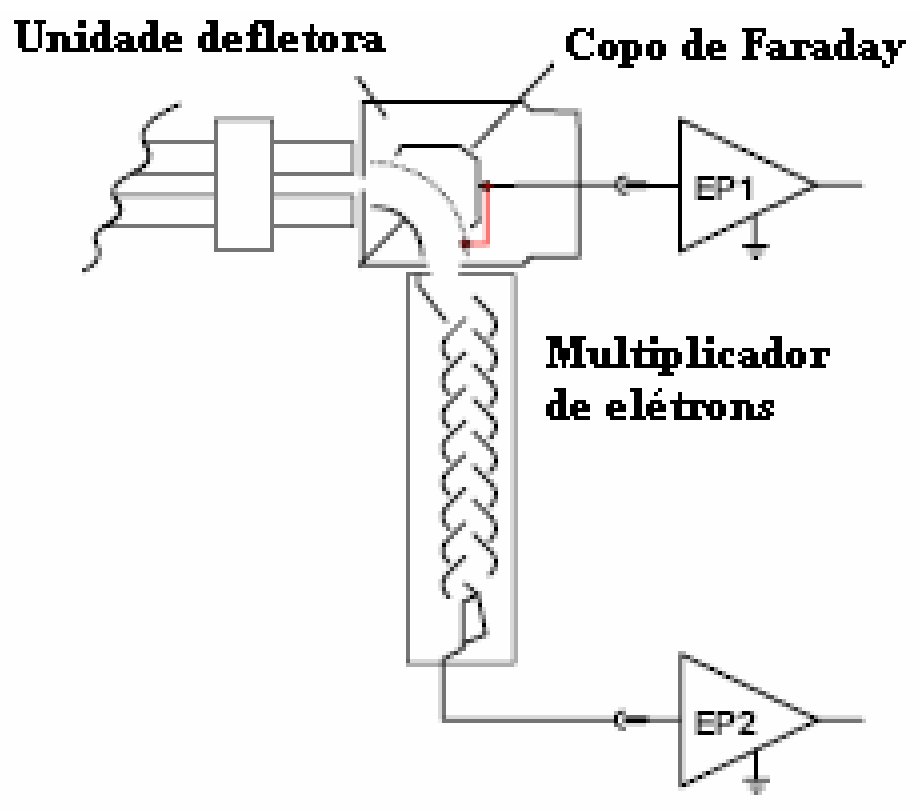

Figura 18. Copo de Faraday e Multiplicador de elétrons ${ }^{28}$.

O pré-vácuo do analisador é feito pelo conjunto de bombeamento do sistema de introdução de amostras, abrindo-se a válvula Y4 (FIG. 14).

As tensões alternada e contínua para o quadrupolo são fornecidas por um gerador de rádio-freqüência, marca Infcom, modelo QMH400-5, com freqüência de 2,25 $\mathrm{MHz}$, amplitude pico a pico variável de 1,5 a $2350 \mathrm{~V}$ e voltagem contínua entre 0,5 e $394 \mathrm{~V}$.

As correntes detectadas pelo copo de Faraday ou pelo multiplicador de elétrons são medidas por eletrômetros da marca Infcom, modelo EP422, com $100 \mathrm{k} \Omega$ de impedância de entrada (EP1 e EP2, na FIG. 18).

Uma unidade de controle, marca Infcom, modelo QMS422, gera as tensões necessárias ao multiplicador de elétrons e à fonte de íons, esta mesma unidade faz o processamento dos sinais recebidos e controla o gerador de rádio-freqüências. A interface 
com um microcomputador, dotado de processador Pentium IV e rodando o programa Quadstar 422, versão 6.0 da IPI permite todos os parâmetros operacionais do espectrômetro de massas, sejam controlados por meio deste.

As válvulas, bombas e medidores de pressão, dos dois sistemas de bombeamento, são controladas por um programador lógico controlável (PLC) da marca Siemens, modelo SCU200, com interface para a unidade de controle do analisador. Deste modo, todo o sistema pode ser controlado através do microcomputador e toda uma seqüência de análises, programada.

\subsubsection{Pacote de programas Quadstar 422}

O Quadstar 422 é um programa aplicativo modular dedicado ao controle do QMS422. Pode realizar análises qualitativas e quantitativas e possibilita a programação de sequiências automáticas de medição.

As seqüências são procedimentos analíticos completos, gravados com nomes individuais, e podem conter diversas instruções sobre medições, controle de válvulas, cálculos e armazenamento e exibição de dados.

O Quadstar 422 consiste dos seguintes programas principais:

Measure é programa de medição. Propicia todos os tipos de medição de armazenamento de dados. É com base neste programa que as sequiências são executadas.

Dispsav é um programa de análise. Os dados armazenados podem ser representados de várias maneiras, ampliados e processados.

Parset é o programa em que são fixados todos os parâmetros de medição e do QMS. As sequiências são escritas com este programa.

Tune up é o programa usado para fixar os parâmetros da fonte de íons, da rádio - frequiência e para otimização da forma do pico. 


\subsubsection{Amostras de $\mathbf{U F}_{6}$}

Nos experimentos realizados foram utilizadas 5 amostras de $\mathrm{UF}_{6}$ armazenadas em ampolas de aço inox, dotadas de válvulas.

Uma amostra não certificada, com razão isotópica natural, foi utilizada nos ensaios em que conhecimento do valor exato do enriquecimento não era necessário.

Quatro amostras de referência, certificadas ${ }^{29}$, foram usadas nos ensaios em que o conhecimento exato da razão isotópica era necessário.

As características isotópicas destas quatro amostras são apresentadas na TAB. 2, onde a incerteza expandida é resultado do produto da incerteza combinada por um fator de abrangência $\mathrm{k}=2$ e define um intervalo que se estima tenha um nível de confiança de $95 \%$.

Tabela 2. Razões isotópicas das amostras de referência ${ }^{29}$.

\begin{tabular}{cccc}
\hline Amostra & Razão isotópica R & Incerteza expandida & Incerteza expandida \% \\
\hline MRI 0.5 & 0,00535470 & 0,00000017 & 0,0032 \\
MRI 0.7 & 0,0072543 & 0,0000016 & 0,022 \\
MRI 3.5 & 0,0354698 & 0,0000047 & 0,013 \\
MRI 4.5 & 0,0465457 & 0,0000065 & 0,014 \\
\hline
\end{tabular}

\subsection{Métodos}

Para que se possa estabelecer um procedimento adequado à realização de análises isotópicas de rotina, é necessário o conhecimento detalhado de algumas características do processo de medição. Estas são a tendência e a variabilidade.

A tendência, que corresponde aos efeitos sistemáticos, é caracterizada e corrigida pelo fator de correção $K$ (equação 38), composto por quatro outros fatores, $K_{d}, K_{l}$, $K_{m}$ e $K_{i}$, conforme a equação (39). 
As variabilidades de curto e longo prazo são determinadas por meio de experimentos repetidos, em um mesmo dia ou em dias diferentes.

Entretanto, para que a tendência e a variabilidade do processo sejam as menores possíveis, é imprescindível que alguns parâmetros instrumentais a analíticos sejam previamente otimizados.

O método seguido para o estabelecimento do melhor procedimento analítico compôs-se dos seguintes passos:

Otimização:

- da fonte de íons;

- do número de ciclos analíticos;

- da resolução.

Caracterização:

- Determinação dos quatro componentes do fator de correção $K$.

- Quantificação da variabilidade dos valores medidos de razão isotópica e, como consequiência, da variabilidade do fator de correção.

\subsubsection{Otimização da fonte de íons e da resolução}

Os processos mais comuns que ocorrem quando um elétron com suficiente energia cinética atinge uma molécula de $\mathrm{UF}_{6}$ na fase gasosa são as dissociações que produzem os íons ${ }^{30}: \mathrm{UF}_{5}{ }^{+}, \mathrm{UF}_{4}{ }^{+}, \mathrm{UF}_{3}{ }^{+}, \mathrm{UF}_{2}{ }^{+}, \mathrm{UF}^{+}$.

Destes, o mais provável é o primeiro processo, aproximadamente $40 \%$ dos íons produzidos ${ }^{30}$ são $\mathrm{UF}_{5}^{+}$.

Para que o consumo da amostra seja o menor possível, é conveniente que a análise seja feita sobre o íon mais abundante, isto é, o $\mathrm{UF}_{5}{ }^{+}$.

Os potenciais de ionização críticos para íons univalentes produzidos quando $\mathrm{UF}_{6}$ gasoso é bombardeado por elétrons lentos são apresentados na TAB. 3 . 
Tabela 3. Potenciais de ionização críticos para o $\mathrm{UF}_{6}$ gasoso ${ }^{31}$.

\begin{tabular}{cccc}
\hline Íon & Potencial (V) & Íon & Potencial (V) \\
\hline $\mathrm{UF}_{5}^{+}$ & 15,5 & $\mathrm{UF}_{2}^{+}$ & 29,9 \\
$\mathrm{UF}_{4}^{+}$ & 20,1 & $\mathrm{UF}_{1}^{+}$ & 37,9 \\
$\mathrm{UF}_{3}^{+}$ & 23,5 & $\mathrm{U}^{+}$ & 50,3 \\
\hline
\end{tabular}

A corrente iônica máxima é produzida, com relativa insensibilidade à energia dos elétrons, na região entre $50 \mathrm{e} 100 \mathrm{eV}^{5,7}$. Entretanto, a corrente máxima não depende apenas da energia dos elétrons, mas de todos os parâmetros elétricos (V1 a V5) da fonte, mostrados na FIG. 17, além da corrente de emissão eletrônica, da montagem e alinhamento da fonte e da resolução do quadrupolo, já que a corrente é medida na saída deste.

O objetivo da otimização da fonte de íons é alcançar alta sensibilidade, um bom formato de pico (curva suave) e baixa discriminação de massas. Os parâmetros otimizados são:

1. Emissão - é a corrente eletrônica. Geralmente a corrente máxima é atingida com emissão abaixo e $1 \mathrm{~mA}$, porque acima deste valor os efeitos de carga espacial são prejudiciais.

2. Potencial na câmara de ionização $(V I)$ - é o potencial no qual os íons são formados. É a referência para todos os outros potenciais. Os principais efeitos são:

- a baixos valores a sensibilidade para massas baixas é alta, ao passo que a sensibilidade máxima para massas maiores só é alcançada com valores altos $V 1$;

- quanto maior $V 1$, menor a discriminação de massas;

- a discriminação de massas é reduzida otimizando-se a fonte no pico de massa mais alta. Assim, para o $\mathrm{UF}_{6}$ a otimização deve ser feita no pico do ${ }^{238} \mathrm{UF}_{5}{ }^{+}$.

3. Catodo (V2) - determina a energia nominal dos elétrons.

4. Foco (V3) - deve ser ajustado para obtenção do pico mais alto. 
5. Campo axial (V4) - é a diferença de potencial entre a câmara de ionização e o quadrupolo e, portanto, define a energia com que os íons entram no quadrupolo. Quanto maior for $V 4$, mais alto será o pico. Porém, menor será a resolução e o formato do pico deteriora. A otimização combinada de $V 4$ de da resolução resulta no pico máximo, com a resolução desejada e formato bom.

6. Extração (V5) - acelera os íons da câmara de formação até o quadrupolo.

7. Deflexão (VO) - caso o multiplicador de elétrons fosse utilizado, seria necessário otimizar o potencial do condensador que provoca a deflexão de $90^{\circ}$, do feixe de íons, para dirigi-lo ao multiplicador. Quando o copo de Faraday é utilizado este potencial é aterrado.

\subsubsection{Otimização do número de ciclos analíticos}

A razão isotópica entre os isótopos ${ }^{235} \mathrm{U}$ e ${ }^{238} \mathrm{U}$ é determinada medindo-se as correntes iônicas para os íons ${ }^{235} \mathrm{UF}_{5}{ }^{+} \mathrm{e}^{238} \mathrm{UF}_{5}{ }^{+}$, que têm $\mathrm{m} / z$ iguais a, respectivamente, 330 e 333. Destas correntes medidas deve-se descontar o valor correspondente à linha de base, isto é, a corrente indicada pelo detector quando não é atingido por íon algum. Esta corrente é medida com $m / z=327$, em que não ocorre nenhum fragmento de ionização do $\mathrm{UF}_{6}$. Assim, a razão isotópica medida $R_{m}$ é:

$$
R_{m}=\frac{{ }^{235} U F_{5}^{+}}{{ }^{238} U F_{5}^{+}}=\frac{I(330)-I(327)}{I(333)-I(327)}
$$

onde $I(\mathrm{~m} / \mathrm{z})=$ corrente iônica medida em $\mathrm{m} / \mathrm{z}$.

À sequiência de medição destas três correntes dá-se o nome ciclo analítico. Cada ciclo analítico é composto dos seguintes passos:

1. Medição da intensidade na linha de base, $I(327)$.

2. Medição da intensidade do pico 330, I(330).

3. Medição da intensidade do pico 333, I(333). 
O programa Quadstar possibilita que todos os parâmetros de um ciclo analítico sejam pré-estabelecidos. Os principais parâmetros e os valores utilizados nesta fase do trabalho são:

Massas dos íons em que a corrente será medida: 327,330 e 333.

Tipo de detector: Copo de Faraday.

Resolução: Unitária $(\Delta M=1)$.

Tempo de medição para cada íon: $2 \mathrm{~s}$.

Intervalo de tempo entre as medidas de íons com massas diferentes: $5 \mathrm{~s}$.

Durante uma análise isotópica, são executados diversos ciclos e as intensidades das correntes dos isótopos, leve e pesado, caem em razão do consumo da amostra. Como conseqüência, as correntes produzidas por cada isótopo não são medidas nas mesmas condições. Este desvio é o corrigido por meio da seguinte interpolação:

\section{Sejam:}

$n=$ número de ciclos medidos.

$I_{0}(n)=$ intensidade do pico 330 no ciclo $n$, subtraída a intensidade da linha de base.

$I_{3}(n)=$ intensidade do pico 333 no ciclo $n$, subtraída a intensidade da linha de base.

A razão isotópica corrigida para o desvio é:

$$
R_{n^{\prime}}=\frac{\left(\frac{I_{0}(n-1)+I_{0}(n+1)}{2}\right)}{I_{3}(n)}
$$

Deste modo, executando-se $n$ ciclos analíticos, obtém-se $n$ ' razões isotópicas corrigidas para o desvio, onde $n^{\prime}=n-2$.

Antes da execução de uma série de ciclos, é necessário determinar-se a posição exata dos picos para as razões $\mathrm{m} / \mathrm{z} 330$ e 333, porque podem ocorrer desvios de até $\pm 0,5$. entre a massa real e a nominal. 
Toda a seqüência da análise isotópica, incluindo, determinação da posição dos picos, realização de um número $n$ de ciclos analíticos, cálculo das $n$ ' razões isotópicas corrigidas, cálculo da média e do desvio-padrão das n' razões, bem como o modo de exibição e armazenamento dos resultados, pode ser programada com a linguagem Quadstar.

Sendo:

- Resultado da medição - a média aritmética dos valores das n’ razões isotópicas determinadas em $n$ ciclos analíticos.

- Resultado da análise - a média aritmética dos valores da razão isotópica determinados em $N$ medições.

Otimizar o número de ciclos analíticos significa encontrar o número de ciclos $n$ e de medições $N$, acima do qual não haja variação no resultado da medição e da análise, respectivamente.

\subsubsection{Otimização da resolução}

Para determinação da razão isotópica ${ }^{235} \mathrm{UF}_{5}{ }^{+} / 238 \mathrm{UF}_{5}{ }^{+}$a resolução deve ser alta apenas o suficiente para manter o pico ${ }^{235} \mathrm{UF}_{5}{ }^{+}$livre da influência do pico vizinho ${ }^{234} \mathrm{UF}_{5}{ }^{+}$, uma vez que evitar o aumento desnecessário da resolução melhora a sensibilidade, a estabilidade e a forma do pico ${ }^{32}$. A influência do pico vizinho pode ser quantificada calculando-se a sensibilidade a abundância, sensibilidades a abundância alta resultam em uma maior influência do valor da razão isotópica no resultado da medição, isto é, efeitos não lineares maiores.

O valor de resolução considerado ótimo foi que minimizou os efeitos não lineares.

\subsubsection{Fator de correção para discriminação de massa $K_{d}$}

Uma vez otimizados os parâmetros da fonte de íons, a resolução e o número de ciclos analíticos, o passo seguinte foi determinar as quatro componentes do fator de correção (equação 39). A metodologia adotada para a determinação destes fatores teve por 
base os trabalhos de De Bièvre ${ }^{17}$ e Oliveira ${ }^{19}$, nos quais cada um dos fatores é determinado por meio de experimentos independentes.

Para determinar-se $\mathrm{K}_{\mathrm{d}}$, o experimento deve ser tal que $K_{l}=K_{i}=K_{m}=1$.

Para que $K_{l}=K_{m}=1$, todas as medições foram feitas em uma mesma amostra, eliminando influência do efeito memória e a dependência entre $\mathrm{R}_{\mathrm{m}}$ e $\mathrm{R}$.

Para que $K_{i}=1$, foram utilizadas amostras puras, isto é, sem a presença de ar.

Como foi visto em 3.3.4, o valor medido da razão isotópica depende da pressão na fonte de íons, que por sua vez é função da pressão no tanque de expansão. Isto significa que a discriminação de massa depende da pressão no tanque, ou seja, $K_{d}=K_{d}(P)$. Portanto, $K_{d}$ teve de ser determinado para várias pressões.

A repetitividade e a reprodutibilidade dos valores de $K_{d}$ foi determinada por meio de medidas repetidas da razão isotópica, em várias pressões, sob condições de repetitividade e de reprodutibilidade.

Além de caracterizar o comportamento da discriminação de massa com relação a pressão, este experimento permitiu escolher a melhor faixa de pressões de trabalho.

\subsubsection{Fator de correção para efeitos não lineares $K_{l}$}

Embora tenha sido minimizado com a otimização da resolução, os efeitos não lineares poderiam continuar presentes. Estes efeitos são dependentes da razão isotópica do material analisado, portanto são quantificados através da medição de amostras certificadas com razões isotópicas diferentes.

A discriminação de massa é corrigida com o uso do fator $K_{d}$ determinado no item anterior, o efeito de impurezas eliminado com o uso de amostras puras e o efeito memória evitado com procedimentos de lavagem dos tanque de expansão e das linhas de introdução da amostra. 


\subsubsection{Fator de correção para efeito memória $K_{m}$ e para efeito de impurezas $K_{i}$}

O efeito memória foi avaliado por medições sucessivas de duas amostras com razões isotópicas diferentes (próximas aos extremos, superior e inferior, dos valores de razão isotópica normalmente analisados no laboratório).

A presença de impurezas, além de poder influenciar o resultado da medição, pode também reduzir a vida útil dos filamentos, em decorrência do aumento da pressão, e aumentar a periodicidade das limpezas da armadilha criogênica. Para evitar estes efeitos indesejados, todas as amostras são purgadas antes das análises e $K_{i}$ será sempre igual a um.

O efeito das impurezas não será considerado, visto que somente foram analisadas amostras purificadas. 


\section{ANÁLISE DOS RESULTADOS}

\subsection{Otimização da fonte de íons}

A otimização da fonte de íons foi realizada com o programa Tuneup, do pacote Quadstar, que possibilita a variação de todos os parâmetros da fonte e da resolução, entretanto, os valores de resolução no programa são fornecidos em unidades arbitrárias sem relação funcional com o valor real da resolução.

Os parâmetros ideais para a fonte de íons foram determinados, para nove resoluções diferentes, utilizando-se a amostra de $\mathrm{UF}_{6}$ de composição isotópica natural não certificada, com pressão no tanque de 0,300 mbar, e velocidade de varredura e $2 \mathrm{~s}$ por unidade de massa, no modo "scan-n".

Os valores de resolução, para os quais a fonte foi otimizada, foram 30, 40, 50, 60, 70, 80, 90, 100 e 120. Estes valores estão dados em unidades arbitrárias utilizadas pelo QMG422. Os valores reais da resolução variam ao longo da escala de massas, mas sua largura não, por isso, foram medidos os valores da largura do pico $333\left(\Delta M_{10}\right)$, para cada um dos valores arbitrários da resolução dados acima.

Os valores de $\Delta M_{10}$ foram determinados introduzindo-se uma amostra de $\mathrm{UF}_{6}$ natural, não certificado, no tanque de expansão T1, a pressão de 0,300 mbar, otimizando-se a fonte de íons, e obtendo-se o espectro de massas, por meio do programa "measure", entre as massas 325 e 335 , com velocidade de varredura de 20 s por unidade de massa. As medidas de altura e largura do pico 333 foram obtidas com o programa "dispsav".

Na TAB. 4, são apresentados os valores ótimos dos parâmetros da fonte e a largura do pico $\left(\Delta M_{10}\right)$ para cada uma das nove resoluções. Deve-se notar que, a resolução em unidades arbitrárias, usada pelo QMG422, é proporcional à largura do pico (FIG. 19), que é independente da massa, e não à resolução real $(M / \Delta M)$, que depende da massa. Portanto, quanto maior a resolução arbitrária, menor a resolução real. 
Tabela 4. Parâmetros da fonte e largura do pico para diferentes resoluções.

\begin{tabular}{|c|c|c|c|c|c|c|c|c|c|}
\hline $\begin{array}{c}\text { Resolução } \\
\text { (unidades } \\
\text { arbitrárias) }\end{array}$ & 30 & 40 & 50 & 60 & 70 & 80 & 90 & 100 & 120 \\
\hline Emissão (mA) & 0,80 & 0,80 & 0,80 & 0,80 & 0,80 & 0,80 & 0,80 & 0,80 & 0,80 \\
\hline V1 (V) & 120 & 120 & 120 & 120 & 120 & 120 & 120 & 120 & 120 \\
\hline V2 (V) & 91 & 91 & 91 & 91 & 91 & 93 & 94 & 94 & 94 \\
\hline V3 (V) & 20,25 & 20,25 & 20,25 & 20,25 & 20,25 & 17,75 & 18,00 & 18,50 & 17,25 \\
\hline V4 (V) & 15,50 & 15,25 & 16,50 & 17,50 & 17,50 & 17,75 & 18,00 & 18,00 & 18,00 \\
\hline V5 (V) & 172 & 172 & 172 & 172 & 172 & 164 & 156 & 170 & 168 \\
\hline$\Delta \mathbf{M}_{10}$ (u.m.a.) & 0,76 & 1,00 & 1,25 & 1,53 & 1,81 & 2,07 & 2,39 & 2,64 & 3,20 \\
\hline
\end{tabular}




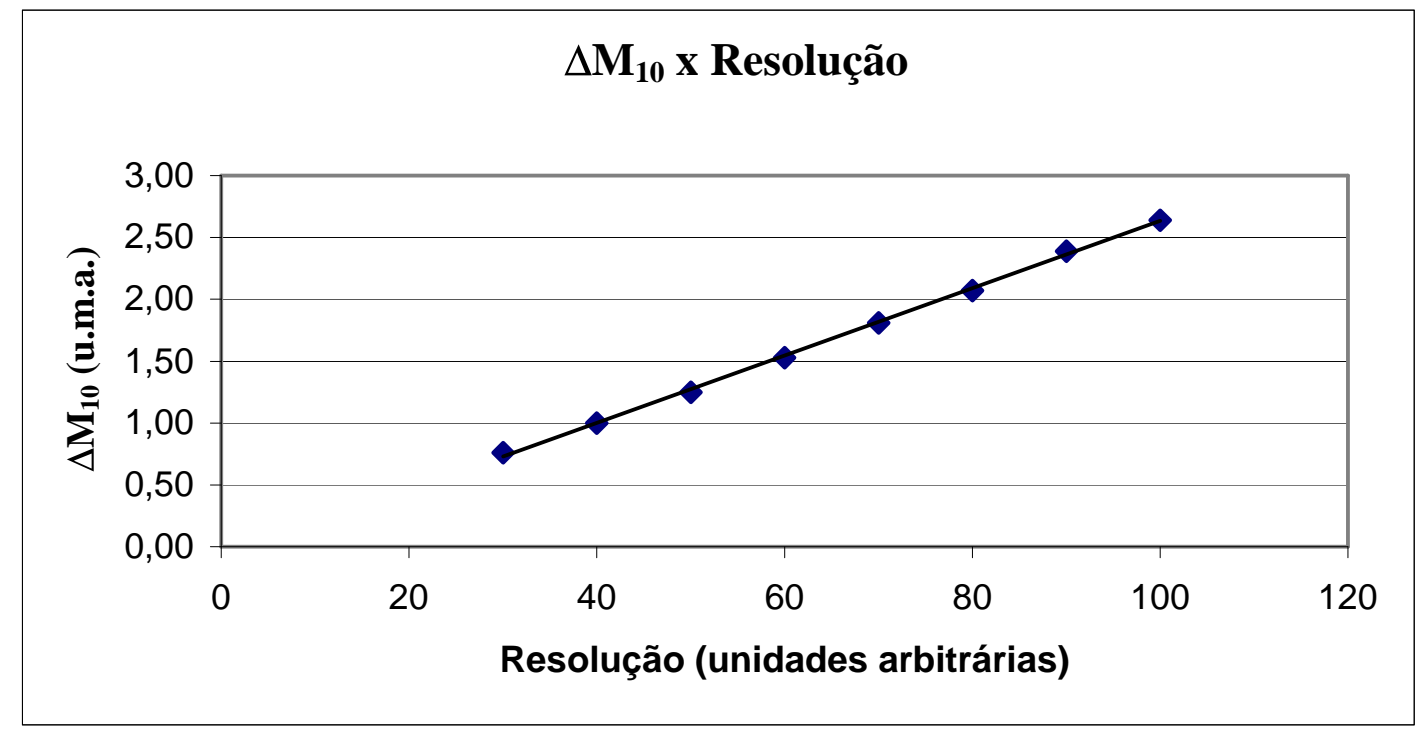

Figura 19. Relação entre a resolução em unidades arbitrárias usada pelo QMG422 e a largura do pico $\Delta M_{10}$.

Na TAB. 4, pode-se observar que, entre as resoluções 30 e 70, a única alteração requerida nos potenciais da fonte de íons foi um aumento no campo axial, isto é na energia dos íons. Para resoluções menores (valor numérico arbitrário maior), foi necessária uma alteração em outros potenciais e, mesmo assim, o formato do pico obtido foi mais achatado do que o recomendável, o que pode trazer dificuldades na localização da posição exata dos picos pelo programa.

$\mathrm{O}$ espectro do $\mathrm{UF}_{6}$ entre as massas 325 e 335 , obtido com resolução $40\left(\Delta M_{10}=\right.$ 1,00, chamada resolução unitária), é mostrado na FIG. 20, onde podem ser bem visualizados os picos de massa 330 e 333. O pico de massa 329 aparece, mas sua intensidade é muito baixa. O mesmo espectro é mostrado na FIG. 21, mas com resolução $70\left(\Delta M_{10}=1,81\right.$ u.m.a. $)$, onde podem ser notados o alargamento e achatamento do pico. 


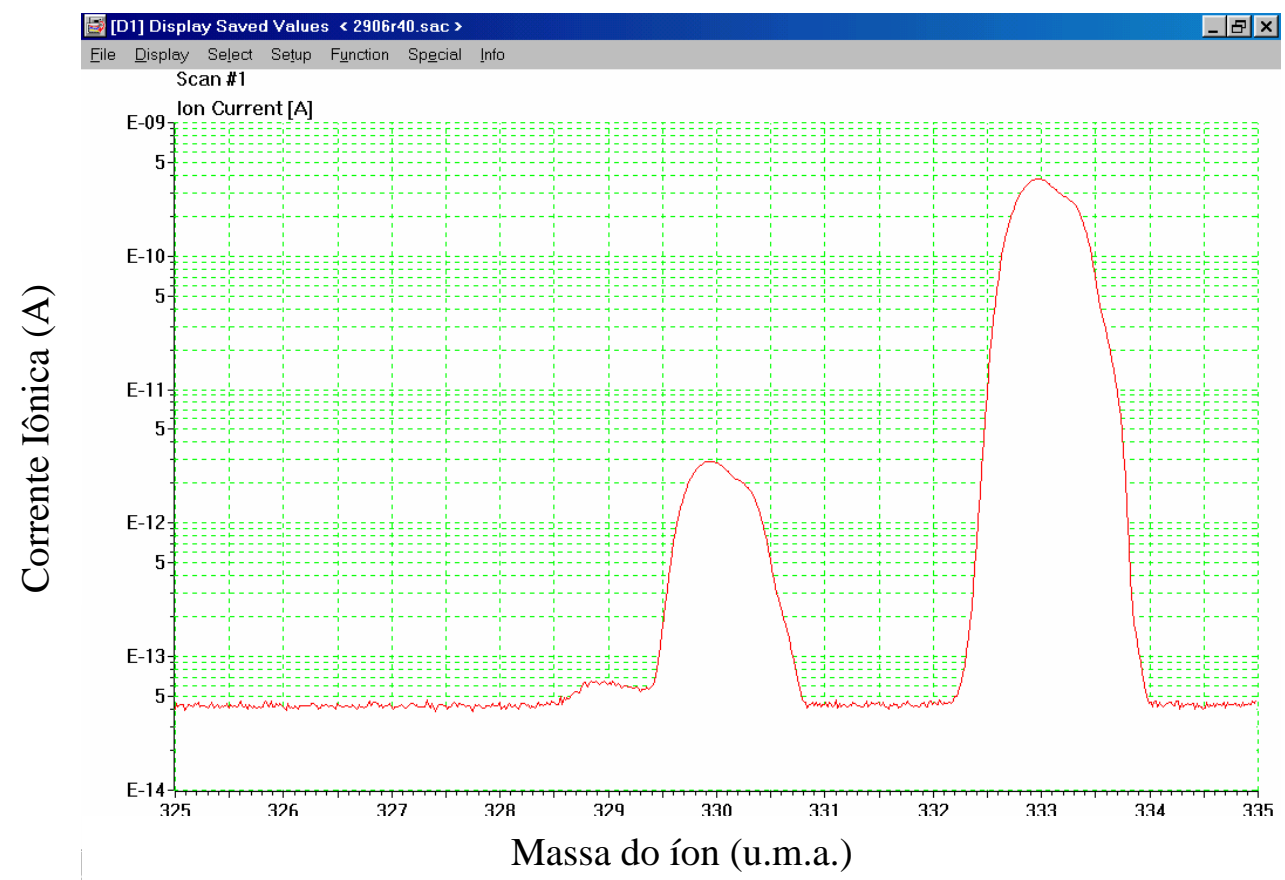

Figura 20. Espectro de massas do $\mathrm{UF}_{6}$ com resolução unitária.

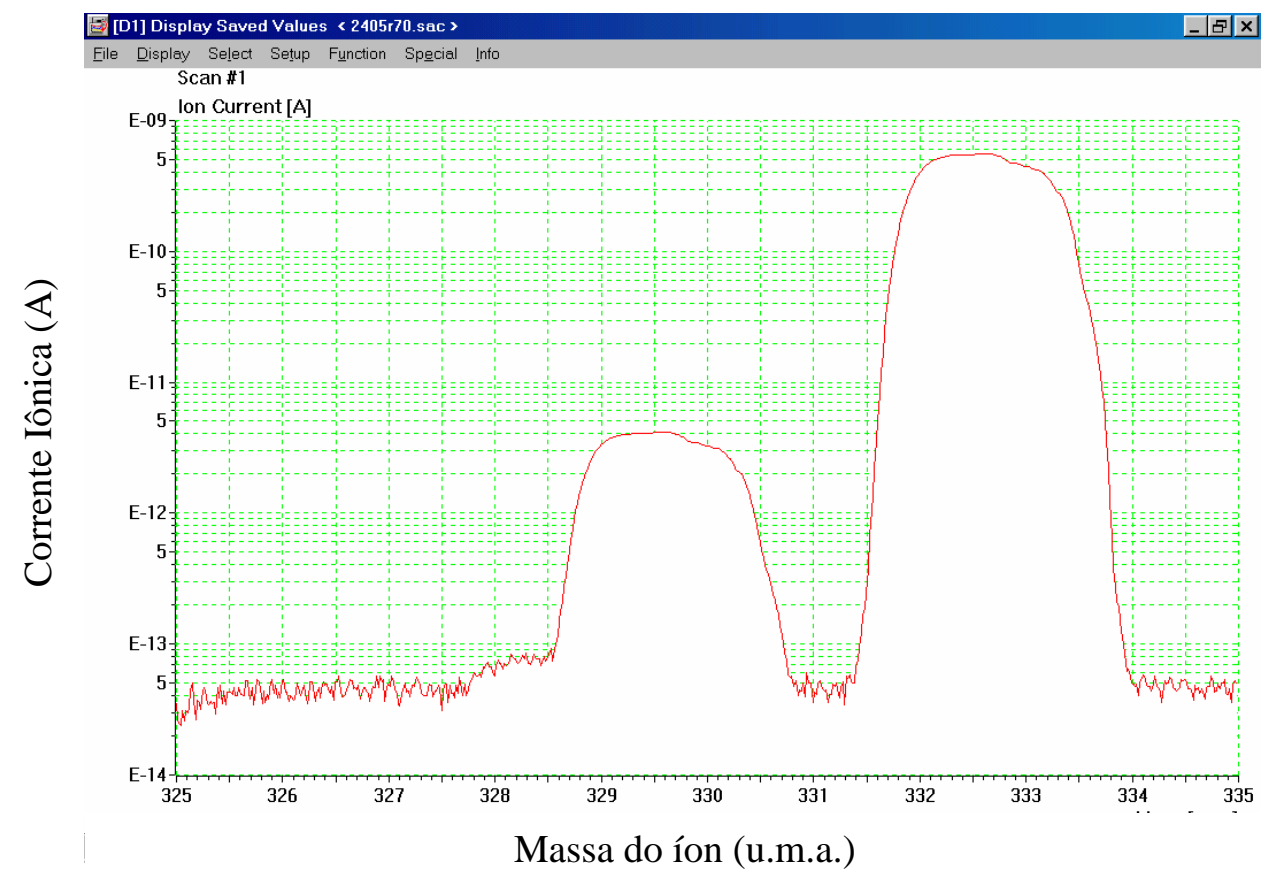

Figura 21. Espectro de massas do $\mathrm{UF}_{6}$ com resolução 70. 


\subsection{Otimização do número de ciclos analíticos}

Para a escolha do número ótimo de ciclos analíticos e de medições, uma amostra de $\mathrm{UF}_{6}$ natural, pura, não certificada, com razão isotópica de aproximadamente 0,00725; foi introduzida em um dos tanques de expansão (T1), a pressão de 0,300 mbar.

Foram realizadas 10 medições $(N=10)$, com 50 ciclos em cada uma delas $(n=50)$. Como o resultado final de uma análise é uma média de médias (média de $N$ medições, nas quais cada medição é uma média de $n$ ciclos), os resultados de análise com $N=2,3,4,5,6,7,8,9$ e 10 medições, nos quais, para cada medição, $n$ variou entre dois e cinqüenta.

Os resultados são apresentados na FIG. 22, onde pode ser observado que a partir de 15 ciclos analíticos o valor de $\left\langle R_{m}\right\rangle$, que é a média (sem correção) dos $N$ resultados de medição de razão isotópica, com $n$ ciclos cada; se mantém praticamente estável, para todos os valores de $\boldsymbol{N}$. Com base nesses dados, o número de ciclos analíticos para todas as análises posteriores foi fixado em 15, isto é, $n=15$.

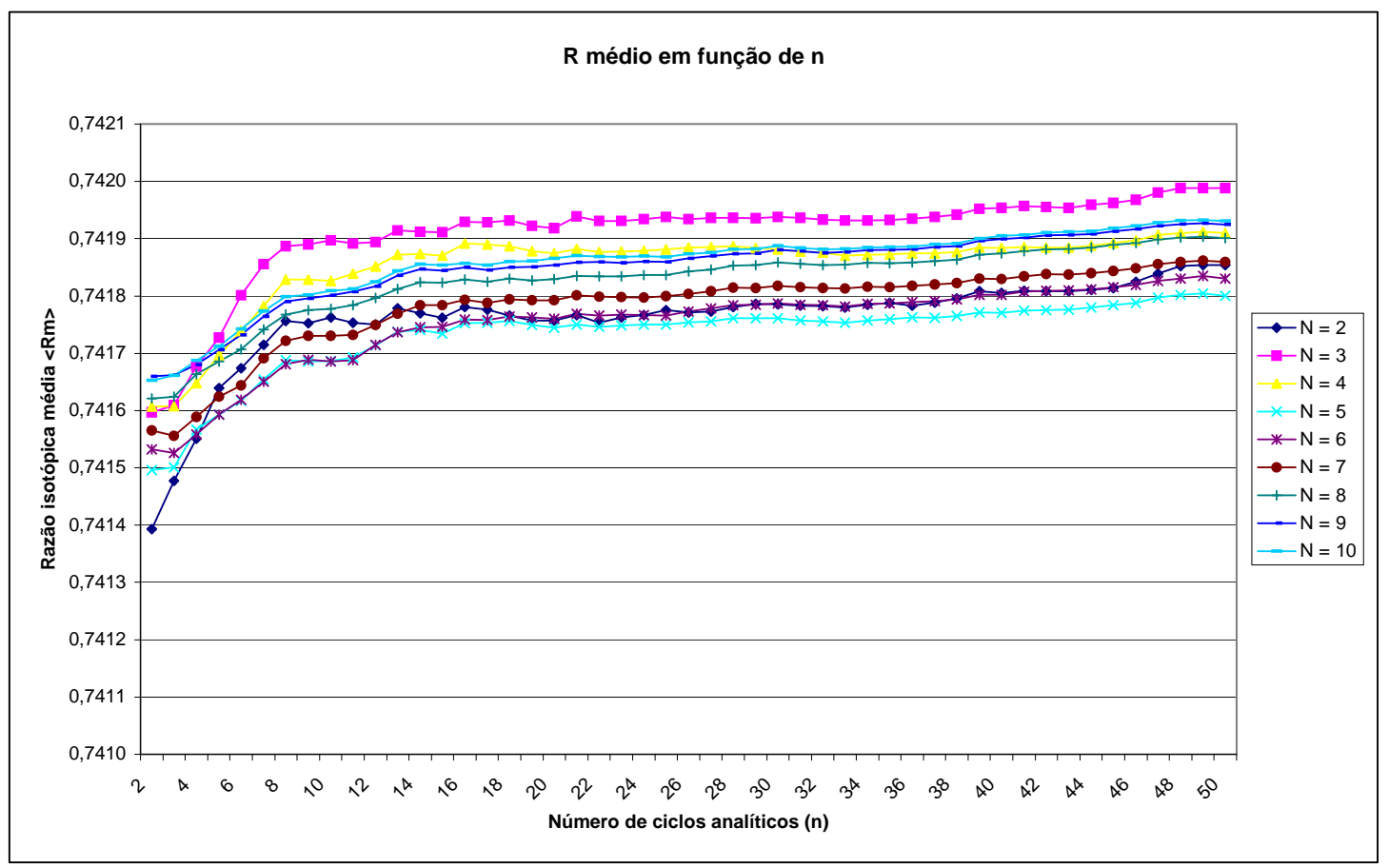

Figura 22. Variação da razão isotópica média com relação a $n$, para diversos valores de $N$. 
Os resultados de análises realizadas com $N$ variando de 2 a $10(\operatorname{com} n=15)$ são mostrados na FIG. 23, onde: as barras de erro correspondem aos desvios padrão dos valores obtidos em $N$ medições de razão isotópica, a linha vermelha contínua corresponde ao valor médio dos nove resultados de análise e as linhas tracejadas ao valor médio mais ou menos seu desvio padrão. Como nenhuma tendência foi observada, durante o restante do trabalho foram adotados os valores para $N$, entre seis e dez ${ }^{16}$.

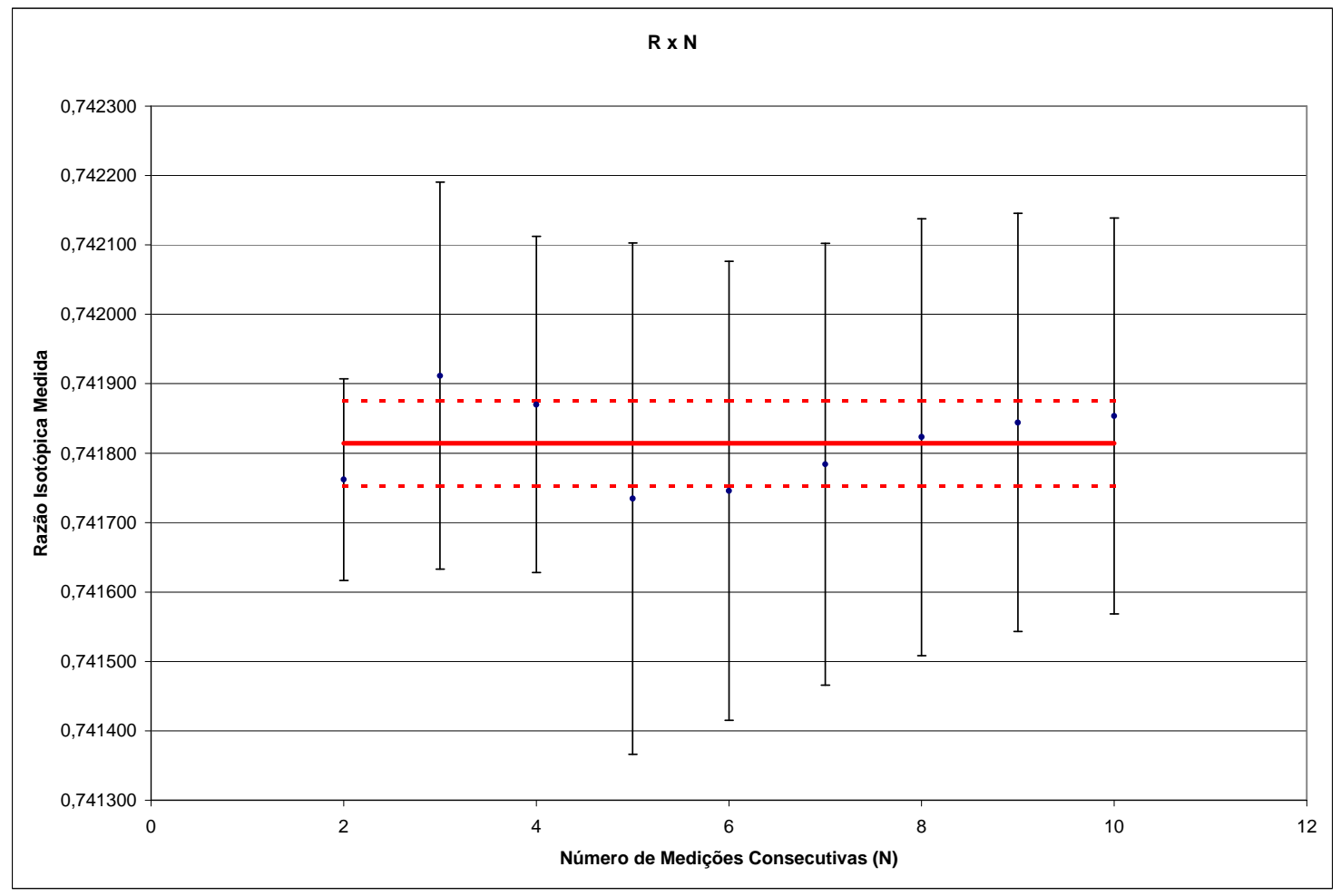

Figura 23. Variação da razão isotópica média com relação a $N, \operatorname{com} n=15$.

\subsection{Otimização da resolução}

Dos quatro fatores que compõe o fator de correção $K$, dado pela equação (39), somente dois podem depender da resolução, são eles o fator de discriminação de massas $K_{d}$ e o fator para efeitos não lineares $K_{l}$. Os fatores para efeito memória $K_{m}$ e para influência de impurezas $K_{i}$, além de não dependerem da resolução, podem ser igualados a um, caso seja usadas de amostras livres de impurezas e seja adotado um procedimento de lavagem entre análises de amostras com razões isotópicas muito diferentes, este procedimento consisti em introduzir o gás a ser analisado no tanque de expansão, com pressão igual ou superior àquela utilizada na análise, e evacuar o tanque em seguida. 
Neste caso o fator de correção fica:

$K=K_{d} K_{l}$

Existem duas alternativas de otimização da resolução, que são:

- Encontrar um valor de resolução que faça $K$ o mais próximo possível da unidade.

- Encontrar um valor de resolução que faça $K_{d}$ ou $K_{l}$ igual a unidade.

Para determinar a resolução ideal foram utilizados dois materiais de referência isotópicos, MRI 0,7 e MRI 4,5.

O MRI 0,7 ( $R_{c}=0,0072543 \pm 0,0000016$, conforme TAB. 2$)$ foi utilizado para determinar o fator de discriminação de massa em função da resolução. Para isso, uma alíquota deste material foi introduzida, no tanque de expansão T1, a pressão de 0,300 mbar e foram efetuadas análises isotópicas, com seis medições em cada análise $(N=6)$, em cada uma das nove resoluções para as quais a fonte foi otimizada. O resultado destes experimentos é apresentado na TAB. 5, onde são mostrados:

- o valor medido da razão isotópica, $R_{m}$, e seu desvio padrão, s, em função da resolução;

- o valor do fator de discriminação de massa, $K_{d}$, calculado pela equação (37), e sua incerteza padrão, $u_{K}$, em função da resolução.

Tabela 5. Razões isotópicas e fatores de correção em função da resolução.

\begin{tabular}{ccccc}
\hline Resolução & $\boldsymbol{R}_{\boldsymbol{m}}$ & $\boldsymbol{s}$ & $\boldsymbol{K}_{\boldsymbol{d}}$ & $\boldsymbol{u}_{\boldsymbol{K} \boldsymbol{d}}$ \\
\hline 30 & 0,00787648 & 0,00000371 & 0,92100793 & 0,00044555 \\
40 & 0,00757695 & 0,00000042 & 0,95741716 & 0,00011817 \\
50 & 0,00738650 & 0,00000423 & 0,98210266 & 0,00057275 \\
60 & 0,00735447 & 0,00000342 & 0,98637971 & 0,00047141 \\
70 & 0,00732665 & 0,00000618 & 0,99012573 & 0,00084228 \\
80 & 0,00732484 & 0,00000016 & 0,99036936 & 0,00011134 \\
90 & 0,00729983 & 0,00000045 & 0,99376299 & 0,00012555 \\
100 & 0,00730202 & 0,00000083 & 0,99346470 & 0,00015734 \\
120 & 0,00730646 & 0,00000064 & 0,99286118 & 0,00013983 \\
\hline
\end{tabular}


A dependência entre $K_{d}$ e a resolução é mostrada graficamente na FIG. 24. Onde pode ser visto que, a medida que o valor da resolução cresce, $K_{d}$ se aproxima de um. Deve-se notar que, como foi mostrado em 6.1, a resolução em unidades arbitrárias segue caminho inverso da resolução real, de modo que, a medida que a resolução real diminui, $K_{d}$ se aproxima de um, mas se estabiliza ao redor de aproximadamente 0,993.

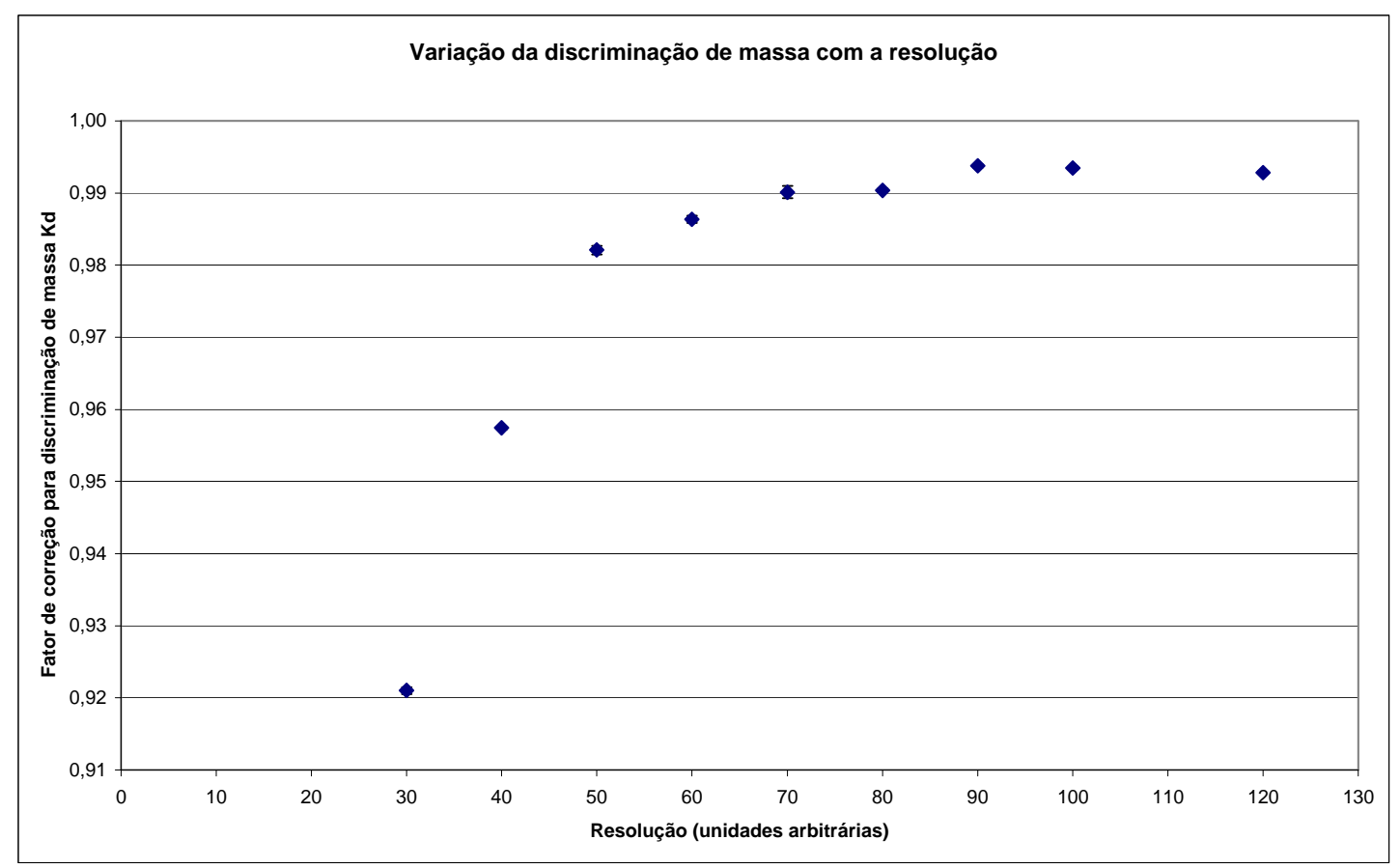

Figura 24. Discriminação de massa em função da resolução.

Como foi dito no item 3.3.7, para resoluções abaixo de um certo valor crítico pode não haver discriminação ao longo de toda a faixa de massas, pode-se concluir que o valor crítico ocorre aproximadamente para resolução 70 ( $\Delta M=1,81$ u.m.a.), para resoluções menores (valor arbitrário maior), $\mathrm{K}_{\mathrm{d}}$ é praticamente independente da resolução, isto é, a discriminação de massa decorre de efeitos não conexos a resolução. Para resoluções maiores (valor arbitrário menor) a discriminação de massa aumenta rapidamente com a resolução.

Portanto, a discriminação de massas é minimizada quando $\Delta M_{10} \geq 1,81$ u.m.a.. Entretanto, para $\Delta M_{10}>1,81$ u.m.a., em decorrência do achatamento do pico, o programa pode apresentar falhas na identificação do seu máximo. 
O fator de correção para não linearidade como função da resolução foi determinado com auxílio do material de referência isotópico MRI 4,5 $\left(R_{c}=0,0465457 \pm\right.$ 0,0000065, conforme TAB. 2). Para isso, foi utilizado o mesmo procedimento usado na análise do material MRI 0,7, isto é, uma alíquota do material foi introduzida, no tanque de expansão T2, a pressão de 0,300 mbar e foram efetuadas análises isotópicas, com seis medições em cada análise $(N=6)$, em cada uma das nove resoluções para as quais a fonte foi otimizada. O resultado destes experimentos é apresentado na TAB. 6, onde são mostrados:

- o valor medido da razão isotópica, $R_{m}$, e seu desvio padrão, $s_{m}$, em função da resolução;

- o valor da razão isotópica medida, corrigido para discriminação de massa, $R_{c o r}$, e sua incerteza padrão combinada, $u_{c}$, em função da resolução;

- o valor do fator de correção para não linearidade, $K_{l}$, calculado pelas equações (37) e (59), e sua incerteza padrão combinada, $u_{K l}$, em função da resolução.

Tabela 6. Razões isotópicas e fatores de correção em função da resolução.

\begin{tabular}{ccccccc}
\hline Resolução & $R_{m}$ & $s_{m}$ & $R_{\text {cor }}$ & $u_{c}$ & $K_{l}$ & $u_{K l}$ \\
\hline 30 & 0,05043875 & 0,00000346 & 0,04645449 & 0,00002270 & 1,00196346 & 0,00049453 \\
40 & 0,04856840 & 0,00000382 & 0,04650022 & 0,00000681 & 1,00097807 & 0,00016232 \\
50 & 0,04742250 & 0,00000849 & 0,04657376 & 0,00002841 & 0,99939744 & 0,00061366 \\
60 & 0,04736890 & 0,00001414 & 0,04672372 & 0,00002633 & 0,99618990 & 0,00056563 \\
70 & 0,04731580 & 0,00000141 & 0,04684859 & 0,00003988 & 0,99353468 & 0,00084853 \\
80 & 0,04699395 & 0,00000134 & 0,04654137 & 0,00000540 & 1,00009307 & 0,00013539 \\
90 & 0,04673735 & 0,00000205 & 0,04644585 & 0,00000621 & 1,00214984 & 0,00015119 \\
100 & 0,04676780 & 0,00000099 & 0,04646216 & 0,00000742 & 1,00179806 & 0,00017468 \\
120 & 0,04716075 & 0,00000290 & 0,04682408 & 0,00000720 & 0,99405481 & 0,00016779 \\
\hline
\end{tabular}

A dependência entre $K_{l}$ e a resolução é mostrada graficamente na FIG. 25, onde pode ser visto que a relação entre a linearidade e a resolução é bem comportada para resoluções entre 30 e 70; e acima disso tem um comportamento mais complexo. 
A resolução $70\left(\Delta M_{10}=1,81\right.$ u.m.a..) parece ser um limiar abaixo do qual ocorrem algumas mudanças de comportamento no sistema. Uma é positiva, a discriminação de massa é mínima e praticamente independente da resolução; as outras negativas, como a forma do pico achatada e os aumentos e quedas abruptos dos efeitos não lineares.

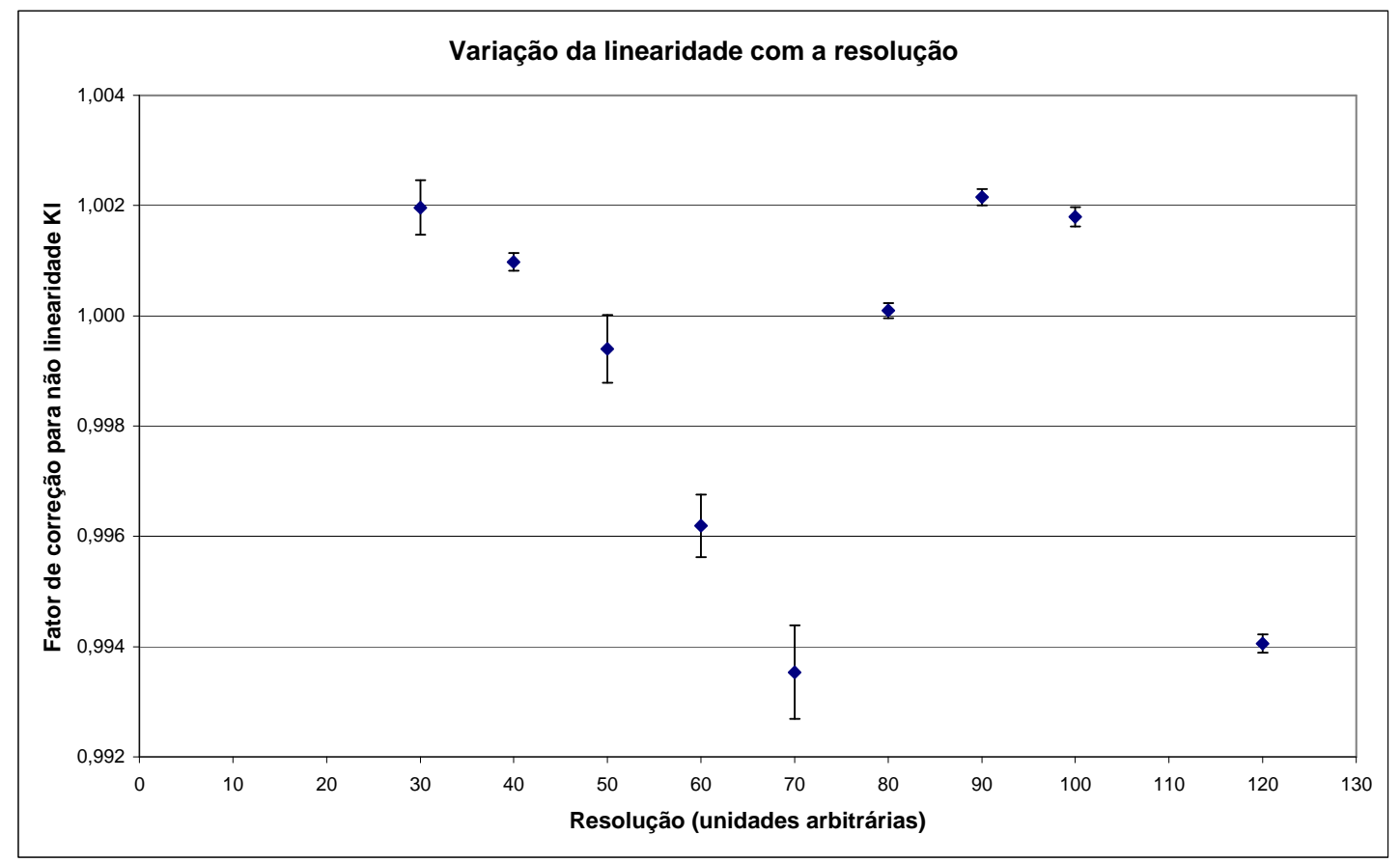

Figura 25. Discriminação de massa em função da resolução..

Como pode ser visto na TAB. 4, quando a resolução está na faixa entre 30 e 70, o ponto ideal de operação da fonte de íons varia muito pouco, apenas variações pequenas no potencial V4, a partir da resolução 70 , cada ajuste na resolução requer um total reajuste da fonte, ou seja, o sistema torna-se mais instável.

Com respeito às variações na magnitude dos efeitos não lineares, a causa provável é o aumento da sensibilidade a abundância, decorrente da redução da resolução, que aumenta a influência dos picos 329 e 331 no pico 330. Este aumento da sensibilidade a abundância pode ser observado na FIG. 26.

A influência dos efeitos não lineares é mínima em três regiões (FIG. 25): entre as resoluções 40 e 50, próximo à resolução 80 e entre as resoluções 100 e 120. Para evitar a 
instabilidade e os problemas analíticos decorrentes dos picos achatados, que surgem para resoluções acima de 70, optou-se por trabalhar na faixa entre 40 e 50. A resolução escolhida foi a 45 , onde $\Delta M_{10}=1,13$ u.m.a..

Ao contrário da discriminação de massas, sempre presente em maior ou menor grau, como pode ser visto na FIG. 24, os efeitos não lineares são praticamente desprezíveis para certos valores de resolução. Do ponto de vista analítico, entre minimizar o produto $K_{l} \cdot K_{d}$ ou fazer $K_{l}=1$, é vantajoso escolher um valor de resolução que elimine os efeitos não lineares, uma vez que evita a necessidade de mais de uma amostra de referência.

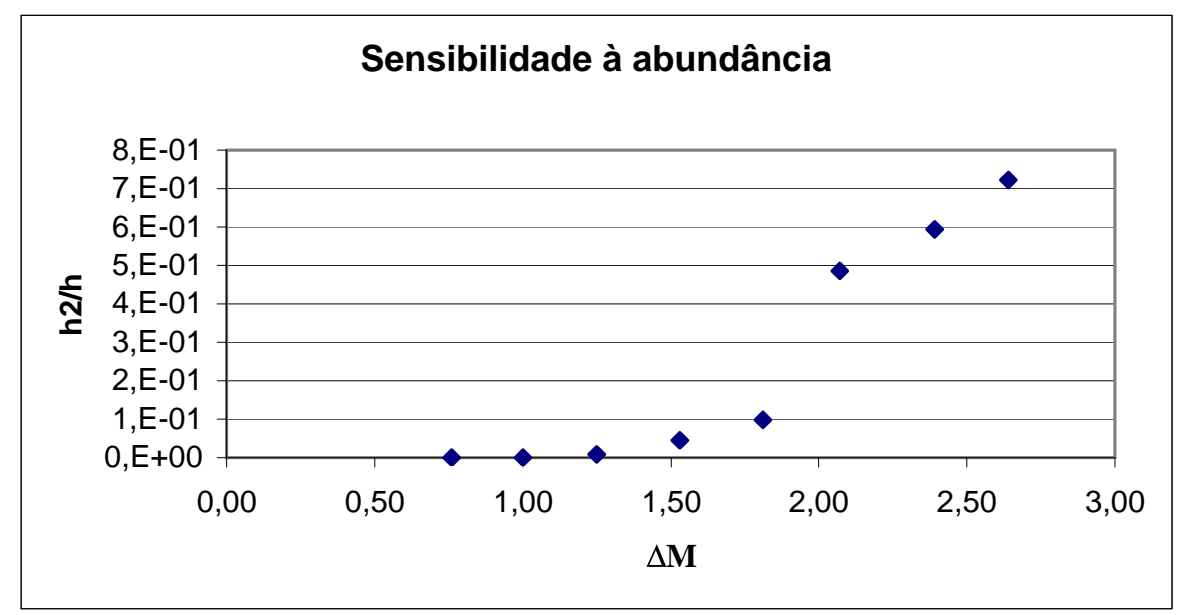

Figura 26. Sensibilidade a abundância para massa alta.

Portanto, os parâmetros da fonte de íons e da resolução otimizados e que serão utilizados em todas as análises são:

Resolução (unidades arbitrárias): $\quad 45$

$\Delta M_{10}$ (u.m.a.): $\quad 1,13$

$V 1(V): \quad 120$

$V 2(V): \quad 91$

$V 3(V): \quad 20,25$

V4 $(V): \quad 15,00$

V5 $(V): \quad 172$ 


\subsection{Dependência entre o valor da razão isotópica medida e a pressão no tanque de expansão, determinação do fator de correção para discriminação de massa}

Para determinar o fator de discriminação de massa e sua relação com a pressão no tanque de amostragem, utilizou-se a amostra de $\mathrm{UF}_{6}$ com razão isotópica certificada, MRI 0,7.

A razão isotópica desta amostra foi medida em dez pressões diferentes entre 0,10 e 0,55 mbar, seguindo o seguinte procedimento:

- uma alíquota da amostra era introduzida no tanque T1, até a pressão desejada;

- $\quad$ seis medições sucessivas de razão isotópica eram executadas e sua média calculada.

- o valor desta média era atribuído a razão isotópica medida nesta pressão.

Este procedimento foi repetido em dez dias diferentes, para que se pudesse conhecer a reprodutibilidade, tanto dos valores medidos em cada pressão, quanto do comportamento geral da razão isotópica medida com relação a pressão.

Os valores obtidos para a razão isotópica, em cada um dos dez dias, para cada pressão, são apresentados na TAB. 7. Onde $\left\langle R_{m}\right\rangle$ é a razão isotópica média para dez dias e as grandezas $s 1$ e $s 2$, que quantificam, respectivamente, a repetitividade e a reprodutibilidade, são dadas pelas equações (42) e (43), onde $K=10$ (número de dias) e $J$ $=6$ (número de repetições em um dia).

Nas FIG. 27 a 36. o comportamento da razão isotópica medida com relação a pressão é mostrado para cada um dos dez dias. Nestas figuras podes-se ver que a medida que a pressão sobe, a razão isotópica medida também sobe. Este efeito da pressão sobre a discriminação de massa ocorre especialmente na fonte de íons, como foi dito em 3.3.4, mas uma descrição teórica mais exata desta dependência está além do escopo deste trabalho, que tem objetivos mais práticos. 
Tabela 7. Valores médios medidos de $R_{m}$ para dez pressões em dez datas.

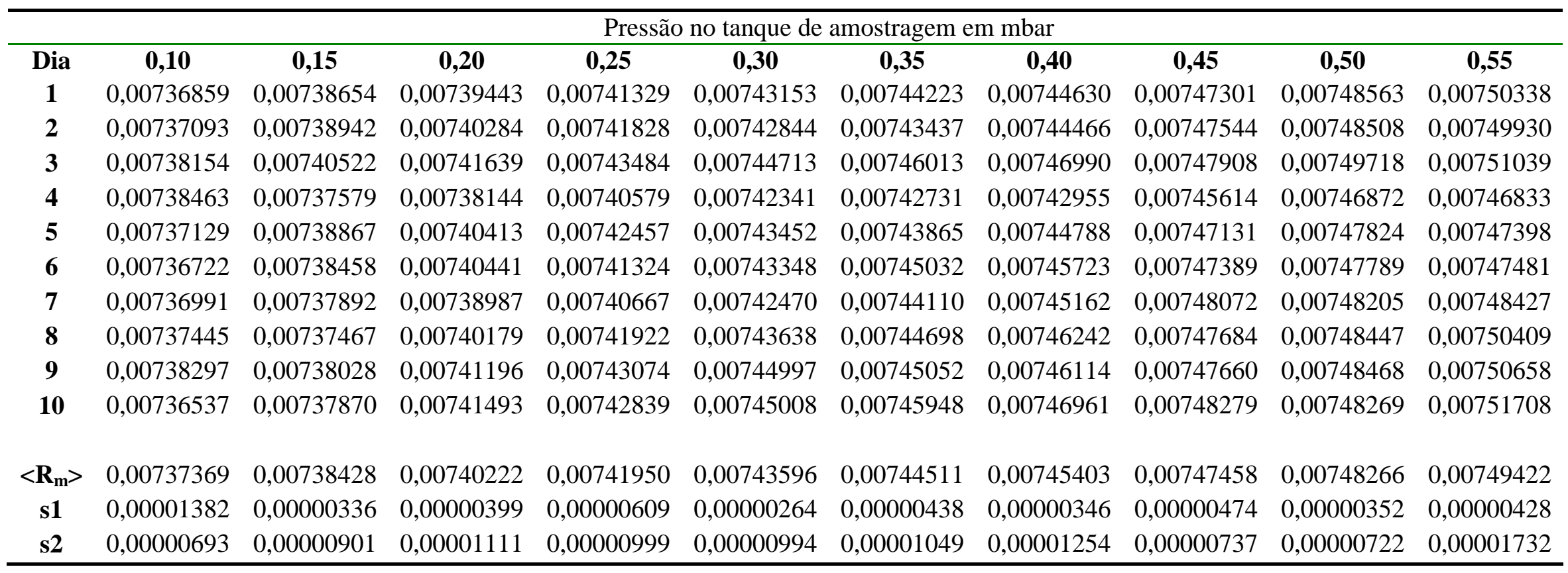




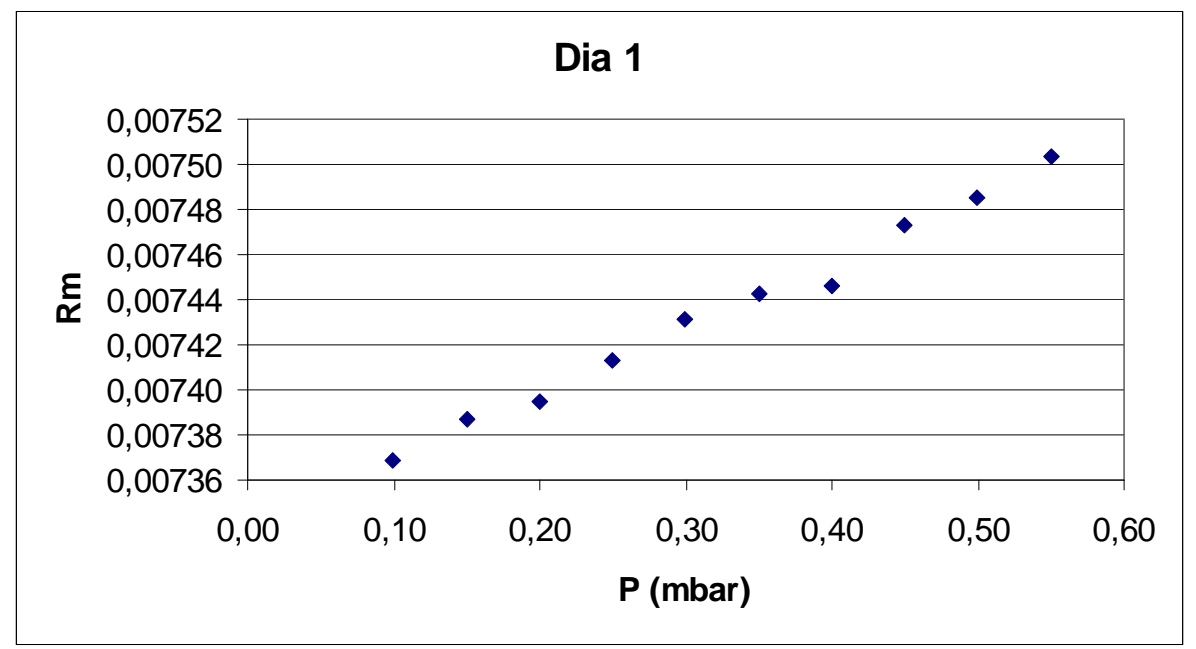

Figura 27. Variação da razão isotópica medida com relação à pressão no tanque ( $1^{\circ}$ dia).

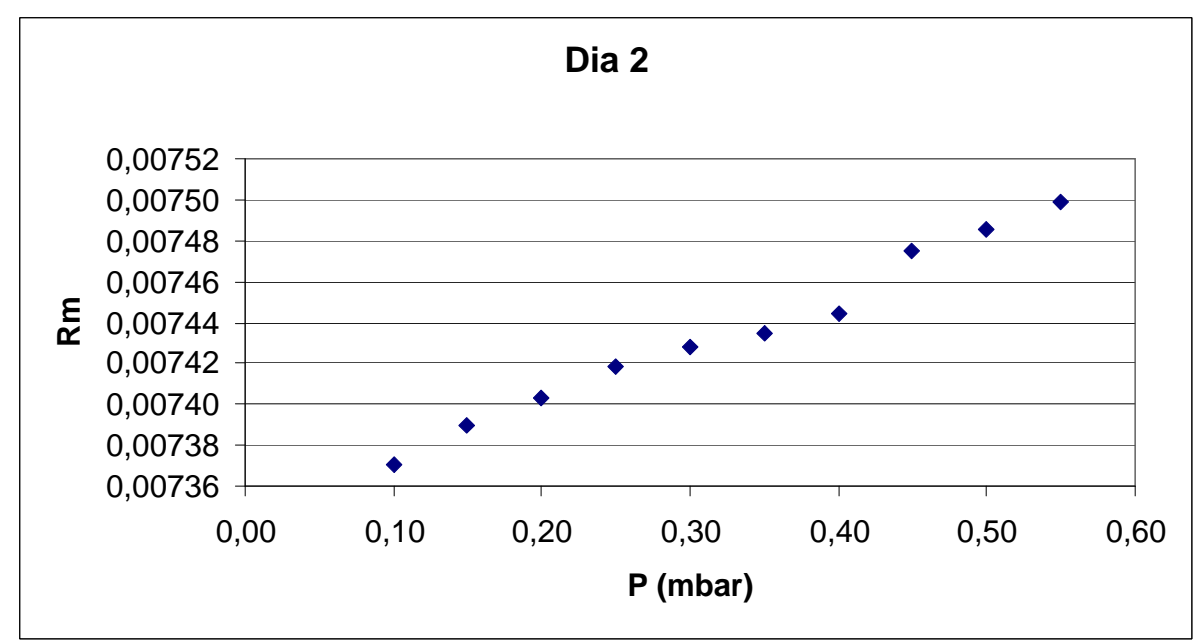

Figura 28. Variação da razão isotópica medida com relação à pressão no tanque ( $2^{\circ}$ dia). 


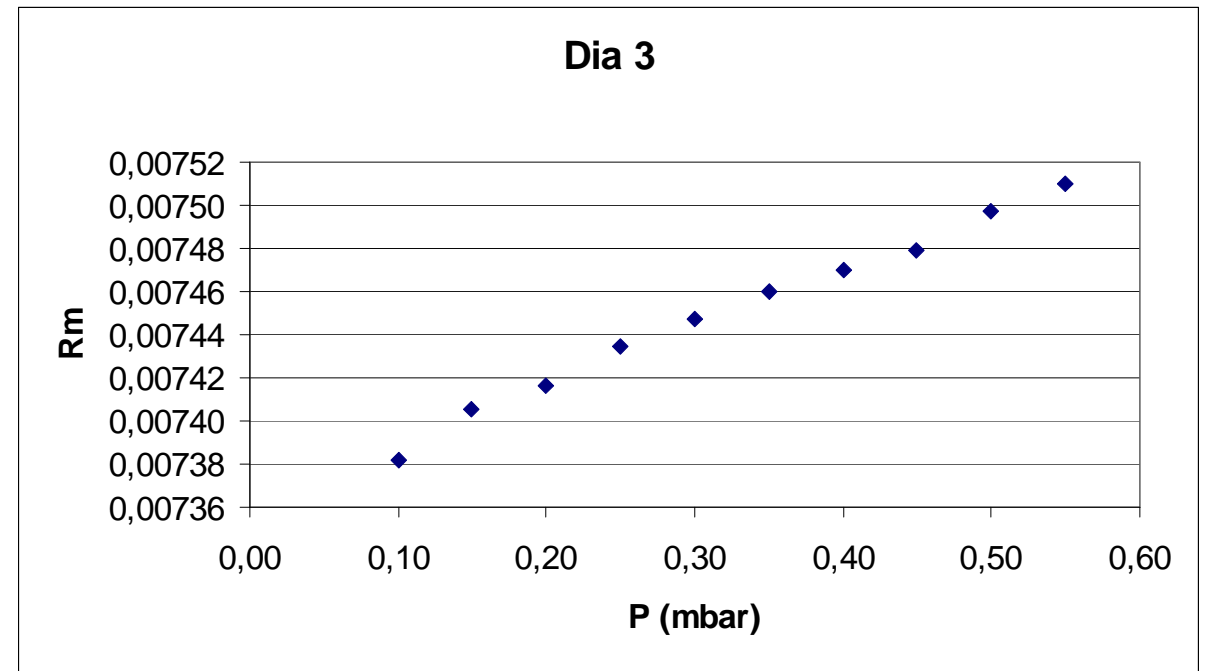

Figura 29. Variação da razão isotópica medida com relação à pressão no tanque ( $3^{\circ}$ dia).

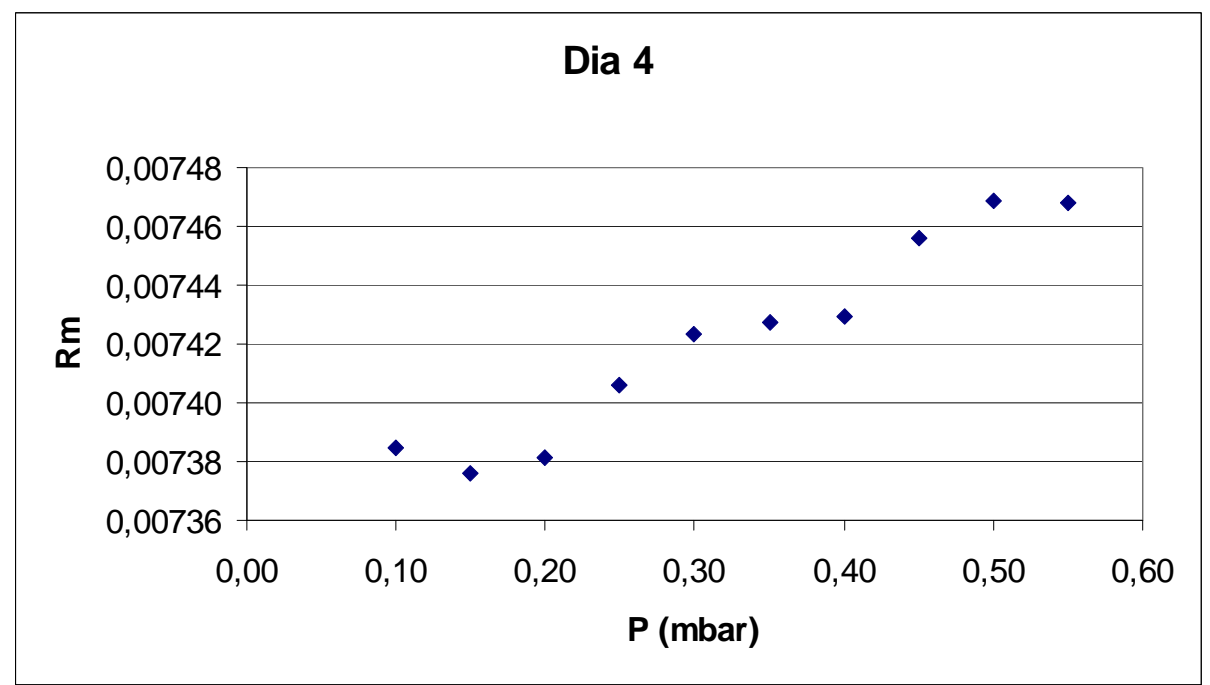

Figura 30. Variação da razão isotópica medida com relação à pressão no tanque (4º dia). 


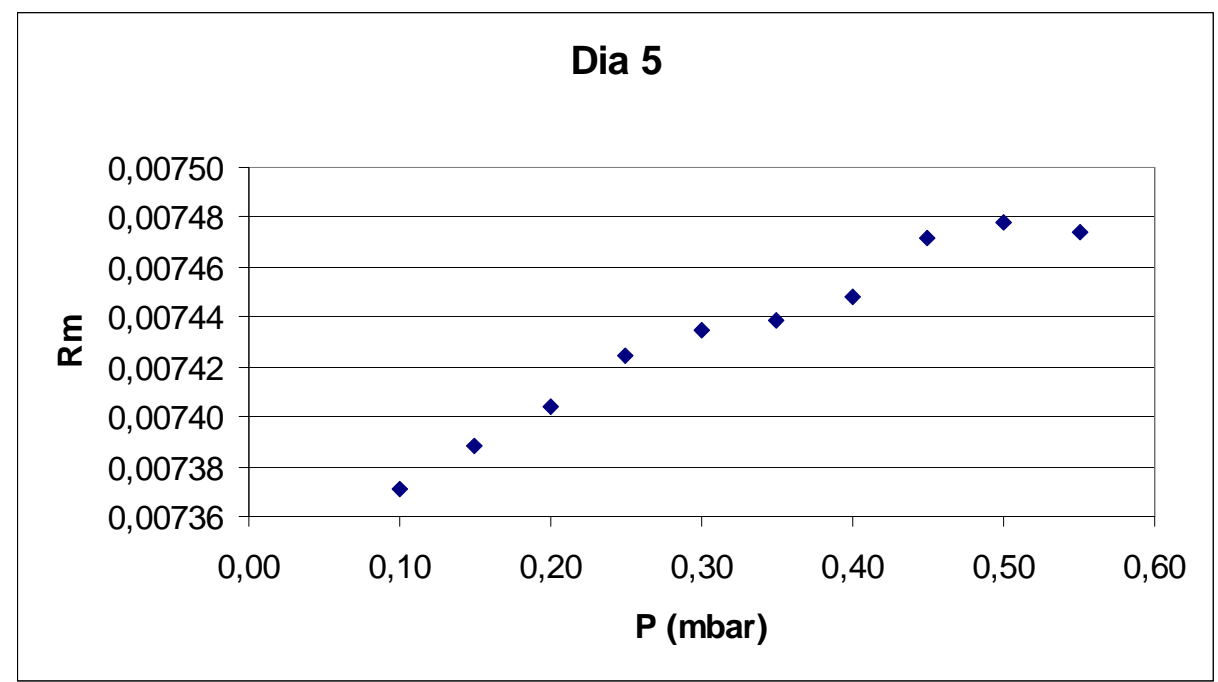

Figura 31. Variação da razão isotópica medida com relação à pressão no tanque ( $5^{\circ}$ dia).

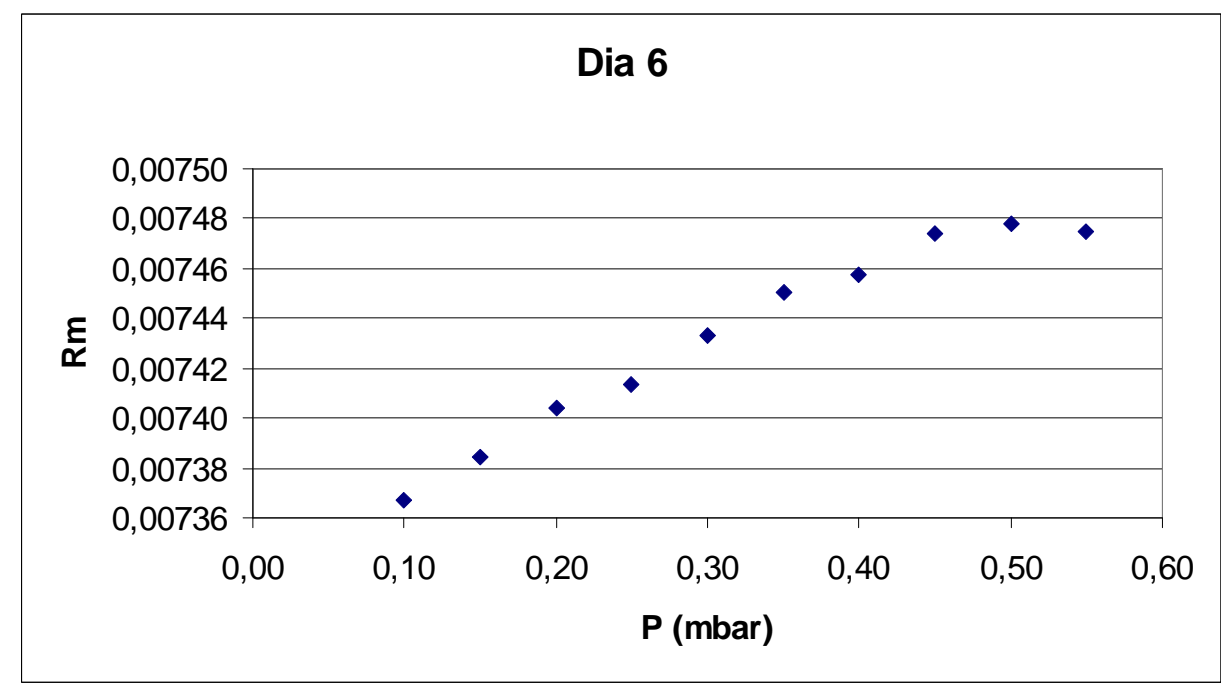

Figura 32. Variação da razão isotópica medida com relação à pressão no tanque ( $6^{\circ}$ dia). 


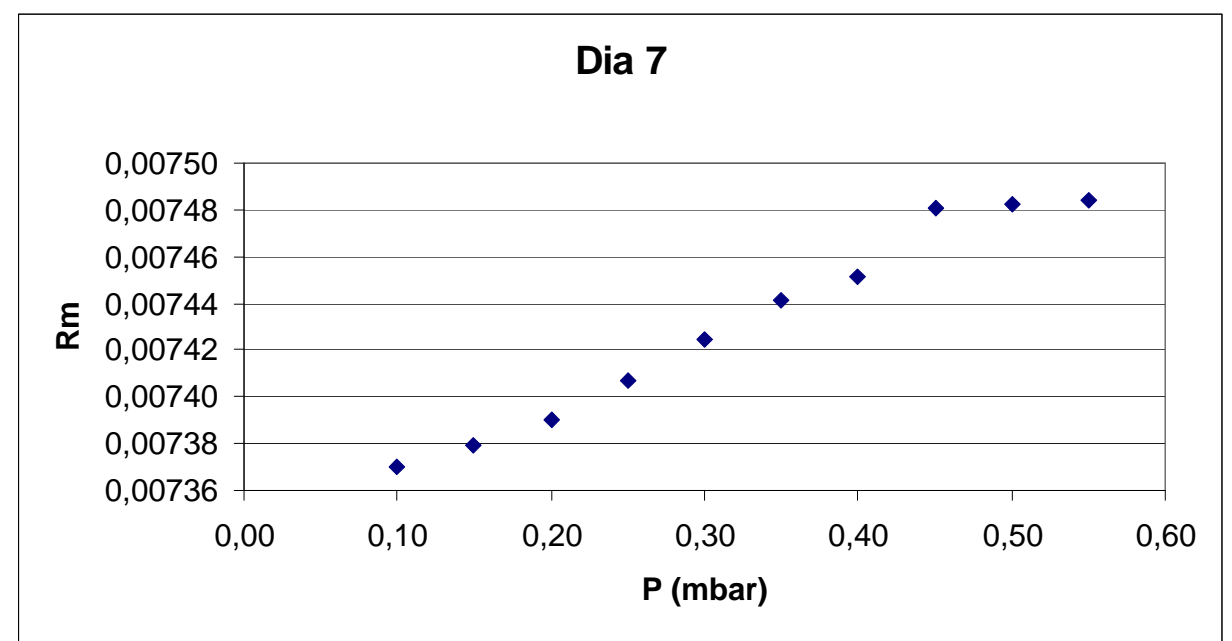

Figura 33. Variação da razão isotópica medida com relação à pressão no tanque ( $7^{\circ}$ dia).

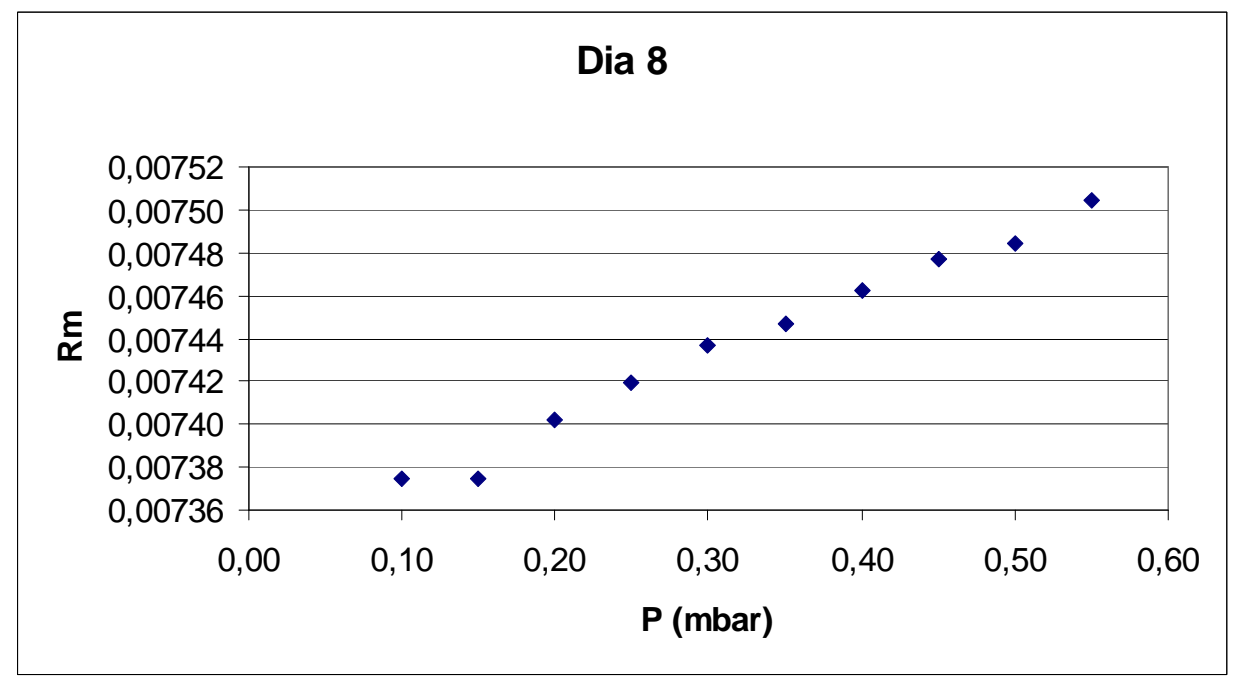

Figura 34. Variação da razão isotópica medida com relação à pressão no tanque ( $8^{\circ}$ dia). 


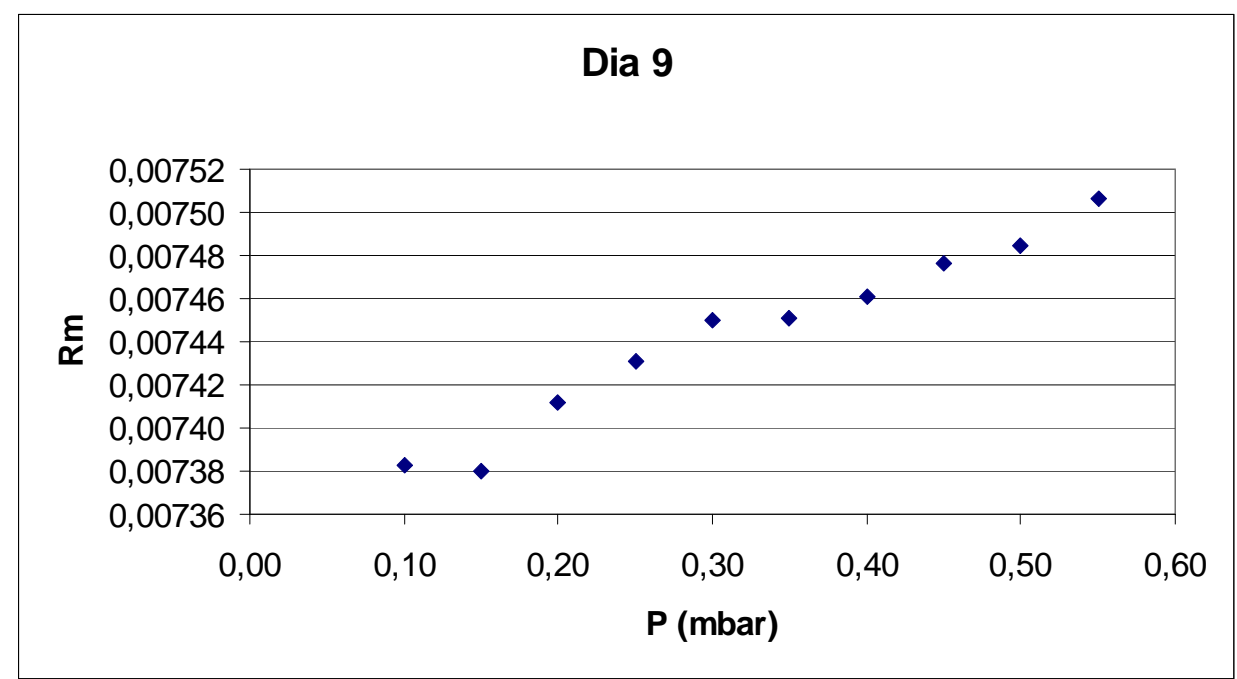

Figura 35. Variação da razão isotópica medida com relação à pressão no tanque ( $9^{\circ}$ dia).

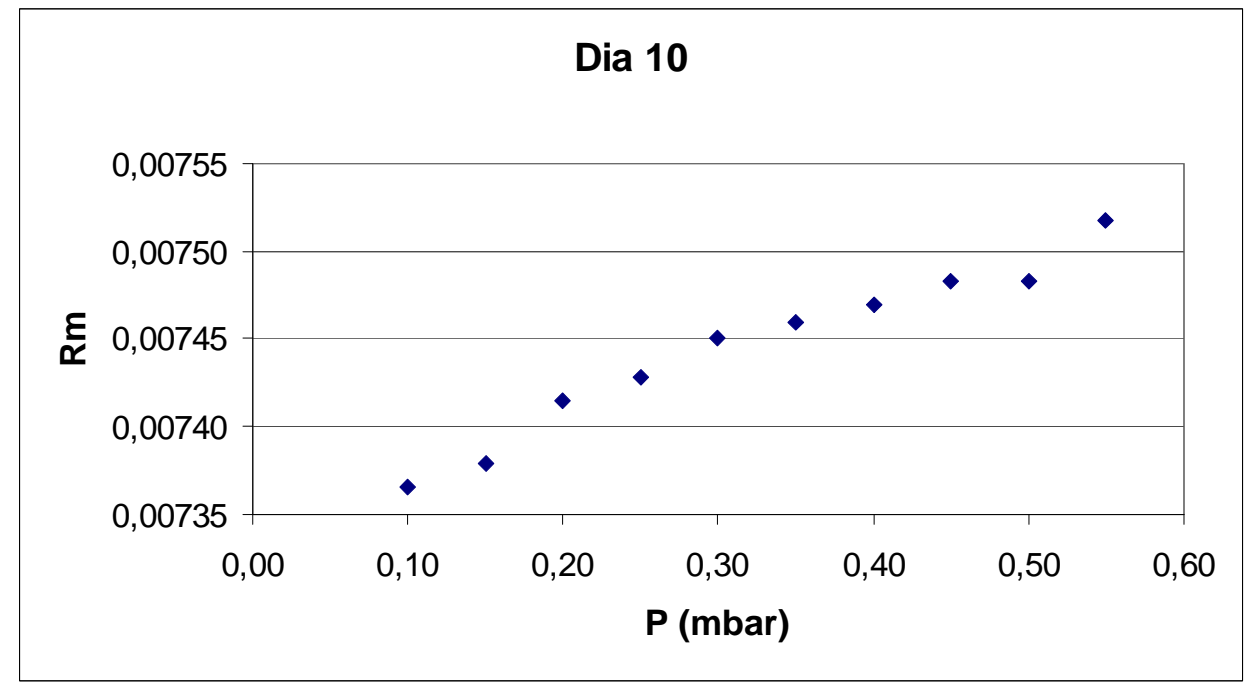

Figura 36. Variação da razão isotópica medida com relação à pressão no tanque ( $10^{\circ}$ dia). 
Nos dias 1, 2, 3, 8 e 10 a relação entre a razão isotópica medida e a pressão foi linear ao longo de toda a faixa de pressão; nos dias 5, 6, 7 e 9 ocorrem uma mudança de inclinação da rampa acima de 0,30 mbar. No dia 4 , a variação foi menos comportada, com os valores da razão isotópica oscilando ao redor de uma linha ascendente. Entretanto, em todos os dias, a relação entre a razão isotópica e a pressão é linear nas faixas de valores de pressão entre 0,15 e 0,30 mbar e entre 0,30 e 0,40 mbar.

Uma equação de reta (60) foi ajustada aos pontos experimentais obtidos, na faixa de pressão entre 0,15 e 0,30 mbar, em cada um dos dias.

$$
R(P)=a P+b
$$

Os valores dos parâmetros $a$ e $b$, obtidos por regressão linear, são dados por ${ }^{25}$ :

$$
\begin{gathered}
a=\frac{\left[\left(\sum_{i=1}^{4} \frac{1}{u_{i}^{2}}\right)\left(\sum_{i=1}^{4} \frac{R_{m i} \cdot P_{i}}{u_{i}^{2}}\right)-\left(\sum_{i=1}^{4} \frac{P_{i}}{u_{i}^{2}}\right)\left(\sum_{i=1}^{4} \frac{R_{m i}}{u_{i}^{2}}\right)\right]}{\left[\left(\sum_{i=1}^{4} \frac{1}{u_{i}^{2}}\right)\left(\sum_{i=1}^{4} \frac{P_{i}^{2}}{u_{i}^{2}}\right)-\left(\sum_{i=1}^{4} \frac{P_{i}}{u_{i}^{2}}\right)^{2}\right]} \\
b=\frac{\left[\left(\sum_{i=1}^{4} \frac{P_{i}^{2}}{u_{i}^{2}}\right)\left(\sum_{i=1}^{4} \frac{R}{R_{m i}^{2}}\right)-\left(\sum_{i=1}^{4} \frac{P_{i}}{u_{i}^{2}}\right)\left(\sum_{i=1}^{4} \frac{R_{m i} \cdot P_{i}}{u_{i}^{2}}\right)\right]}{\left[\left(\sum_{i=1}^{4} \frac{1}{u_{i}^{2}}\right)\left(\sum_{i=1}^{4} \frac{P_{i}^{2}}{u_{i}^{2}}\right)-\left(\sum_{i=1}^{4} \frac{P_{i}}{u_{i}^{2}}\right)^{2}\right]}
\end{gathered}
$$

onde:

- $\mathrm{P}_{\mathrm{i}}$ é o valor da pressão, com o índice i variando de um a quatro para representar os quatro valores de pressão utilizados: $\mathrm{P}_{1}=0,15$ mbar; $\mathrm{P}_{2}=$ 0,20 mbar; $\mathrm{P}_{3}=0,25$ mbar e $\mathrm{P}_{4}=0,30$ mbar.

- $\mathrm{R}_{\mathrm{mi}}=$ razão isotópica medida (média das seis análises do dia) na pressão $\mathrm{P}_{\mathrm{i}}$. 
- $\mathrm{u}_{\mathrm{i}}=$ incerteza padrão no valor de $\mathrm{R}_{\mathrm{mi}}$, dada pelo desvio padrão dos seis valores de razão isotópica medidos a pressão $P_{\mathrm{i}}$.

As variâncias dos parâmetros ajustados são dadas por:

$$
\begin{aligned}
& u_{a}^{2}=\frac{\sum_{i=1}^{4} \frac{1}{u_{i}^{2}}}{\left[\left(\sum_{i=1}^{4} \frac{1}{u_{i}^{2}}\right)\left(\sum_{i=1}^{4} \frac{P_{i}^{2}}{u_{i}^{2}}\right)-\left(\sum_{i=1}^{4} \frac{P_{i}}{u_{i}^{2}}\right)^{2}\right]} \\
& \left.u_{b}^{2}=\frac{\sum_{i=1}^{4} \frac{P_{i}^{2}}{u_{i}^{2}}}{\left[\left(\sum_{i=1}^{4} \frac{1}{u_{i}^{2}}\right)\left(\sum_{i=1}^{4} \frac{P_{i}^{2}}{u_{i}^{2}}\right)-\left(\sum_{i=1}^{4} \frac{P_{i}}{u_{i}^{2}}\right)^{2}\right]}\right]
\end{aligned}
$$

A incerteza para o ajuste e covariância entre os parâmetros $a$ e $b$ são ${ }^{25}$ :

$$
u(P)=\sqrt{u_{b}^{2}+P^{2} u_{a}^{2}+2 \operatorname{cov}(a b)}
$$

$$
\operatorname{cov}(a b)=-\frac{\sum_{i=1}^{4} \frac{P_{i}}{u_{i}^{2}}}{\left[\left(\sum_{i=1}^{4} \frac{1}{u_{i}^{2}}\right)\left(\sum_{i=1}^{4} \frac{P_{i}^{2}}{u_{i}^{2}}\right)-\left(\sum_{i=1}^{4} \frac{P_{i}}{u_{i}^{2}}\right)^{2}\right]}
$$

Os valores obtidos para os parâmetros $a$ e $b$, suas respectivas incertezas $u_{a}$ e $u_{b}$ e covariância, são mostrados na TAB. 8 . 
Tabela 8. Parâmetros das funções ajustadas para os 10 dias.

\begin{tabular}{cccccc}
\hline Dia & $\boldsymbol{a}$ & $\boldsymbol{u}_{\boldsymbol{a}}$ & $\boldsymbol{b}$ & $\boldsymbol{u}_{\boldsymbol{b}}$ & $\boldsymbol{c o v}(\boldsymbol{a b})$ \\
\hline 1 & 0,00031257 & 0,00003753 & 0,00733694 & 0,00000928 & $-3,36 \mathrm{E}-10$ \\
2 & 0,00025877 & 0,00003281 & 0,00735191 & 0,00000828 & $-2,67 \mathrm{E}-10$ \\
3 & 0,00028483 & 0,00002723 & 0,00735995 & 0,00000550 & $-1,49 \mathrm{E}-10$ \\
4 & 0,00033558 & 0,00002531 & 0,00732132 & 0,00000601 & $-1,47 \mathrm{E}-10$ \\
5 & 0,00030643 & 0,00001181 & 0,00734279 & 0,00000272 & $-3,05 \mathrm{E}-11$ \\
6 & 0,00032227 & 0,00001612 & 0,00733687 & 0,00000428 & $-6,69 \mathrm{E}-11$ \\
7 & 0,00031183 & 0,00002678 & 0,00733104 & 0,00000762 & $-2,01 \mathrm{E}-10$ \\
8 & 0,00041229 & 0,00003295 & 0,00731541 & 0,00000735 & $-2,35 \mathrm{E}-10$ \\
9 & 0,00046180 & 0,00001604 & 0,00731304 & 0,00000353 & $-5,41 \mathrm{E}-11$ \\
10 & 0,00043620 & 0,00001814 & 0,00732125 & 0,00000427 & $-7,52 \mathrm{E}-11$ \\
\hline
\end{tabular}

As médias para os dez valores diários de razão isotópica são mostrados na FIG. 37, onde: $\left\langle R_{m}\right\rangle$ é o valor médio da razão isotópica medida (TAB. 7), as barras de erro correspondem à reprodutibilidade (aplicações do teste-F mostraram que em todas as pressões s2 é significativamente maior que s1, portanto a variabilidade total dos resultados é melhor representada por $s 2$ ). A linha reta contínua vermelha corresponde à curva ajustada entre as pressões 0,15 e 0,30 mbar (primeira região linear) e a reta contínua azul corresponde à curva ajustada entre as pressões 0,30 e 0,40 mbar (segunda região linear). As linhas tracejadas representam aos valores da reta mais ou menos a incerteza padrão do ajuste (equação 65). Os parâmetros da equação (60) nestas duas regiões são:

$$
\begin{array}{lllll}
a & u_{a} & b & u_{b} & \operatorname{Cov}(a b)
\end{array}
$$

$\begin{array}{llllll}\text { Primeira região } & 0,00034520 & 0,00008535 & 0,00733278 & 0,00001959 & -1,62 \times 10^{-09}\end{array}$

$\begin{array}{lllllll}\text { Segunda região } & 0,00018086 & 0,00015851 & 0,00738174 & 0,00005457 & -8,61 \times 10^{-9}\end{array}$

Estes parâmetros foram obtidos com as equações (61 a 64) e (66), onde:

- $\mathrm{R}_{\mathrm{mi}}=$ razão isotópica medida (média dos 10 dias) na pressão $\mathrm{P}_{\mathrm{i}}$.

- $\mathrm{u}_{\mathrm{i}}=$ incerteza padrão no valor de $\mathrm{R}_{\mathrm{mi}}$, dado pelo s2 para cada pressão. 


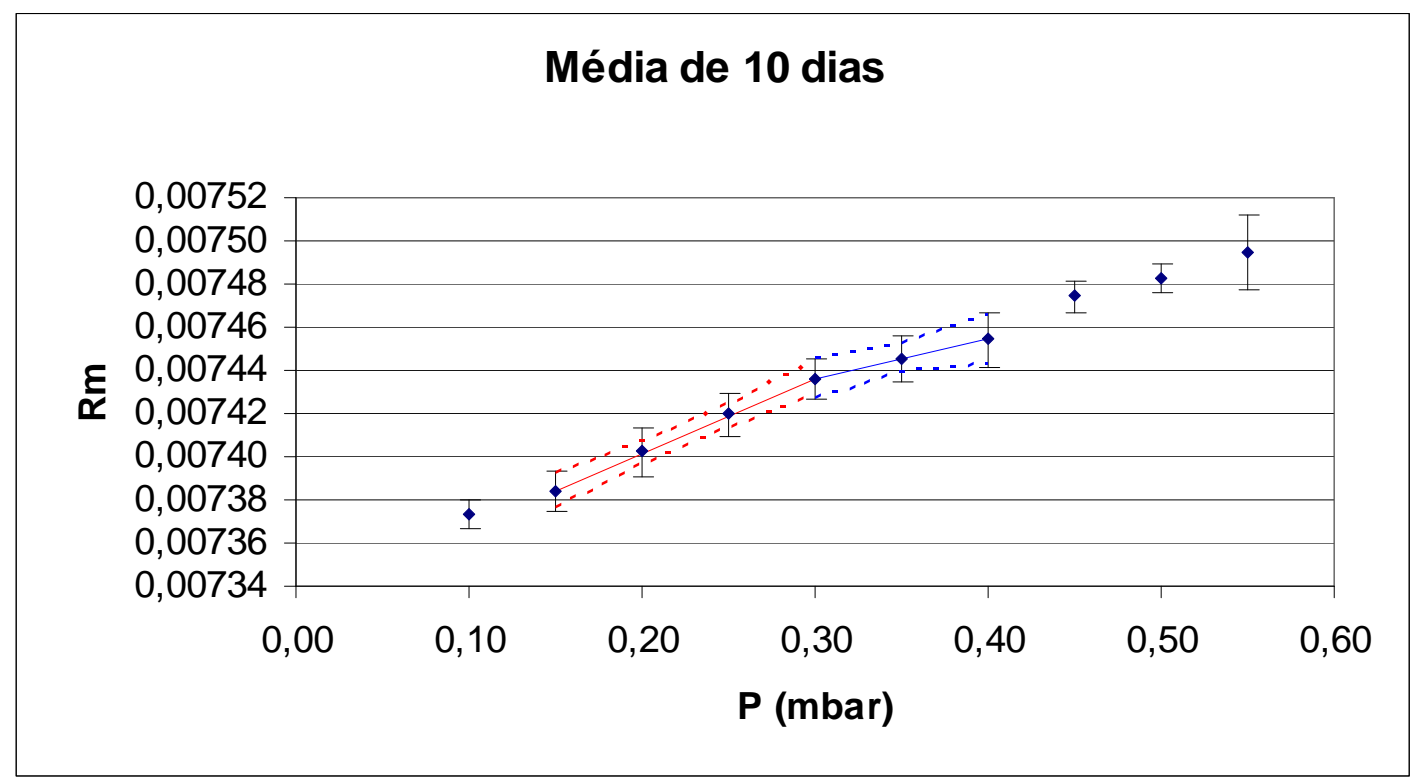

Figura 37. Valores médios (10 dias) das razões isotópicas medidas em função da pressão.

Não se pode dizer que haja uma pressão ideal para análise, a variabilidade dos valores, tanto de curto prazo quanto de longo prazo, não se mostrou significativamente diferente entre as diversas pressões.

Pressões acima de 0,40 mbar não são recomendáveis, porque reduzem o período entre as paradas de manutenção, provocam maior consumo de amostra e a intensidade do sinal decresce mais rapidamente, durante a análise, do que em pressões menores.

Se a análise da amostra desconhecida e da amostra de referência puderem ser feitas na mesma pressão, qualquer pressão abaixo de 0,40 mbar dará bom resultado. Entretanto, isto requererá intervenção cuidadosa do operador, para que a pressão, ou intensidade do sinal, seja idêntica nas duas análises. Como o objetivo é um procedimento que possa ser realizado de maneira automática pelo espectrômetro, que não permite um ajuste tão acurado das pressões, o procedimento deve levar em conta que possa existir diferença entre as pressões de análise do padrão e da amostra.

Portanto, deve-se escolher uma região de pressões de trabalho e não apenas uma pressão. Não existe nenhuma região em que razão isotópica medida se mantenha 
constante, mas existem duas regiões de comportamento linear, uma, entre as pressões 0,15 e 0,30 mbar; outra, entre as pressões 0,30 e 0,40 mbar.

Nas regiões em que a relação entre $R_{m}$ e a pressão no tanque for linear, a relação entre $K_{d}$ (aqui $K_{d}=K$, dado pela equação 37) e a pressão também será. Deste modo, medindo-se a razão isotópica de uma amostra de referência em duas pressões distintas, dentro de uma mesma região linear, pode-se determinar uma função $K_{d}(P)$. Conhecendo-se os parâmetros desta equação pode-se determinar o fator de correção a ser usado para qualquer amostra desconhecida, desde que sua pressão esteja na região de pressões para a qual a equação determinada é válida.

Na TAB. 9 são apresentados os valores médios para $K_{d}$ juntamente com sua incerteza padrão combinada, $u_{k d}$.

Tabela 9. Fator de discriminação de massa em função de da pressão.

\begin{tabular}{ccc}
\hline Pressão (mbar) & $\mathbf{K}_{\mathbf{d}}$ & $\mathbf{u}_{\mathbf{k d}}$ \\
\hline 0,10 & 0,98380867 & 0,00093151 \\
0,15 & 0,98239803 & 0,00120293 \\
0,20 & 0,98001702 & 0,00147502 \\
0,25 & 0,97773401 & 0,00132082 \\
0,30 & 0,97556955 & 0,00130849 \\
0,35 & 0,97437118 & 0,00137706 \\
0,40 & 0,97320521 & 0,00164132 \\
0,45 & 0,97052923 & 0,00096287 \\
0,50 & 0,96948126 & 0,00094196 \\
0,55 & 0,96798608 & 0,00223962 \\
\hline
\end{tabular}

Os dados da TAB. 9 são apresentados graficamente na FIG. 38. Neste gráfico também podem ser vistas as retas ajustadas para a $1^{\circ}$ região, de 0,15 a 0,30 mbar (linha vermelha contínua), e para a segunda região, de 0,30 a 0,40 mbar (linha verde contínua). 


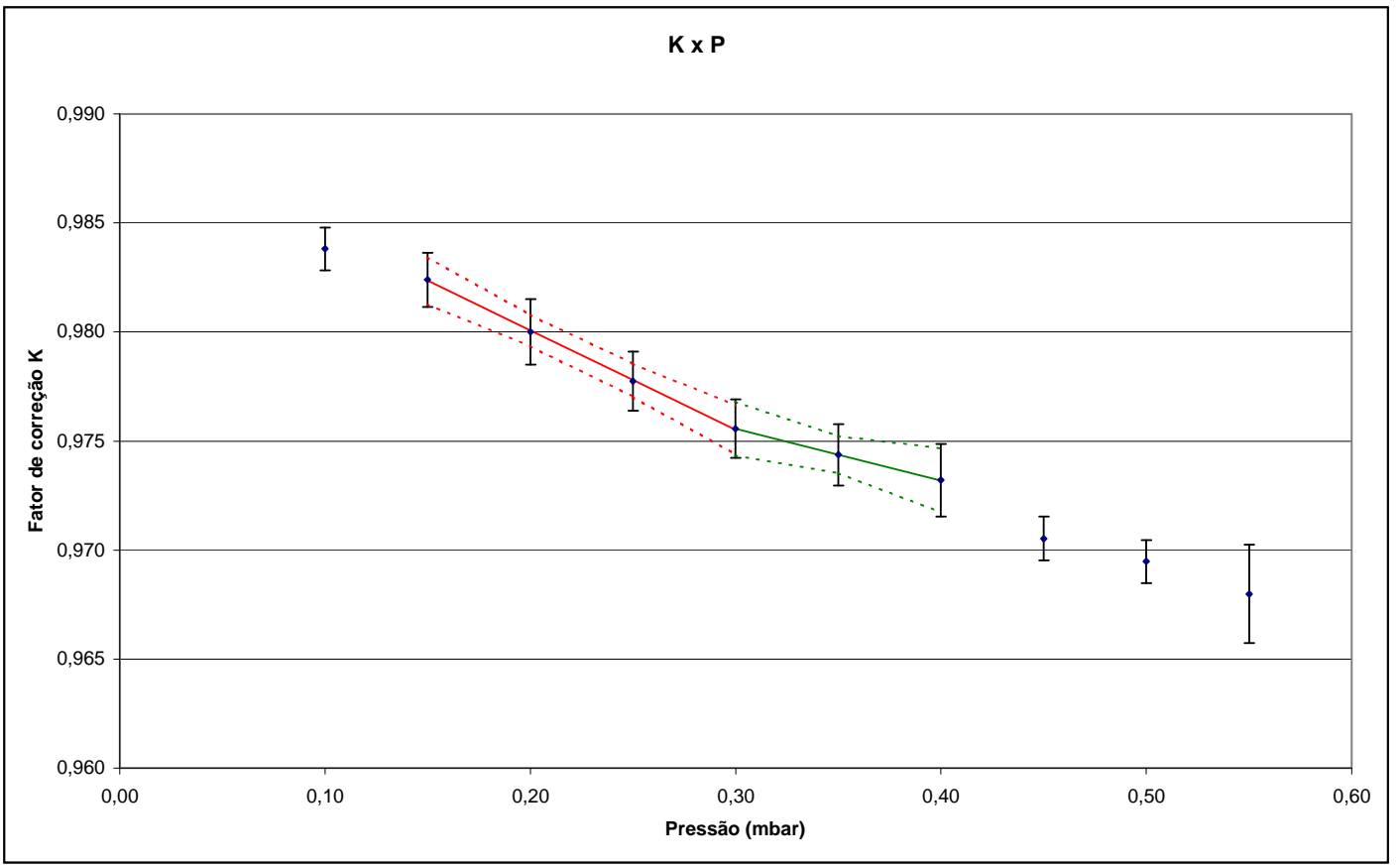

Figura 38. Fator de discriminação de massa em função da pressão no tanque.

Sendo a equação da reta ajustada dada por:

$$
K_{d}(P)=c P+d
$$

os parâmetros $c$ e $d$, suas variâncias $u_{c}{ }^{2}$ e $u_{d}$, e sua covariância cov(cd), para as duas regiões, são calculados pelas equações ${ }^{25}$ :

$$
c=\frac{\left[\left(\sum_{i=1}^{n} \frac{1}{u_{i}^{2}}\right)\left(\sum_{i=1}^{n} \frac{K_{d i} P_{i}}{u_{i}^{2}}\right)-\left(\sum_{i=1}^{n} \frac{P_{i}}{u_{i}^{2}}\right)\left(\sum_{i=1}^{n} \frac{K_{d i}}{u_{i}^{2}}\right)\right]}{\left[\left(\sum_{i=1}^{n} \frac{1}{u_{i}^{2}}\right)\left(\sum_{i=1}^{n} \frac{P_{i}^{2}}{u_{i}^{2}}\right)-\left(\sum_{i=1}^{n} \frac{P_{i}}{u_{i}^{2}}\right)^{2}\right]}
$$


$d=\frac{\left[\left(\sum_{i=1}^{n} \frac{P_{i}^{2}}{u_{i}^{2}}\right)\left(\sum_{i=1}^{n} \frac{K}{u_{i}^{2}}\right)-\left(\sum_{i=1}^{n} \frac{P_{i}}{u_{i}^{2}}\right)\left(\sum_{i=1}^{n} \frac{K}{d i} u_{i}^{2}\right)\right]}{\left[\left(\sum_{i=1}^{n} \frac{1}{u_{i}^{2}}\right)\left(\sum_{i=1}^{n} \frac{P_{i}^{2}}{u_{i}^{2}}\right)-\left(\sum_{i=1}^{n} \frac{P_{i}}{u_{i}^{2}}\right)^{2}\right]}$

$u_{c}^{2}=\frac{\sum_{i=1}^{n} \frac{1}{u_{i}^{2}}}{\left[\left(\sum_{i=1}^{n} \frac{1}{u_{i}^{2}}\right)\left(\sum_{i=1}^{n} \frac{P_{i}^{2}}{u_{i}^{2}}\right)-\left(\sum_{i=1}^{n} \frac{P_{i}}{u_{i}^{2}}\right)^{2}\right]}$

$u_{d}^{2}=\frac{\sum_{i=1}^{n} \frac{P_{i}^{2}}{u_{i}^{2}}}{\left[\left(\sum_{i=1}^{n} \frac{1}{u_{i}^{2}}\right)\left(\sum_{i=1}^{n} \frac{P_{i}^{2}}{u_{i}^{2}}\right)-\left(\sum_{i=1}^{n} \frac{P_{i}}{u_{i}^{2}}\right)^{2}\right]}$

$\operatorname{cov}(c d)=-\frac{\sum_{i=1}^{n} \frac{P_{i}}{u_{i}^{2}}}{\left[\left(\sum_{i=1}^{n} \frac{1}{u_{i}^{2}}\right)\left(\sum_{i=1}^{n} \frac{P_{i}^{2}}{u_{i}^{2}}\right)-\left(\sum_{i=1}^{n} \frac{P_{i}}{u_{i}^{2}}\right)^{2}\right]}$

onde:

- $\mathrm{K}_{\mathrm{di}}=$ fator de correção para discriminação de massas (TAB. 9), na pressão $\mathrm{P}_{\mathrm{i}}$.

- $\mathrm{u}_{\mathrm{i}}=\mathrm{u}_{\mathrm{kd}}\left(\mathrm{P}_{\mathrm{i}}\right)=$ incerteza padrão no valor de $\mathrm{K}_{\mathrm{di}}(\mathrm{TAB}$. 9). 
Os valores obtidos para os parâmetros das curvas ajustadas, nas duas regiões, suas incertezas padrão e covari6ancia são:

$\begin{array}{cccccc} & \boldsymbol{c} & \boldsymbol{u}_{\boldsymbol{c}} & \boldsymbol{d} & \boldsymbol{u}_{\boldsymbol{d}} & \boldsymbol{c o v}(\boldsymbol{c d}) \\ \text { Primeira região } & -0,046 & 0,012 & 0,9892 & 0,0026 & -0,00003 \\ \text { Segunda região } & -0,024 & 0,021 & 0,9827 & 0,0073 & -0,00015\end{array}$

As linhas tracejadas representam aos valores da reta mais ou menos a incerteza padrão do ajuste, $u\left(K_{d}\right)$ :

$$
u\left(k_{d}\right)=\sqrt{u_{d}^{2}+P^{2} u_{c}^{2}+2 \operatorname{cov}(c d)}
$$

\subsection{Dependência entre o valor da razão isotópica medida e a razão isotópica real, determinação do fator de correção para não linearidade}

O fator de correção para não linearidade $K_{l}$, foi determinado com o uso das quatro amostras certificadas, MRI 0.5; MRI 0.7; MRI 3.5 e MRI 4.5. Estas amostras foram acopladas, respectivamente, nos bocais S4, S3, S2 e S1 do espectrômetro (FIG. 14), e o seguinte procedimento foi adotado, para as quatro amostras:

a. Com o objetivo de eliminar o efeito memória, uma alíquota da amostra era introduzida no tanque de expansão correspondente, até a pressão de 0,300 mbar e o gás deixado fluir para o analisador durante um minuto.

b. No tanque, a linha de introdução e o distribuidor eram evacuados até que a intensidade da corrente iônica para a massa 333 atingi-se a da linha de base.

c. O gás era novamente introduzido no tanque, até a pressão de 0,200 mbar, e 10 medições sucessivas executadas.

Este procedimento foi repetido em dez dias diferentes e os resultados são apresentados na TAB. 10, juntamente com a média da razão isotópica medida $\left\langle R_{m}\right\rangle$ e os 
valores dos desvios padrão de repetitividade $(s 1)$ e reprodutibilidade (s2), calculados utilizando-se as equações (42) e (43), respectivamente.

Os valores de $\left\langle R_{m}\right\rangle$ foram corrigidos para discriminação de massa com o uso da equação (38), onde $K=K_{d}$ e $K_{d}$ é dado pela equação (67) com $\mathrm{P}=0,200$ mbar, $K_{d}(0,200)=0,9800$, cuja incerteza padrão, calculada pela equação (73), é $u\left(K_{d}\right)=0,0007$. Os valores corrigidos são mostrados na TAB. 11 como $\left\langle R_{m}\right\rangle_{c o r}$, juntamente com suas incertezas padrão combinadas $u_{c o r}$.

O fator de correção para efeitos não lineares foi determinado aplicando-se a equação (37) aos $\langle R\rangle_{\text {corr }}$ da TAB. 11. Os resultados obtidos, apresentados na TAB. 12, mostram valores para o fator de correção $K_{l}$ ligeiramente diferentes para cada um dos quatro materiais certificados. Esta diferença foi atribuída a efeitos não lineares dependentes da razão isotópica.

Tabela 10. Valores certificados e valores medidos da razão isotópica para as quatro amostras padrão.

\begin{tabular}{ccccc}
\hline \multicolumn{5}{c}{ Valores medidos da razão isotópica } \\
\hline Dia & MRI 0,5 & MRI 0,7 & MRI 3,5 & MRI 4,5 \\
$\mathbf{1}$ & 0,00546342 & 0,00741324 & 0,03628247 & 0,04762167 \\
$\mathbf{2}$ & 0,00545227 & 0,00738753 & 0,03617675 & 0,04749158 \\
$\mathbf{3}$ & 0,00546017 & 0,00739610 & 0,03623125 & 0,04753950 \\
$\mathbf{4}$ & 0,00546163 & 0,00740134 & 0,03624345 & 0,04755188 \\
$\mathbf{5}$ & 0,00546829 & 0,00740839 & 0,03628193 & 0,04757340 \\
$\mathbf{6}$ & 0,00547064 & 0,00740942 & 0,03627572 & 0,04758912 \\
$\mathbf{7}$ & 0,00547322 & 0,00741497 & 0,03631680 & 0,04759650 \\
$\mathbf{8}$ & 0,00544770 & 0,00738524 & 0,03619905 & 0,04748525 \\
$\mathbf{9}$ & 0,00545628 & 0,00739606 & 0,03622893 & 0,04749772 \\
$\mathbf{1 0}$ & 0,00546617 & 0,00740233 & 0,03625723 & 0,04758867 \\
& & & & \\
$\mathbf{R}$ & 0,00546198 & 0,00740146 & 0,03624936 & 0,04755353 \\
$\mathbf{s 1}$ & 0,00000530 & 0,00000384 & 0,00001661 & 0,00002970 \\
$\mathbf{s 2}$ & 0,00000813 & 0,00001027 & 0,00004222 & 0,00004853 \\
\hline
\end{tabular}


Tabela 11. Valores das razões isotópicas medidas das amostras de referência, corrigidos para discriminação de massa.

\begin{tabular}{ccccc}
\hline & MRI 0,5 & MRI 0,7 & MRI 3,5 & MRI 4,5 \\
\hline$\langle\boldsymbol{R}\rangle_{\text {cor }}$ & 0,00535315 & 0,00725399 & 0,03552709 & 0,04660603 \\
$\boldsymbol{u}_{\text {cor }}$ & 0,00000885 & 0,00001134 & 0,00004867 & 0,00005824 \\
\hline
\end{tabular}

Tabela 12. Valores dos fatores de correção para efeitos não lineares $K_{l}$.

\begin{tabular}{ccccc}
\hline & MRI 0,5 & MRI 0,7 & MRI 3,5 & MRI 4,5 \\
\hline $\boldsymbol{K}_{\boldsymbol{l}}$ & 1,00028974 & 1,00004302 & 0,99838729 & 0,99870552 \\
$\boldsymbol{u}_{\boldsymbol{l}}$ & 0,00165470 & 0,00156725 & 0,00136939 & 0,00125002 \\
\hline
\end{tabular}

Entretanto, a diferença entre os quatro valores de $K_{l}$ é pequena se comparada às incertezas padrão destes valores, como pode ser visto na FIG. 39.

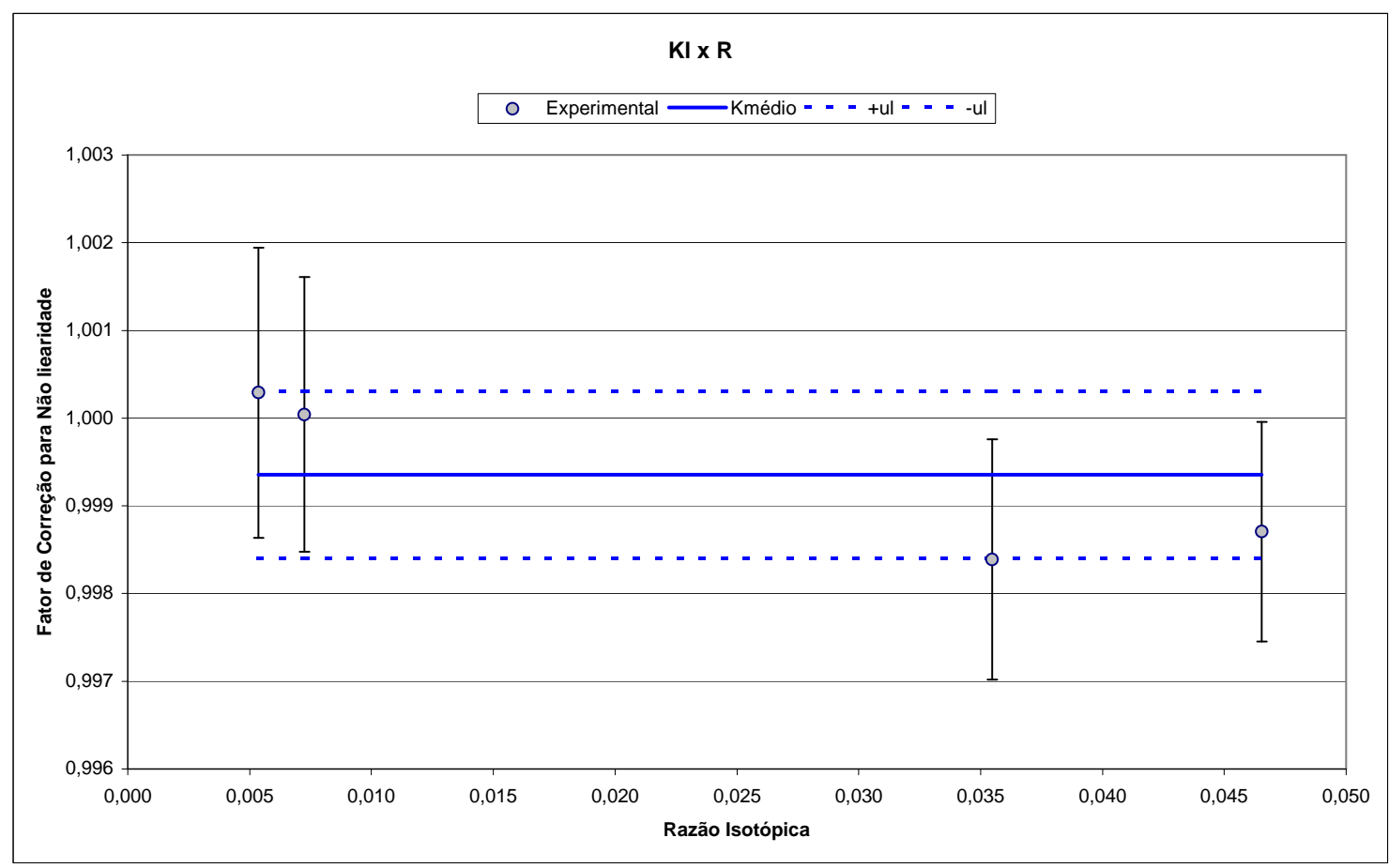

Figura 39. Fator de correção para efeitos não lineares $\left(K_{l}\right)$ em função da razão isotópica da amostra certificada. 
O valor ideal para o fator de não linearidade é $K_{l}=1$, que significa que não ocorrem efeitos não lineares. Pode-se observar na FIG. 39, que dentro da precisão do experimento, os efeitos não lineares na faixa de razões isotópicas analisadas podem ser desconsiderados. O valor médio obtido para $K_{l}\left(K_{l}=0,9994\right.$ com incerteza padrão $\left.u_{K l}=0,0009\right)$ é praticamente 1 . Apesar de não ser necessária a correção de não linearidade, a sua incerteza deve fazer parte da declaração final de incerteza do fator de correção $K$.

\subsection{Avaliação do efeito memória}

Os dois componentes principais onde pode ocorrer efeito memória são o tanque de expansão e a fonte de íons.

O efeito memória na fonte de íons foi estimado pelo seguinte procedimento:

Uma amostra de $\mathrm{UF}_{6}$ empobrecida (amostra de referência MRI 0,5), foi acoplada ao bocal S3 e uma amostra enriquecida (amostra de referência MRI 4,5) ao bocal S1.

A amostra MRI 0,5 foi introduzida no tanque T1 a pressão de 0,250 mbar.

A amostra MRI 4,5 foi introduzida no tanque T2 a pressão de 0,250 mbar.

As amostras em T1 e T2 foram analisadas alternadamente oito vezes, sendo realizadas seis medições em cada análise.

Entre a análise de um tanque e outro, o distribuidor foi evacuado até que a intensidade do pico 333 atingisse a intensidade da linha de base, mas nenhum procedimento de lavagem foi adotado.

Os resultados obtidos são apresentados na TAB. 13, onde $\langle R\rangle_{p}$ é a razão isotópica média medida para a amostra MRI $0,5 \mathrm{e}\langle R\rangle_{\mathrm{r}}$ é a razão isotópica média medida para a amostra MRI 4,5. 
Tabela 13. Razões isotópicas das amostras enriquecida e empobrecida obtidas em medições sucessivas, com as amostras enriquecida e empobrecida em tanques diferentes.

\begin{tabular}{ccc}
\hline & MRI 0,5 & MRI 4,5 \\
\hline $\mathbf{1}$ & 0,00558492 & 0,04860000 \\
$\mathbf{2}$ & 0,00560052 & 0,04855520 \\
$\mathbf{3}$ & 0,00558511 & 0,04856100 \\
$\mathbf{5}$ & 0,00558725 & 0,04856040 \\
$\mathbf{6}$ & 0,00558972 & 0,04857260 \\
$\mathbf{7}$ & 0,00558925 & 0,04856390 \\
$\mathbf{8}$ & & \\
\hline $\boldsymbol{8}$ & 0,00558784 & 0,04855200 \\
& & 0,04856226 \\
\hline
\end{tabular}

Inserindo-se os valores medidos médios das razões isotópicas, das amostras enriquecida e empobrecida, obtidos na TAB. 13 acima, e os valores certificados nas equações (34), (35) e (36), obteve-se, para o fator de memória da fonte, $M_{f}$, o valor:

$M_{f}=1,000$ com desvio padrão $s_{f}=0,001$

O efeito memória nos tanques de expansão foi estimado pelo seguinte procedimento: 
Uma amostra de $\mathrm{UF}_{6}$ empobrecida (amostra de referência MRI 0,5), foi acoplada ao bocal S3 e uma amostra enriquecida (amostra de referência MRI 4,5) ao bocal S4.

As amostras foram introduzidas, alternadamente, no tanque T1.

Cada mostra foi analisada cinco vezes, sendo realizadas seis medições em cada análise.

Entre as análises de uma amostra e outra, o distribuidor e o tanque foram evacuados até que a intensidade do pico 333 atingisse a intensidade da linha de base, mas nenhum procedimento de lavagem foi adotado.

Os resultados obtidos são apresentados na TAB. 14, onde $\langle R\rangle_{p}$ é a razão isotópica média medida para a amostra MRI $0,5 \mathrm{e}\langle R\rangle_{r}$ é a razão isotópica média medida para a amostra MRI 4,5.

Tabela 14. Razões isotópicas das amostras enriquecida e empobrecida obtidas em medições sucessivas, com as amostras enriquecida e empobrecida no mesmo tanque.

\begin{tabular}{ccc}
\hline & MRI 0,5 & MRI 4,5 \\
\hline $\mathbf{1}$ & 0,00557031 & 0,04841310 \\
$\mathbf{3}$ & 0,00559149 & 0,04844530 \\
$\mathbf{4}$ & 0,00558206 & 0,04846510 \\
$\mathbf{5}$ & 0,00560724 & 0,04852580 \\
& & \\
$\langle\boldsymbol{R}\rangle_{\boldsymbol{p}}$ & 0,00560173 & 0,04846233 \\
\hline $\boldsymbol{R}\rangle_{\boldsymbol{r}}$ & & \\
\hline
\end{tabular}


Inserindo-se os valores medidos médios das razões isotópicas, das amostras enriquecida e empobrecida, obtidos na TAB.14, e os valores certificados nas equações (34), (35) e (36), obteve-se, para o fator de memória do tanque, $M_{t}$, o valor:

$$
M_{t}=1,003 \text { com desvio padrão } s_{t}=0,003
$$

Nenhum efeito memória foi detectado na fonte de íons. Os tanques de amostragem apresentam efeito memória que, embora pequeno, deve ser eliminado pela lavagem do tanque com o gás a ser analisado.

\subsection{Procedimento a ser adotado na realização de análises isotópicas}

Este procedimento leva em conta todos os resultados anteriores.

A faixa de pressões escolhida para trabalho vai de 0,15 a 0,30 mbar, uma vez que esta faixa de pressões é mais ampla que a segunda e tem um consumo menor de amostra.

Como o espectrômetro mostrou-se bastante linear, a amostra de referência MRI 0.7, com razão isotópica do urânio natural, será utilizada na correção de todas as análises em todas as análises.

Procedimentos de lavagem dos tanques serão adotadas para evitar influência do efeito memória.

As amostras deverão ser purgadas com nitrogênio líquido para eliminar influência de impurezas.

O procedimento é o que segue:

\section{Análise da amostra de referência.}

- Introduzir $\mathrm{UF}_{6}$ da amostra de referência MRI 0,7 no tanque de expansão T1, até a pressão de 0,30 mbar.

- Medir $N$ vezes a razão isotópica $R_{c m}\left(P_{l}\right)$. 
- Reduzir a pressão no tanque T1 para 0,25 mbar.

- Medir $N$ vezes a razão isotópica $R_{c m}\left(P_{2}\right)$.

- Reduzir a pressão no tanque T1 para 0,20 mbar.

- Medir $N$ vezes a razão isotópica $R_{c m}\left(P_{3}\right)$.

- Reduzir a pressão no tanque T1 para 0,15 mbar.

- Medir $N$ vezes a razão isotópica $R_{c m}\left(P_{4}\right)$.

- Evacuar o tanque, a linha de introdução de amostra e o distribuidor.

$R_{c m}\left(P_{i}\right)$ é o valor medido da amostra certificada na pressão $P_{i}$.

A partir do valor certificado e das razões isotópicas medidas e da equação (37), com $K_{d}=K$, determinam-se os valores de $K_{d}$ para as quatro pressões, a partir dos quais ajusta-se uma equação $K_{d}(P)$ por meio das equações (67), (68) e (69); onde:

- $K_{d i}=$ valor do fator de correção para discriminação de massa na pressão $P_{i}$.

- $u_{i}=$ valor da incerteza padrão combinada para $K_{d i}$, determinada pela fórmula ${ }^{22}$ :

$u_{i}=K_{d i} \sqrt{\left(\frac{s_{2 i}}{R_{i}}\right)^{2}+\frac{J-N}{N J}\left(\frac{s_{1 i}}{R_{i}}\right)^{2}+\left[\frac{u\left(R_{c}\right)}{R_{c}}\right]^{2}+\left[\frac{u\left(P_{i}\right)}{P_{i}}\right]^{2}}$

$s_{1 i}=$ repetitividade na pressão $P_{i},($ Tab. 7).

$s_{2 i}=$ reprodutibilidade na pressão $P_{i}$ (Tab. 7 ).

$J=6=\mathrm{n}^{\circ}$ de análises sucessivas usada da determinação de $s_{1}$.

$N=\mathrm{n}^{\circ}$ de análises sucessivas realizadas para determinação de $R_{c m}$.

$R_{i}=$ valor médio das $N$ medições $R_{c m}\left(P_{i}\right)$.

$u\left(P_{i}\right)=0$, porque a incerteza da pressão é componente da variabilidade observada e já está incluída nas componentes de incerteza obtidas por análise estatística das observações ${ }^{25}$.

Medindo-se seis vezes $(N=6)$ a razão isotópica da amostra certificada em cada pressão, teremos $N=J$ e $u_{i}$ será a combinação da incerteza padrão associada a reprodutibilidade e da incerteza padrão do valor certificado da amostra de referência, ou seja: 


$$
u_{i}=K_{d i} \sqrt{\left(\frac{s_{2 i}}{R_{i}}\right)^{2}+\left[\frac{u\left(R_{c}\right)}{R_{c}}\right]^{2}}
$$

A expressão ajustada para $K_{d}(P)$ será usada para a correção de discriminação de massa.

\section{Análise da amostra desconhecida.}

As amostras desconhecidas a serem analisadas poderão ser acopladas a quaisquer dos pontos de acoplagem.

- Resfriar as ampolas com nitrogênio líquido e em seguida evacuar até a pressão de $10^{-5}$ mbar.

- Introduzir uma alíquota da amostra de referência, em um dos tanques de expansão, até uma pressão dentro da faixa de linearidade.

- Evacuar o tanque, o distribuidor e as linhas de introdução até que o sinal da massa 333 atinja a linha de base (procedimento de lavagem), e encher o tanque novamente, até uma pressão $P$, entre 0,15 e 0,30 mbar.

- Realizar $N$ medições de razão isotópica.

- O valor medido $R_{m}(P)$ da amostra será a média das $N$ medições a pressão $P$.

\section{Correç̃̃o}

Inserir o valor da pressão, na qual a análise foi feita, na expressão para $K_{d}(P)$ (equação 67) e usar o valor encontrado para corrigir o valor medido da razão isotópica, equação (38). O valor $R$ para a razão isotópica da amostra será:

$$
R=K_{d}(P) R_{m}(P)
$$

Onde $P$ é a pressão na qual a amostra foi analisada. 
Estimativa da incerteza no resultado de análises isotópicas.

Seguindo-se o fluxograma da FIG. 13.

Primeiro passo. Especificar o mensurando.

O mensurando é a razão isotópica da amostra desconhecida, dada por:

$R=R_{m} K$

Substituindo-se a equação (59) em (38), obtêm-se:

$R=R_{m} K_{d} K_{l}$

onde:

$R=\mathrm{o}$ valor corrigido da razão isotópica da amostra.

$R_{m}=$ o valor medido da razão isotópica da amostra.

$P=$ pressão da amostra no tanque de expansão durante a análise.

$c$ e $d$ são os parâmetros da reta ajustada para $K_{d}(P)$.

Segundo passo. Identificar as fontes de incerteza (FIG. 40).

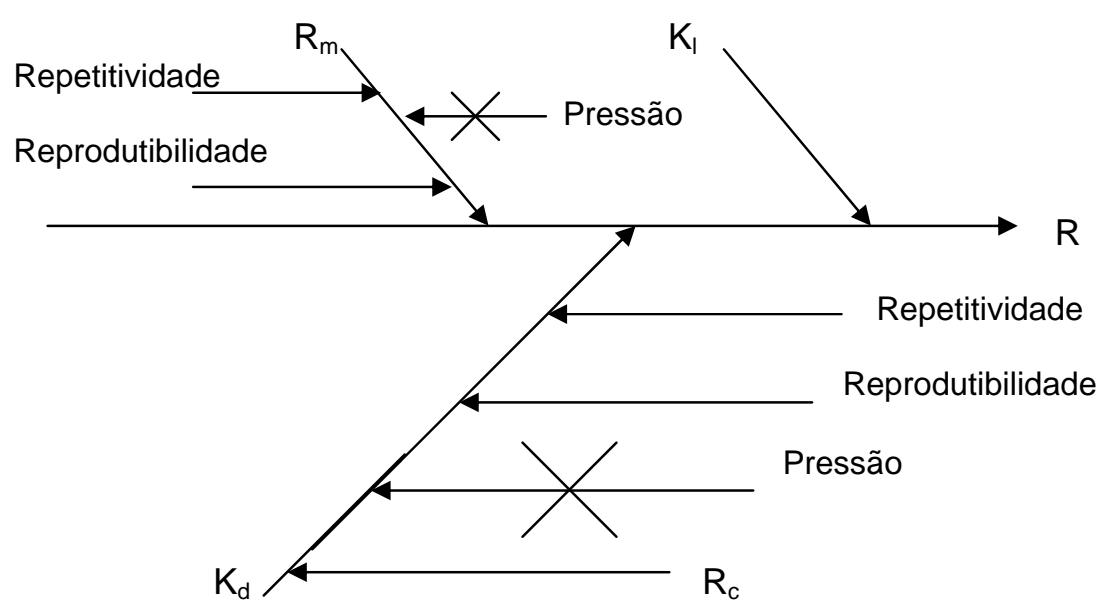

Figura 40. Diagrama de Ishikawa com os componentes da incerteza. 
Terceiro passo. Quantificar os componentes da incerteza.

1) Incerteza do fator de correção para discriminação de massa.

Todas as incertezas, que compõe a incerteza de $K_{d}$, mostradas na Fig. 34, estão englobadas na incerteza do ajuste da equação (67), $u\left(K_{d}\right)$, expressa pela equação (73).

$$
u\left(k_{d}\right)=\sqrt{u_{d}^{2}+P^{2} u_{c}^{2}+2 \operatorname{cov}(c d)}
$$

onde: $u_{d}, u_{c}$ e $\operatorname{cov}(c d)$ são calculados, respectivamente pelas equações (70), (71) e (72); com $u_{i}$ dado pela equação (75).

A incerteza $u\left(K_{d}\right)$ abrange à incerteza do tipo $\mathrm{B}$, correspondente ao valor certificado da amostra de referência, e às incertezas do tipo A decorrentes da repetitividade e da reprodutibilidade. O número de graus de liberdade de $u\left(K_{d}\right)$ é $v_{1}=3$.

2) Incerteza do fator de correção para não linearidade

O espectrômetro mostrou-se linear ao longo da faixa de valores de razão isotópica encontrado nas análises de $\mathrm{UF}_{6}$ proveniente de cascatas de enriquecimento isotópico, portanto $K_{l}=1$. Entretanto o valor desta incerteza, determinado em $6.5, u\left(K_{l}\right)=$ 0,0009; será incorporado à incerteza da razão isotópica. O número de graus de liberdade de $u\left(K_{l}\right)$ é $v_{2}=39$.

3) Incerteza da razão isotópica medida

O valor da razão isotópica medida será a média das $N$ medições realizadas e sua incerteza será composta pelas incertezas da pressão, da repetitividade e da reprodutibilidade, calculada pela equação ${ }^{22}$ :

$$
u\left(R_{m}\right)=\sqrt{s_{2}^{2}+\frac{J-N}{N J} s_{1}^{2}}
$$

$s 1=$ repetitividade das análises a pressão em que $R_{m}$ foi medida.

$s 2=$ reprodutibilidade das análises a pressão em que $R_{m}$ foi medida.

$J=6=\mathrm{n}^{\circ}$ de análises sucessivas usada da determinação de $s l$. 
$N=\mathrm{n}^{\circ}$ de análises sucessivas realizadas para determinação de $R_{m}$.

O número de graus de liberdade de $u\left(R_{m}\right)$ é dado por (56):

$$
v_{3}=\frac{u^{4}\left(R_{m}\right)}{\frac{s_{2}^{4}}{9}+\frac{s_{1}^{4}}{9}}
$$

Quarto passo. Combinar as componentes da incerteza.

A incerteza padrão combinada $u_{c}$, associada a $R$, será dada por:

$$
u_{c}=R\left\{\left[\frac{u\left(R_{m}\right)}{R_{m}}\right]^{2}+\left[\frac{u\left(K_{d}\right)}{K_{d}}\right]^{2}+\left[\frac{u\left(K_{l}\right)}{K_{l}}\right]^{2}\right\}
$$

Quinto passo. Multiplicar a incerteza combinada por um fator de abrangência.

Utilizando-se a equação (55), obtemos a incerteza padrão expandida $U$.

$$
U=k \cdot u_{c}
$$

Onde: $k=k_{95 \%}=t_{95 \%}\left(v_{e f}\right)$, com $v_{e f}$ dado pela equação (56).

$$
v_{e f}=\frac{\left(\frac{u_{c}}{R}\right)^{4}}{\frac{\left[\frac{u\left(K_{d}\right)}{K_{d}}\right]^{4}}{v_{1}}+\frac{\left[\frac{u\left(K_{l}\right)}{K_{l}}\right]^{4}}{v_{2}}+\frac{\left[\frac{u\left(R_{m}\right)}{R_{m}}\right]^{4}}{v_{3}}}
$$




\section{CONCLUSÕES}

A fonte de íons pode ser otimizada para diversas resoluções, entretanto, para $\Delta M_{10}>1,81$ u.m.a., o pico se torna bastante achatado, deixando de ser adequado para análises isotópicas precisas.

A largura do pico $\Delta M_{10}$ é diretamente proporcional ao valor da resolução na escala de valores arbitrários de resolução usada pelo aparelho.

A única alteração necessária nos potenciais da fonte de íons, quando se altera a resolução, é um ajuste na energia dos íons.

O menor efeito de discriminação de massa foi obtido com resolução 70 $\left(\Delta M_{10}=1,81\right.$ u.m.a..), acima deste valor a discriminação de massa se mantém estável, mas a forma do pico achatada, que impede o bom desempenho do programa, e os aumentos e quedas abruptos dos efeitos não lineares, proíbem o uso da região com $\Delta M_{10}>1,81$ u.m.a..

Embora minimize a discriminação de massa, $\Delta M_{10}=1,81$ u.m.a. não é a largura ideal de pico para as análises, porque não minimiza os efeitos não lineares. A largura ideal de pico é $\Delta M_{10}=1,13$ u.m.a., visto que neutraliza os efeitos não lineares.

O valor da medição, calculado como a média de $n$ ciclos analíticos, somente se estabiliza após 13 ciclos. Optou-se, por medida de segurança, trabalhar com medições de 15 ciclos analíticos.

O valor médio das análises feitas com várias medições sucessivas, não varia com $N$ (número de medições). As análises posteriores foram feitas com $N$ variando entre seis de dez, valores comumente encontrados na literatura.

O valor medido da razão isotópica de uma amostra de referência depende da pressão da amostra na fonte e, portanto, da pressão do gás no tanque de expansão. 
Não existe uma pressão ideal para análise, mas a faixa mais adequada vai de 0,15 mbar a 0,40 mbar, abaixo de 0,15 mbar o ajuste de pressão torna-se muito trabalhoso e acima de 0,40 mbar a contaminação da fonte torna a necessidade de manutenção mais freqüente.

A dependência entre a razão isotópica medida e a pressão, mostrou-se linear em duas faixas de pressão: a primeira, entre 0,15 e 0,30 mbar e a segunda, entre 0,30 e 0,40 mbar. Conseqüentemente, nestas mesmas faixas de pressão, existe uma relação linear entre o fator de correção para discriminação de massa $K_{d}$ e a pressão.

Entre 0,15 e 0,40 mbar qualquer pressão é adequada, desde que as análises da amostra de referência e da amostra desconhecida sejam realizadas à mesma pressão.

O procedimento totalmente automático não permite um ajuste tão rigoroso das pressões. Neste caso, a amostra de referência deve ser analisada em pelo menos duas pressões diferentes dentro de uma das faixas de linearidade, para a determinação de uma função $K_{d}(P)$, válida para a faixa de pressões. Os valores obtidos nas análises da razão isotópica de amostras desconhecidas serão corrigidos pelo $K_{d}(P)$ correspondente a pressão em que a análise foi executada.

A primeira faixa de linearidade é a mais adequada ao procedimento automático para análises de rotina, uma vez que pressões mais baixas implicam em menor consumo de amostra, menor contaminação da fonte e menor acúmulo de material nas armadilhas criogênicas.

Os efeitos não lineares, na faixa de razões isotópicas analisada, podem ser desconsiderados, $K_{1}=1$, entretanto sua incerteza deve ser computada na declaração final de incerteza de uma determinação de razão isotópica. Esta linearidade do sistema permite que todas as amostras de rotina, com razão isotópica até 0,045 , sejam corrigidas por uma mesma amostra de referência.

O efeito memória na fonte de íons, dentro da faixa de razões isotópicas analisadas, pôde ser considerado nulo, portanto, análises sucessivas de amostras com razões isotópicas distintas, mas expandidas em tanques diferentes, não necessitam de 
correção para efeito memória ou da execução de qualquer procedimento de lavagem do tanque ou da fonte.

O efeito memória devido às linhas de introdução e ao tanque de expansão, embora baixo, foi uma ordem de grandeza superior ao da fonte, mas pode ser eliminado seguido-se um procedimento de lavagem dos tanques, toda vez que amostras de razões isotópicas diferentes forem analisadas, sucessivamente, no mesmo tanque.

Um procedimento totalmente automático pode ser introduzido, para determinação da razão isotópica ${ }^{235} \mathrm{U} /{ }^{238} \mathrm{U}$ de amostras de rotina do $\mathrm{UF}_{6}$, proveniente de cascatas de enriquecimento isotópico.

Como continuidade a este trabalho, sugere-se o estabelecimento de um procedimento semelhante, para determinação das razões isotópicas ${ }^{234} \mathrm{U} /{ }^{238} \mathrm{U}$ e ${ }^{234} \mathrm{U} /{ }^{235} \mathrm{U}$ em amostras de $\mathrm{UF}_{6}$.

Outro trabalho sugerido é uma avaliação do efeito das impurezas mais comuns nas amostras de $\mathrm{UF}_{6}$ no resultado das razões isotópicas medidas. 


\section{REFERÊNCIAS BIBLIOGRÁFICAS}

[1] BENEDICT, M.; PIGFORD, T.H.; LEVI, H.W. Nuclear Chemical Engineering, 2.ed. New York, N.Y.: McGraw-Hill, 1981.

[2] INTERNATIONAL UNION OF PURE AND APPLIED CHEMISTRY. Atomic weights of the elements: review 2000. Pure Appl. Chem., v. 75, n. 6, p. 683-800, 2003. Disponível em

[3] PLATZNER I.T.; HABFAST K.; WALDER A.J.; GOETZ A. Modern Isotope Ratio Mass Spectrometry. Chichester, U.K.: Wiley, 1999.

[4] SKOOG, D.A.; LEARY, J.J. Principles of Instrumental Analysis. 4.ed. Fort Worth: Saunders, 1992.

[5] McDOWELL, C.A. (Ed.). Mass Spectrometry. New York, N.Y.: McGraw-Hill, 1963.

[6] MURRAY, K.K. (Coord.). Standard Definitions of Terms Relating to Mass_Spectrometry. First Public Draft. IUPAC, agosto, 2006. Disponível em LWWW.Msterms.com $>$. Acesso em: 18/08/2006.

[7] DUCKWORTH, H.E.; BARBER, R.C.; VENKATASUBRAMANIAN, V.S. Mass spectroscopy. 2.ed. Cambridge : Cambridge, 1986.

[8] BEYNON, J.H.; MORGAN, R.P. The development of mass spectrometry: an historical account. International Journal of Mass Spectrometry and Ion Physics, v. 27, p. 1-30, 1978.

[9] SVEC, H.J. Mass spectroscopy - ways and means. A historical prospectus. International Journal of Mass Spectrometry and Ion Processes, v. 66, p. 3-29, 1985.

[10] VEGA BUStillos, J.O.W.; SASSINE, A.; MARCH, R. A Espectrometria de Massas Quadrupolar. São Paulo, S.P.: Scortecci, 2003.

[11] DAWSON, P.H. (Ed.). Quadrupole Mass Spectrometry and its Applications. Woodbury, N.Y.: American Institute of Physics, 1995.

[12] BRUNNEE, C. Advances in Mass Spectrometry, v. 2, p. 230, , 1963.

[13] RETTINGHAUS, G. Quadrupole Mass Spectrometer System for Isotope and Impurity Analysis of Uranium Hexafluoride. $7^{\text {th }}$ International Mass Spectrometry Conference, Florence, 1976. 
[14] MONTASER, A. (Ed.). Inductively Coupled Plasma Mass Spectrometry. New York, N.Y.: Wiley, 1998.

[15] BRUBAKER, W.M.; NASA Rep. NASW 1298 (1970) apud DAWSON, P.H. (Ed.). Quadrupole Mass Spectrometry and its Applications, American Institute of Physics, Woodbury, NY, 1995.

[16] ROTH, A. Vacuum Technology. Netherlands: North-Holland, 1976.

[17] De BIÈVRE, P. Accurate Isotope Ratio Mass Spectrometry: Some problems and possibilities. Advances in Mass Spectrometry, v. 7A, p. 395-447, 1978.

[18] RODDEN, C. J. (Ed.). Analysis of Essential Nuclear Reactor Materials. New Brunswick Laboratory (NBL), US Atomic Energy Commission, 1964.

[19] OLIVEIRA JÚNIOR, O.P. Analise multielementar e isotopica em compostos de uranio por espectrometria de massa com fonte de plasma induzido ( ICPMS ). 2000. Dissertação (Mestrado) - Instituto de Pesquisas Energéticas e Nucleares, São Paulo.

[20] NAGATORO, Y.; OCHIAI, K.; KAYA, A. Development of new type ion source of quadrupole type mass spectrometer for UF6 analysis. Journal of Nuclear Science and Technology, v. 17, n. 9, p. 687-693, 1980.

[21] DE BIÈVRE, P. (Coord.). "Uncertainties" and "Certainties" in Isotopic Measurements of Uranium: Keys to Accuracy. For presentation at the International Conference on Nuclear and Radiochemistry, Beijuing, China, 1986.

[22] NATIONAL INSTITUTE OF STANDARDS AND TECHNOLOGY. Engineering statistics e-handbook. 2003. Disponível em Acesso em: 18/03/2006.

[23] INSTITUTO NACIONAL DE METROLOGIA, NORMALIZAÇÃO E QUALIDADE INDUSTRIAL. Vocabulário internacional de termos fundamentais e gerais de metrologia - VIM. 3.ed. Rio de Janeiro, 2003.

[24] TAYLOR, B.N.; KUYATT, C.E. Guidelines for evaluating and expressing the uncertainty of NIST measurements results. NIST technical note 1297 , 1994.

[25] VUOLO, J.H. Fundamentos da teoria dos erros. 2.ed. São Paulo, S.P.: Edgard Blücher, 2002.

[26] INSTITUTO NACIONAL DE METROLOGIA, NORMALIZAÇÃO E QUALIDADE INDUSTRIAL. Guia para a expressão da incerteza de medição. 2.ed. Rio de Janeiro, R. J.: 1998.

[27] EURACHEM. Quantifying uncertaninty in analytical measurement. 2. ed., 2000. Disponível em LWWW.eurachem.org 
[28] IN PROCESS INSTRUMENTS. UF 6 Mass Spectometer IMU200 Operating Instructions. Bremen: IPI, 2002.

[29] OLIVEIRA JÚNIOR, O.P. Preparação, caracterização e certificação de materiais de referência isotópica de urânio. 2006. Tese (Doutorado) - Instituto de Pesquisas Energéticas e Nucleares, São Paulo.

[30] CAMERON, A.E. Determination of isotopic composition of uranium. Oak Ridge, Tenn., United States Atomic Comission, 1950 (TID - 5213) apud KUSAHARA, H.S. Determinação da razão isotópica ${ }^{235} \mathbf{U}^{238} \mathbf{U}$ em $\mathbf{U F}_{6}$ usando espectrometria de massas por quadrupolo. 1979. Dissertação (Mestrado) - Instituto Pesquisas Energéticas e Nucleares, São Paulo.

[31] KATZ, J.J.; RABINOWITCH, E. Chemistry of Uranium. National nuclear energy series, 1951.

[32] RETTINGHAUS, G. Quadrupole Mass Spectrometer System for Isotope and Impurity Analysis of Uranium Hexafluoride. Advances in Mass Spectrometry, v. 7A, p. 495-498, 1978. 
This document was created with Win2PDF available at http://www.daneprairie.com. The unregistered version of Win2PDF is for evaluation or non-commercial use only. 